Old Dominion University

ODU Digital Commons

Communication Disorders \& Special Education

Theses \& Dissertations

Communication Disorders \& Special Education

Spring 2020

\title{
Using the Question-Answer Relationship Strategy to Improve Listening Comprehension in Young Children with Autism Spectrum Disorder
}

Lisa A. Phalen

Old Dominion University, Iphal001@odu.edu

Follow this and additional works at: https://digitalcommons.odu.edu/cdse_etds

Part of the Clinical Psychology Commons, Early Childhood Education Commons, Language and Literacy Education Commons, and the Special Education and Teaching Commons

\section{Recommended Citation}

Phalen, Lisa A.. "Using the Question-Answer Relationship Strategy to Improve Listening Comprehension in Young Children with Autism Spectrum Disorder" (2020). Doctor of Philosophy (PhD), Dissertation, Communication Disorders \& Special Education, Old Dominion University, DOI: 10.25777/zn4p-5055

https://digitalcommons.odu.edu/cdse_etds/19

This Dissertation is brought to you for free and open access by the Communication Disorders \& Special Education at ODU Digital Commons. It has been accepted for inclusion in Communication Disorders \& Special Education Theses \& Dissertations by an authorized administrator of ODU Digital Commons. For more information, please contact digitalcommons@odu.edu. 
USING THE QUESTION-ANSWER RELATIONSHIP

STRATEGY TO IMPROVE LISTENING

COMPREHENSION IN YOUNG CHILDREN WITH

AUTISM SPECTRUM DISORDER

by

Lisa A. Phalen

B.S. December 1992, Old Dominion University

M.S.Ed. December 1994, Old Dominion University

A Dissertation Submitted to the Faculty of Old Dominion University in Partial Fulfillment of the Requirements for the Degree of

DOCTOR OF PHILOSOPHY

EDUCATION-SPECIAL EDUCATION CONCENTRATION

OLD DOMINION UNIVERSITY

May 2020

Approved by:

Peggy Hester (Chair)

Laura Chezan (Member)

Sabra Gear (Member)

Kim Murphy (Member) 


\title{
ABSTRACT \\ USING THE QUESTION-ANSWER RELATIONSHIP STRATEGY TO IMPROVE LISTENING COMPREHENSION IN YOUNG CHILDREN WITH AUTISM SPECTRUM DISORDER
}

\author{
Lisa A. Phalen \\ Old Dominion University, 2020 \\ Committee Chair: Dr. Peggy Hester
}

A well-established research base indicates that many children diagnosed with autism spectrum disorder (ASD) experience deficits in reading comprehension skills. There is currently limited research which examines the relation between the communication and language impairments in ASD and emergent literacy skills in early childhood. Listening comprehension has been identified as one emergent literacy skill closely linked to reading comprehension development. The purpose of the study is to examine the effects of the question-answer relationship strategy (QAR) and QAR cue cards as a shared book reading intervention package on the listening comprehension skills of children with ASD. A single-subject concurrent multiple-baseline design across participants with continuous acquisition probes was used to evaluate the effect of the QAR strategy on the correct answers to four levels of comprehension questions: Fact, Search, Inference, and Connection. Visual analysis and Tau-U statistical analysis were used to determine the treatment effects on each participant. Results showed that all or some aspects of the intervention were effective for each of the five participants in the study. Practitioners and participants reported positive social validity of the intervention. An examination of the results, along with implications for future research and educational practices are discussed. 
Copyright, 2020, by Lisa A. Phalen, All Rights Reserved. 
This dissertation is dedicated to educators and practitioners everywhere who make a difference every day. 


\section{ACKNOWLEDGMENTS}

I would like to first thank Dr. Peggy Hester who has worn many hats as my advisor, professor, boss, and dissertation chair throughout the course of my doctoral program. I am indebted to her for hiring me to work on her grant, which opened a world of opportunities I would have otherwise never had. I am inspired by her knowledge of single subject research, her youthful spirit, and her commitment to social justice. One of my favorite memories of Dr. Hester is when she took the research team to see The Ruth Bader Ginsberg documentary at the Naro Theater and surprised us afterwards with RBG coffee mugs (which I proudly display). Knowing Dr. Hester has helped me to learn and grow as a student, teacher, and researcher. She ensures that I stay apprised of all current education legislation and developments in Washington, D.C. One lesson from Dr. Hester that I will always carry with me is the importance of graphs in educational research. I will especially remember her words "Let me see it in a graph" whenever we discussed data. Whenever I see a graph, I will think of Dr. Hester.

My sincere thanks to committee member Dr. Laura Chezan who helped to refine my research idea of improving comprehension skills in young children with autism into a cohesive research design. She was instrumental in guiding me through a pilot study, as well as my dissertation study. I greatly admire her dedication and expertise in autism research. Her feedback was invaluable, and she was always generous with her time.

Many thanks to committee member Dr. Sabra Gear who I also had the pleasure of working with on Dr. Hester's research grant. Dr. Gear's expertise in early education and specialization in comprehension skills was extremely beneficial. Her enthusiasm for my research 
study gave me the boost of confidence I needed when I was feeling unsure. Her feedback was always delivered with intelligence and warmth.

Special thanks to committee member Dr. Kim Murphy for her knowledge and expertise of early childhood literacy. She was endlessly patient in helping me to choose the correct terminology for describing language skills, as well as the criteria for selecting books, assessments, and writing the questions that I used in my dissertation study. She always had her eye on current research and took the time to send me relevant articles. Her assistance undoubtably raised my study to a higher level.

Thanks, and gratitude to program director Dr. Jonna Bobzien. I met Dr. Bobzien as my professor in the Autism Certificate program and she was my inspiration to apply for the $\mathrm{PhD}$ program. She was never too busy to help offer guidance or a dose of humor throughout my time as a doctoral student.

I owe great thanks to Dr. Lisa Morin who was my teammate during the first three years of Dr. Hester's research grant. Lisa was a true mentor and friend who never failed to stop whatever she was doing to help with my research, and even cat advice. Working with her is truly one of the highlights of my doctoral program at Old Dominion University.

I am grateful to the entire special education faculty at Old Dominion University for their support and guidance throughout the program. Each and every professor helped me to complete this journey.

I would also like to extend thanks to Autism Consulting and Therapy for allowing me to conduct both my pilot study and dissertation study at their site. They could not have been more gracious or welcoming. Thanks also to the parents who allowed their children to participate in 
the study, and the wonderful children themselves. I could not have asked for a for a better group of children and staff with whom to work. I looked forward to each day that I spent with them. Great thanks to my fantastic coders Jawhaina and Monique. I could not have done it without you.

I am also grateful to many members of my family. I am proud to be a third generation teacher after my grandmother and mother. My mother passed when my son was going through evaluations for autism. Later, I found her notes and books on autism along with requests for materials from the public library. This was well before the convenience of the internet and computers in the home. It is gratifying to know we shared this quest together. I am thankful to still have my dad who called, emailed, and checked on me continuously throughout the program. He was excited at my progress and celebrated each step along the way with me. I am also thankful for the unbreakable bond that I share with my siblings Mary, Greg, and Matt and for the collective resilience that carries us forward.

The greatest thanks to my husband George who provided unconditional love and support, cooked many dinners, and never let me give up. He went on walks with me, took me skating, bought me cake, listened to me vent, and never wavered in his support and belief in me. He took it all in stride as another adventure in our 30 years of marriage.

Heartfelt thanks to my son Kyle who is the driving force behind everything that I do. His encouragement when I was stuck or frustrated never failed and he never failed to make me laugh. His courage, intellect, humor, and empathy have shaped him into the best person that I know. His strive for independence, talent, and determination inspire me every day. 


\section{TABLE OF CONTENTS}

Page

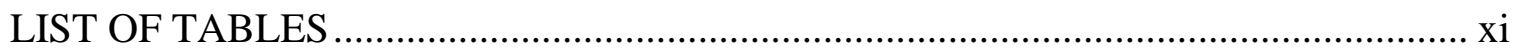

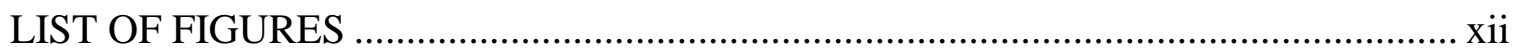

Chapter

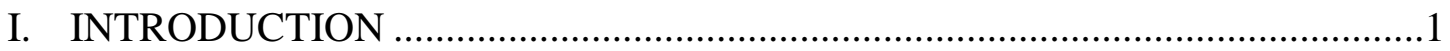

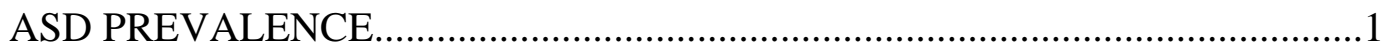

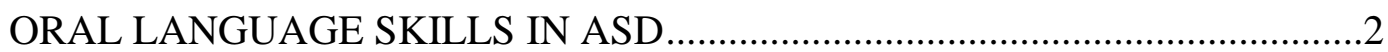

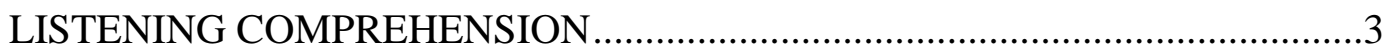

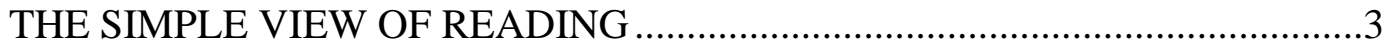

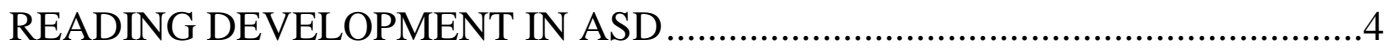

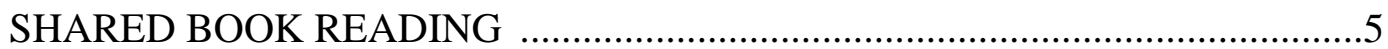

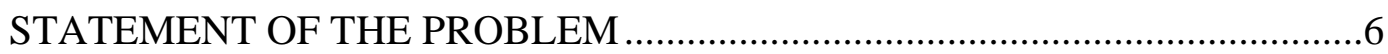

II. REVIEW OF THE LITERATURE ………………….................................

LISTENING COMPREHENSION REVIEW OF THE LITERATURE..................7

COMPARATIVE EMERGENT LITERACY SKILLS ……................................

LANGUAGE AND COGNITIVE HETEROGENEITY IN ASD .........................11

SHARED BOOK READING INTERVENTIONS ………………………........16

The QUESTION-ANSWER RELATIONSHIP STRATEGY (QAR) ……….......20

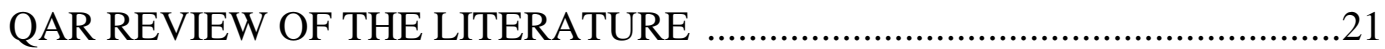

READING PROFILES IN ASD POPULATION ...............................................22

COGNITIVE BASED THEORIES OF READING DEFICITS IN ASD ............23

THE USE OF QUESTION-ANSWER STRATEGIES FOR ASD ......................24

QAR ADAPTATIONS USING VISUAL SUPPORTS ……………………......25

SUMMARY OF EMPIRICAL GAPS IN THE LITERATURE ……..................25

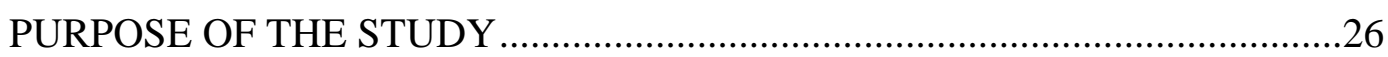

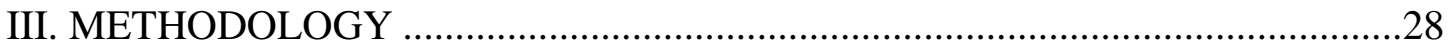

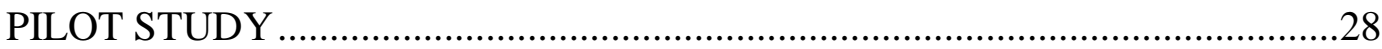

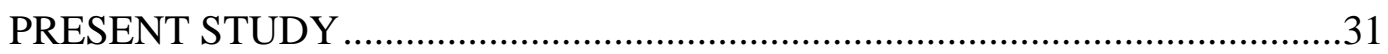

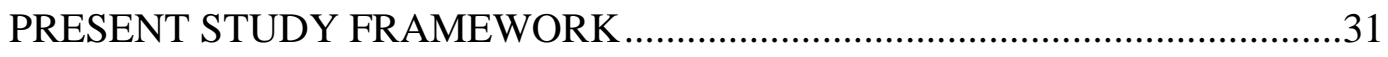

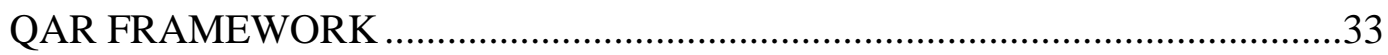

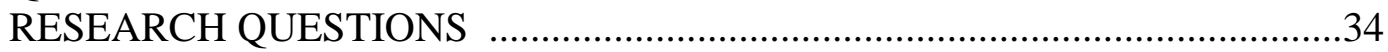

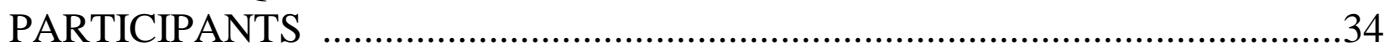

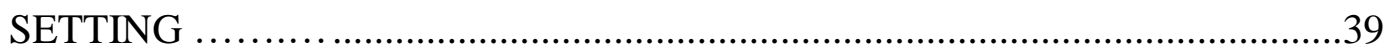

INSTITUTIONAL REVIEW BOARD AND CONSENT PROCEDURES ..........39

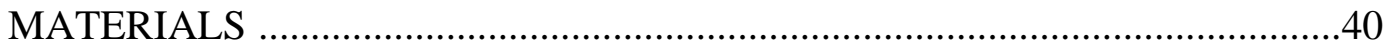


INDEPENDENT AND DEPENDENT VARIABLES ......................................40

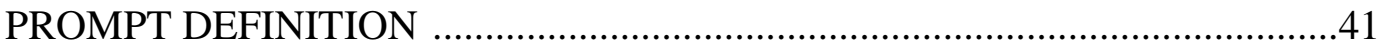

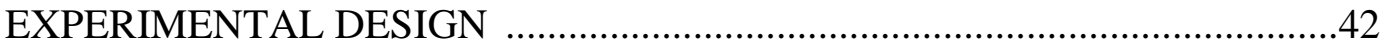

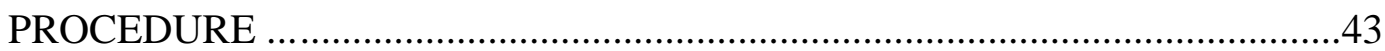

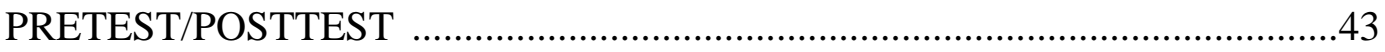

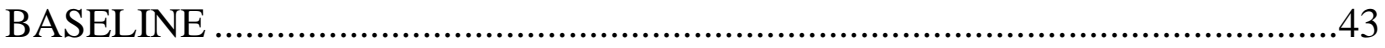

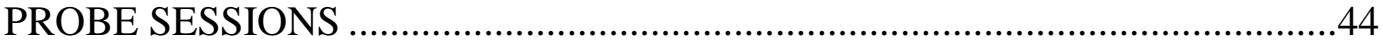

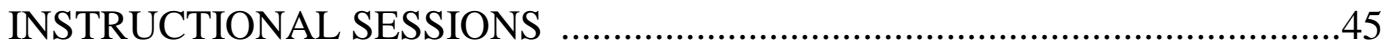

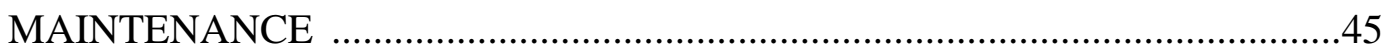

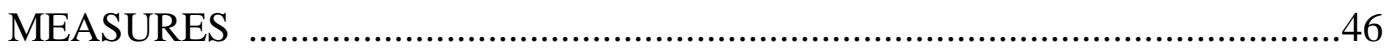

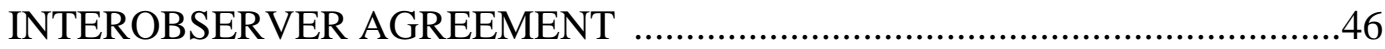

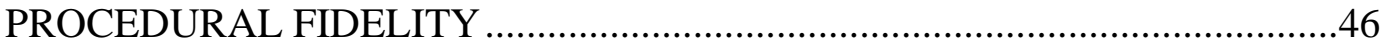

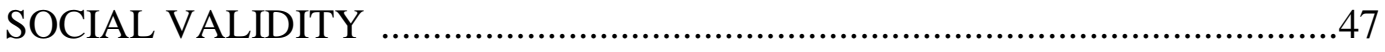

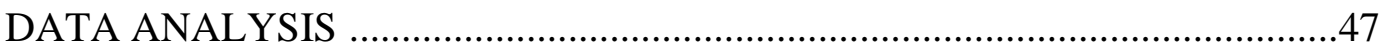

IV. RESULTS ....

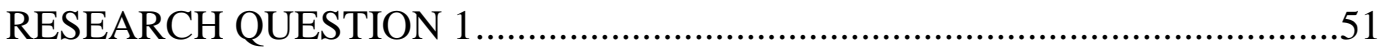

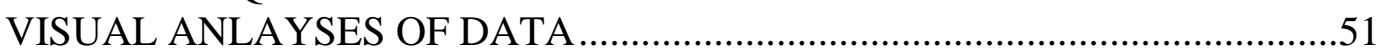

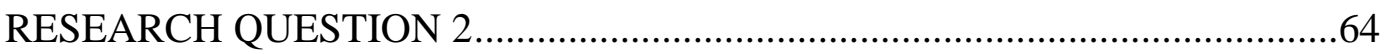

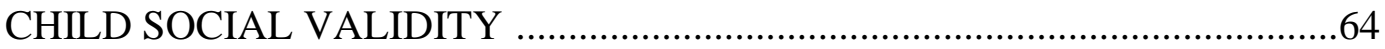

REGISTERED BEHAVIOR TECHNICIAN (RBT) SOCIAL VALIDITY .........65

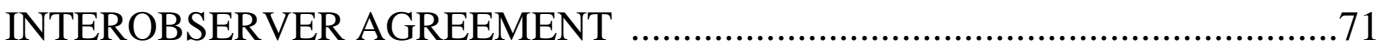

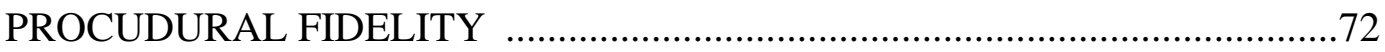

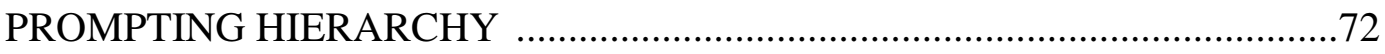

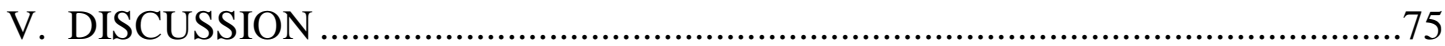

CHILD CO-MORBID AND MITIGATING CONDITIONS ……......................75

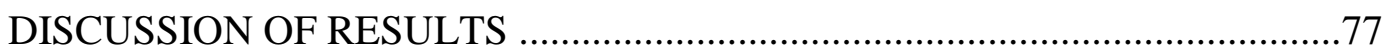

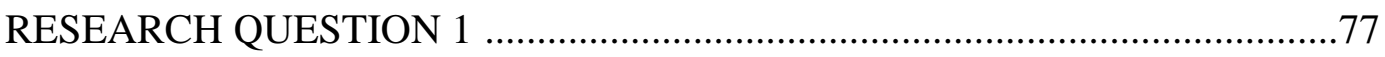

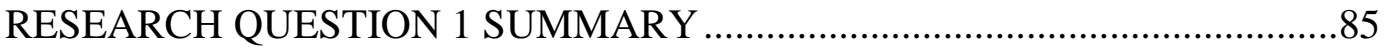

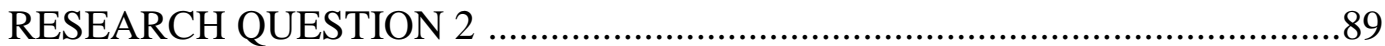

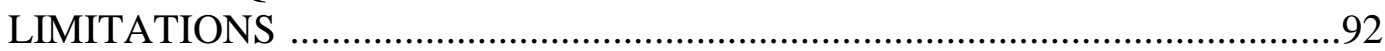

IMPLICATIONS FOR FUTURE RESEARCH AND PRACTICE ....................93

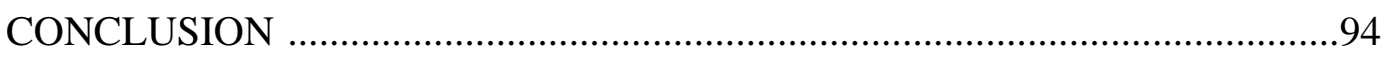

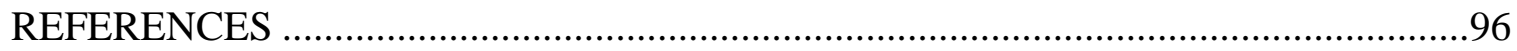

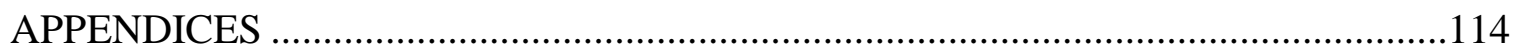

A. QAR VISUAL SUPPORT CARDS ......................................................114

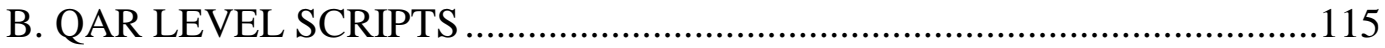

C. PARENT RECRUITMENT LETTER ………........................................116

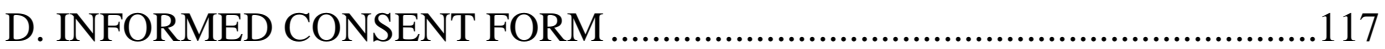

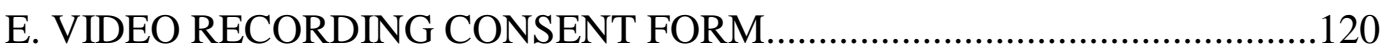

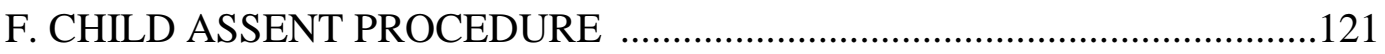


G. QAR STUDY BOOK LIST ……………………….................................122

H. THE SNOWY DAY QUESTION AND ANSWER KEY ….........................123

I. HARRY THE DIRTY DOG QUESTION AND ANSWER KEY ...................125

J. CORDUROY QUESTION AND ANSWER KEY ……………....................127

K. BUNNY CAKES QUESTION AND ANSWER KEY ...................................129

L. I TOOK MY FROG QUESTION AND ANSWER KEY …………...............131

M. WHISTLE FOR WILLIE QUESTION AND ANSWER KEY .....................133

N. ALEXANDER/WIND-UP MOUSE QUESTION AND ANSWER KEY .....135

O. DUCK ON A BIKE QUESTION AND ANSWER KEY …….....................137

P. THE WOLF'S CHICKEN STEW QUESTION AND ANSWER KEY .........139

Q. TAXI DOG QUESTION AND ANSWER KEY ……................................141

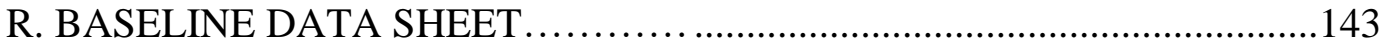

S. INTERVENTION PROBE DATA SHEET ……….......................................144

T. INTERVENTION INSTRUCTIONAL DATA SHEET ................................145

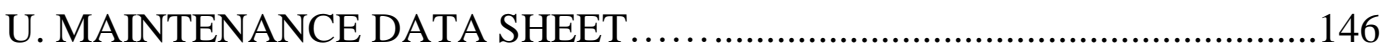

V. BASELINE/MAINTENANCE PROCEDURAL FIDELITY. .......................147

W. INTERVENTION PROCEDURAL FIDELITY ……................................149

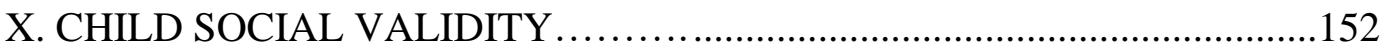

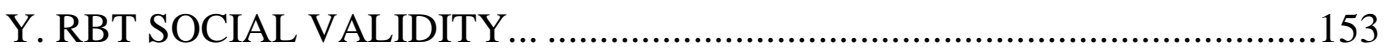

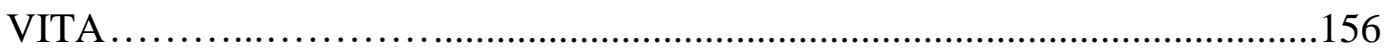




\section{LIST OF TABLES}

Table

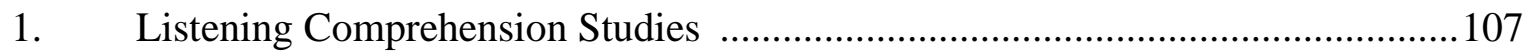

2. QAR Reading Comprehension Studies....................................................... 111

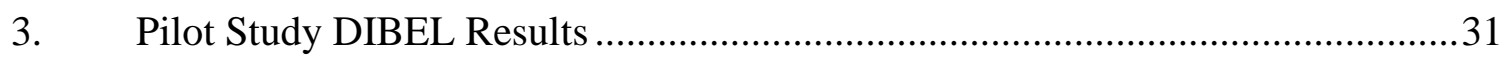

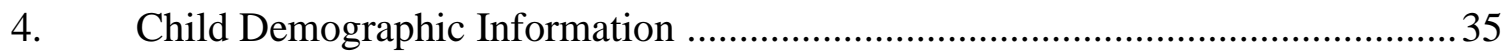

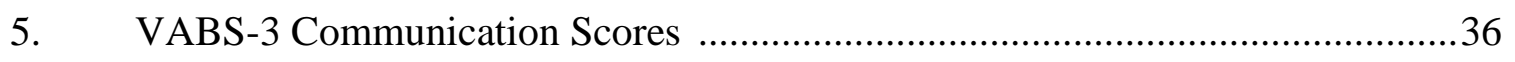

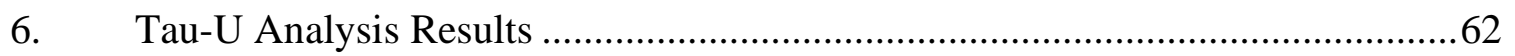

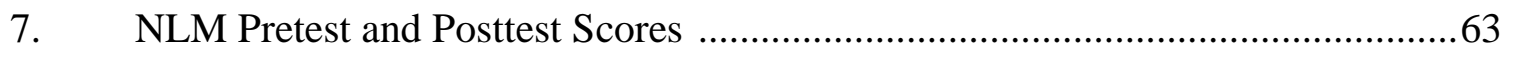

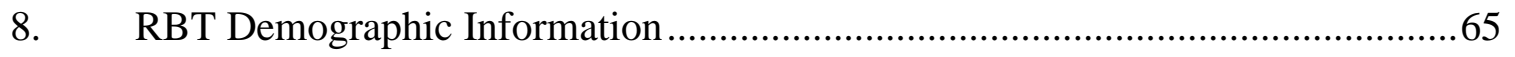

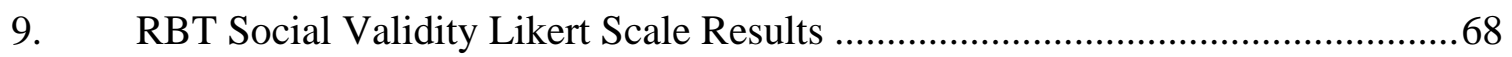

10. RBT Social Validity Open Ended Question Responses ...................................70

11. Interobserver Agreement Results........................................................... 71

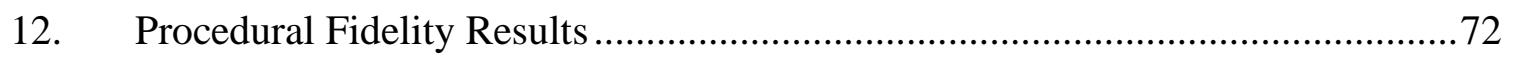

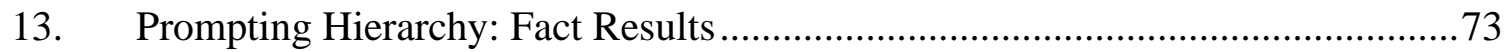

14. Prompting Hierarchy: Search Results .................................................... 73

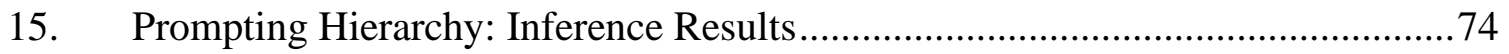

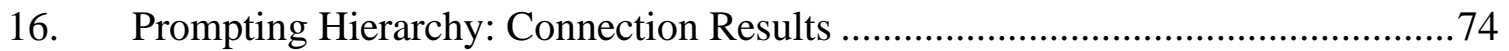




\section{LIST OF FIGURES}

$\begin{array}{lll}\text { Figure } & \text { Page }\end{array}$

1. Pilot Study Baseline: Individual Mean of Correct Responses ............................30

2. Pilot Study Intervention: Individual Mean of Correct Responses ........................30

3. Percentage of Correct Responses to QAR Questions .........................................58

4. Baseline: Individual Mean of Correct Responses ..........................................59

5. Intervention: Individual Mean of Correct Responses .....................................59

6. Maintenance: Individual Mean of Correct Responses .......................................59

7. Baseline: Combined Mean of Correct Responses ...........................................61

8. Intervention: Combined Mean of Correct Responses ...................................61

9. Maintenance: Combined Mean of Correct Responses .......................................61 


\section{CHAPTER ONE INTRODUCTION}

Reading comprehension is a skill that is critical to academic success. (Finnegan and Mazin, 2016; Hogan, Bridges, Justice \& Cain, 2011; Kinniburgh and Prew, 2010). Although children with autism spectrum disorder (ASD) tend to have typical decoding skills, they are known to be at risk for reading comprehension difficulties (McIntyre, Solari, Gonzales, et al., 2017; McIntyre, Solari, Grimm, et al., 2017; Nation, Clarke, Wright, \& Williams, 2006; Whalen \& Hart, 2011). Listening comprehension is a skill which develops in early childhood and is predictive of reading comprehension in primary grades (e.g., Fleury \& Lease, 2018; National Early Literacy Panel [NELP], 2008; National Institute of Child Health and Human Development [NICHD], 2005). Moreover, correlational studies have linked the language and communication deficits of children diagnosed with ASD to challenges in developing reading comprehension skills (McIntyre, Solari, Gonzales, et al., 2017; Nation et al., 2006; Norbury \& Nation, 2011). Researchers have identified a need for effective interventions to facilitate the early development of listening comprehension skills in order to foster the later ability to formally read and comprehend in children with ASD and language disorders (McCauley, Fey, \& Gillam, 2006; McIntyre, Solari, Gonzales, et al., 2017; McIntyre, Solari, Grimm, et al., Paynter, Westerveld, \& Trembath, 2016).

\section{ASD Prevalence}

ASD affects approximately one in 59 children (Centers for Disease Control and Prevention $[C D C], 2018)$. Characteristics that may lead to a diagnosis include impairments in social-communication skills combined with repetitive and restricted behaviors and interests (American Psychiatric Association [APA], 2013). The severity of symptoms varies within each of these characteristics and due to this heterogeneity ASD is termed a spectrum disorder. ASD 
includes three levels which are defined by the amount of support an individual requires to function in the natural environment. Level 1 requires supports as deficits in social communication cause noticeable impairments, Level 2 requires substantial support due to marked deficits in verbal and nonverbal social communication skills, and Level 3 requires very substantial support due to severe deficits in verbal and nonverbal social communication skills (APA, 2013). It is a lifelong condition with symptoms present in early childhood. ASD can occur in any combination of these deficits and levels of severity, and therefore, manifests in a variety of ways from one individual to another. One of the earliest symptoms that can occur in ASD are deficits in oral language skills (Lanter, Watson, Erickson, \& Freeman, 2012; Ricketts, Jones, Happé \& Charman, 2013; Whalon, Otaiba, \& Delano, 2009).

\section{Oral Language Sills in ASD}

Oral language skills include expressive and receptive vocabulary, syntax, pragmatics, and semantics. Due to the complexity of the diagnosis children with ASD also display variance in terms of oral language skills. Some children with ASD develop minimal to no expressive language skills (sometimes described as nonverbal) while others may show expressive skills akin to their typically developing (TD) peers (Asberg \& Sandberg, 2012; Fleury, Miramontez, Hudson \& Schwartz, 2014; McIntyre, Solari, Grimm, et al., 2017). Along with expressive skills, children with ASD can also have specific difficulties in comprehending oral language including vocabulary, syntax, morphology, and pragmatics (McIntyre, Solari, Gonzales, et al., 2017;

McIntyre, Solari, Grimm, et al., 2017; Nation et al., 2006; Whalon \& Hart, 2011). The ability to comprehend oral language has been found to be critical to the development of reading comprehension as it applies to the gradual acquisition of words and their meanings in the early 
stages of development (Hogan, Bridges, Justice \& Cain, 2011; NICHD, 2005; Ricketts et al., 2013). Additionally, in a comprehensive report on the development of emergent literacy skills, The National Early Literacy Panel (2008) discovered that oral language skills were related to later reading comprehension. Specifically, listening comprehension in preschool-aged children has been found to be predictive of reading comprehension in typically developing (TD) students in primary grades (e.g., NELP, 2008; NICHD, 2005; Tunmer \& Prochnow, 2006).

\section{Listening Comprehension}

Listening comprehension is a term used to describe oral language comprehension skills in young children. It is defined as the ability to understand spoken language at the discourse level including conversations, stories, and informational texts in which meaning is constructed and extracted through vocabulary, background knowledge, and inferencing (Hogan, Adlof, \& Alonzo, 2014; Kim \& Pilcher, 2016). Listening comprehension is a primary component in the development of reading comprehension skills as described by the simple view of reading discussed in the following section.

\section{The Simple View of Reading}

The simple view of reading is a theoretical framework which explains reading comprehension as a product of two components: decoding and language comprehension (Gough \& Tunmer,1986; Hoover \& Gough, 1990). Decoding is defined as the ability to learn lettersound combinations and letter patterns to recognize familiar words and learn new words while language comprehension is the ability to understand and construct meaning from words or texts (NELP, 2008; National Reading Panel [NRP], 2000). The language comprehension component is also referred to as listening comprehension which is the term that will be used throughout this paper. Even as early as preschool, indicators of the of simple view components are predictive of 
later reading comprehension, specifically listening comprehension and word recognition (Language and Reading Research Consortium \& Chiu, 2018). An extensive body of research supports the simple view of reading by demonstrating that both components contribute to the development of reading comprehension of TD readers and children with reading disorders (e.g., Catts, Hogan, \& Fey, 2003; Hoover \& Gough, 1990). In the simple view of reading theory, reading comprehension difficulties can arise from difficulty in one or both components of decoding and listening comprehension (Gough \& Tunmer,1986; Hoover \& Gough, 1990). Children who display weak listening comprehension and adequate decoding skills are referred to as poor comprehenders (Catts et al., 2003; Hoover \& Gough, 1990).

\section{Reading Development in ASD}

Previous studies have shown that many children with ASD fit the profile of the poor comprehender displaying average to above average decoding skills, yet struggling with tasks involving listening comprehension which contributes to difficulties with reading comprehension (e.g., Nation et al. 2006; Nguyen, Leytham, Whitby, \& Gelfer, 2015; Norbury \& Nation, 2011). Many children with ASD display strengths in visual processing which may facilitate their ability to recognize letter patterns and learn new words (McIntyre, Solari, Gonzales, et al., 2017; McIntyre, Solari, Grimm, et al., 2017; Nation, Clarke, Wright, \& Williams, 2006; Whalen \& Hart, 2011).

Reading comprehension develops over time and builds upon two brain regions present from infancy: the visual object recognition and oral language systems. These areas combine to facilitate phonological and phonemic awareness, and eventually decoding skills from simple to more complex words. The ability to identify words by sight supplements the decoding or phonological pathway and oral language processing creates meaning from the words. These two 
processes develop independently and the relationship between these factors on reading comprehension develops and changes over time (Finnigan \& Mazin, 2016; McIntyre, Solari, Grimm, et al., 2017). Implementing interventions that address weaknesses in listening comprehension prior to compulsory reading instruction in primary grades may decrease the risk of later reading comprehension difficulties in children with ASD (McIntyre, Solari, Gonzales, et al., 2017; Ricketts et al., 2013; Whalon et al., 2009). Early intervention strategies designed to facilitate the comprehension of stories read aloud can effectively target listening comprehension skills during early childhood development (Hogan et al., 2011; Raphael \& Au, 2005).

\section{Shared Book Reading}

It is well established that reading aloud to children has positive impacts on their language and literacy development and is a staple in early education classrooms (e.g., Lonigan \& Shanahan, 2009; National Research Council, 1998). Shared book reading has emerged as a practice which has been successful in enhancing the language and literacy skills, including listening comprehension of young children (e.g., Coyne, Simmons, \& Kame'enui, 2004; Hargrave \& Senechal, 2006; Henry \& Solari, 2020; Lonigan, Anthony, Bloomfield, Dyer, \& Samwel, 1999, Pollard-Durodola et al., 2011). During shared book reading, an adult reads a book to a child or a group of children and uses structured interactive techniques to actively engage the children in the text. For example, the adult can direct the child's attention to illustrations, print, or word meanings or engage children in discussions focused on understanding the meaning or sequence of events in a story. Additionally, adults may ask children questions, give explanations, and draw connections between events in the text and children's background knowledge to support language development, emergent reading, and comprehension. 
Specific strategies are typically divided between re-tell strategies, such as dialogic reading which focuses on increasing the length of the child responses to comprehension questions, and question-answering strategies in which children learn to answer specific types of comprehension questions (Whalon \& Hart, 2011; What Works Clearinghouse [WWC], 2010). WWC lists shared book reading interventions as an evidence-base practice to facilitate early literacy in young children, specifically in the areas of comprehension, alphabetics, general reading achievement and language devlopment (WWC, 2015).

\section{Statement of the Problem}

The language and communication deficits in ASD which are present in early childhood may impact the development of reading comprehension skills when formal reading instruction

begins in primary grades (McIntyre, Solari, Gonzales, et al., 2017; Nation et al., 2006; Norbury \& Nation, 2011). Identifying interventions to increase listening comprehensions skills for children with ASD in early education settings has the potential to facilitate effective reading comprehension skills in later grades. 


\section{CHAPTER TWO}

\section{REVIEW OF THE LITERATURE}

This section highlights two literature reviews, the first conducted to examine the development of listening comprehension and effective interventions for children with ASD, and the second to examine reading profiles of children with ASD and the efficacy of QAR as a shared book reading intervention for children with ASD.

\section{Listening Comprehension Review of the Literature}

The first review of the literature review examined 1) the extent to which the communication and language impairments in ASD impact the development of listening comprehension and 2) what evidence-based interventions can be implemented in early education settings to facilitate listening comprehension skills for young children with ASD.

\section{Inclusion and Exclusion Criteria}

The articles for the literature review were identified by conducting an electronic search of the educational databases: Education Research Information Center (ERIC), EBSCOhost, Scopus, APA PsychNet, and the Psychological Information Database (PsycINFO). The keywords used in the search were: autism spectrum disorder $(A S D)$ in combination with emergent literacy, reading comprehension, oral language comprehension, evidence-based interventions. The following variables were examined in each article: participants, setting, independent variables, dependent variables, measures, and research design. To be included in the review, the following inclusion criteria were required: (a) the study needed to be published in a peer-reviewed journal between the years 2002 to the present time. The year 2002 was chosen as a cutoff date as this was the year that the use of evidence-based practices in education was federally mandated; (b) participants had a formal diagnosis of ASD based on DSM criteria at the 
time of diagnosis; (c) participants attended an educational program from preschool through grade three to cover the period of emergent literacy development and early reading instruction; (d) the authors of the study examined emergent literacy skills and reading comprehension; (f) the authors measured listening comprehension or an orally administered pre-reading oral comprehension measure such as narrative comprehension, text comprehension, or auditory comprehension.

Studies were excluded if (a) the participants included in the study had a primary disability other than ASD; (b) the study focused on the implementation of alternative augmentative communication (AAC); (c) the participants were English Learners (EL); (d) the authors conducted a review of the literature. The following themes emerged from this analysis: studies which examined differences in how comprehension skills develop in children with ASD and TD children, the heterogeneity of cognitive and language skills in children with ASD and their relationship to comprehension skills, and shared book reading interventions designed to facilitate listening comprehension skills of children with ASD. A total of ten studies were reviewed.

\section{Comparative Emergent Literacy Skills in Children with ASD and TD Children}

Two of the identified studies examined emergent literacy skills as precursors to the development of reading comprehension skills of children with a diagnosis of ASD and TD children (Dynia, Brock, Logan, Justice, \& Kaderavek, 2016; Fleury \& Lease, 2018). Dynia and colleagues (2016) conducted a longitudinal study which analyzed emergent literacy skills in children with ASD in comparison to TD children at three-time points across two years (fall, spring, following spring). The participants were 70 preschool and kindergarten children, 35 with ASD and 35 TD who were matched by age and gender. The study took place among 48 different 
early childhood preschool and kindergarten classrooms. The Phonological Awareness Literacy Screening (PALS) was used to measure alphabet knowledge, and the Preschool Word and Print Awareness (PWPA) was used to measure comprehension skills. The comprehension skills consisted of book and print organizational knowledge and orally administered narrative text questions. Language abilities of the children were assessed using the Clinical Evaluation of Language Fundamental, Preschool, Second Edition (CELF-2).

Results demonstrated that the children with ASD displayed lower oral language abilities $(M=68.3$, range $45-106)$ than their TD peers $(M=93.9$, range $86-106)$. Furthermore, the children with ASD showed equivalent levels of alphabet knowledge compared to their TD peers but performed lower on the print awareness comprehension measures. Specific results for each time period were: Alphabet Knowledge: Time 1 (ASD: $M=27.29$; TD: $M=23.66$, ns), Time 2 (ASD: $M=33.97$; TD: $M=32.70, \mathrm{~ns}$ ), Time 3 (ASD: $M=41.20$; TD: $M=43.23$, ns). Print Awareness: Time 1 (ASD: $M=3.09$, TD: $M=7.74, p<.001$ ), Time 2 (ASD: $M=5.28$; TD: $M=11.03, p<$ .001 ), Time 3 (ASD: $M=7.48 ;$ TD: $M=12.65, P<.001)$.

Although the PWPA measures reached statistical significance at $99 \%$ confidence intervals, no effect sizes were reported. The receptive language skills of the children with ASD and TD children were not included in the study; therefore, it is unknown if oral language skills reflected the overall cognitive ability between the two groups.

Next, Fleury and Lease (2018) compared the emergent literacy skills between ASD and TD children to inform pre-reading instructional practices. The study included 38 participants. Eighteen children with ASD and 20 TD children between the ages 3-5. The study took place in a clinical setting at a university where parents brought children in to be assessed for language and cognitive skills. The measures used were the Battelle Developmental Inventory-Second Edition 
(BDI-2) and the Test of Preschool Early Literacy (TOPEL). The BDI-2 measured the language and cognitive scores of the two groups.

The language scores of the children with ASD and TD children were as follows: Receptive (ASD: $M=8.44$; TD: $M=16.1$ ); Expressive (ASD: $M=8.00$; TD: $M=15.85$ ), Standard Score (ASD: $M=16.44$, TD $M=31.95, p<.001$ ). The cognitive domain scores of the children with ASD and TD children were as follows: Attention and Memory (ASD: $M=5.39$; TD: $M=11.70$ ); Reasoning and Academic Skills (ASD: $M=9.94$; TD: $M=14.70$ ); Perception and Concepts (ASD: $M=7.56$; TD: $M=15.80$ ), Standard Score (ASD: $M=22.89$; TD: $M=$ 42.40, $p<.001)$. Effect sizes were not reported for the BDI-2.

The emergent literacy skills between the groups were compared using the TOPEL and Cohen's $d$ to measure effect sizes. The results revealed statistical significance in the orally administered comprehension measure of Definitional Vocabulary (ASD: $M=91.60$; TD: $M$ $=107.35, p<.001, d=1.12)$. Although the ASD group produced lower mean scores on the remaining subscales, these differences did not reach statistical significance: Phonological Awareness (ASD: $M=93.17$, TD: $M=102.45$, ns); and Early Literacy Index (ASD: $M=93.33$, TD: $M=107.45, \mathrm{~ns})$. The $d=1.12$ effect size in the Definitional Vocabulary category was considered large.

Overall, both studies demonstrated that the ASD children performed at comparable levels to their TD peers in decoding skills; however, they performed lower in the orally administered comprehension measures. This parallels research of the poor comprehender profile in children with ASD. This information may be useful in recognizing that this profile can first present in early childhood during the development of emergent literacy skills and enable educators to target classroom instruction in comprehension related skills for children with ASD. The next set of 
studies examined how differences within the ASD population may impact the development of reading skills in early childhood.

\section{Language and Cognitive Heterogeneity in Children with ASD}

Four studies examined the language and cognition skills of children with ASD and their relationship to early reading development (Davidson \& Weismer, 2014; Knight \& Blancher, 2018; Westerveld et al., 2017; Westerveld \& Roberts, 2017). Two studies were longitudinal, one was an experimental group study, and one was a correlational study.

First, Davidson and Weismer (2014) conducted a longitudinal study to investigate the predictors of reading ability in children with ASD that consisted of two-time points over three years. The participants were 101 children with a confirmed diagnosis of ASD. The children were seen at the first time point at age 2.5. and at the second time point at age 5.5. The measures used were the Mullen Early Scales of Learning (MESL), Preschool Language Scale, Fourth Edition (PLS-4), the Vineland Adaptive Behavior Scales-Second Edition (VABS-2), and The Test of Early Reading Ability-3rd Edition (TERA-3). The study took place in a clinical setting at a university where children were brought in by their parents to participate in the various assessments.

The orally administered PLS-4 subscale of Auditory Comprehension was used to evaluate the scope of language comprehension by assessing basic vocabulary, concepts, morphology, syntax, comparisons, and inferences. The scores revealed language skills ranging from severely impaired to average in Auditory Comprehension $(\mathrm{SS}=50-117)$ at time one and $(\mathrm{SS}=50-129)$ at time two; The PLS-4 also measured Expressive Communication ( $\mathrm{SS}=50-103)$ at time one and (SS = 103-133) at time two. The Tera-3 was administered at the last time point at age 5.5 and measured decoding and related comprehension skills: alphabet, letter name/sound, 
phonological awareness, print awareness, as well as comprehension at word, sentence, and paragraph levels. The participants showed relative strengths on the Alphabet subtest $(M=11$, range 3-19) compared with their performance on both the Print Awareness subtests $(M=6.80$, range $2=18)$ and Comprehension $(M=6.91$, range $=1-19)$. A combination of all scores combined gave a reading quotient $(\mathrm{RQ})$ score $(M=88.64$, range $=51-49)$.

When the heterogeneity in the sample was examined four early reading profiles were revealed: (a) Profile 1 accounted for $7 \%$ of the population who achieved high levels across all subtests: (RQ range $=121-149$ ), (b) Profile 2 and Profile 3 accounted for $62 \%$ of the population with higher alphabet scores and lower comprehension scores with Profile 3 performing lower than Profile 2 in the comprehension subscales: Profile $2(R Q=91-119)$, Profile $3(R Q=66-91)$, and (c) Profile 4 accounted for $31 \%$ of the population who achieved low scores across all subscales of alphabet and comprehension $(\mathrm{RQ}=51-87)$.

Longitudinal predictors of the TERA-3 RQ were correlated through multiple regression with the measures taken from time point one on the PLS-4, MSEL, and VABS-2. The results of longitudinal predictors were: Non-Verbal IQ $(p<.001)$; Autism Severity $(p<.001)$; Social Ability ( $\mathrm{p}<.001)$; Auditory Comprehension $(p<.001)$; and Expressive Language $(p<.001)$. No effect sizes were reported for the longitudinal predictors. The majority of the participants, represented in Profiles 2 and 3 demonstrated average decoding and weak comprehension skills which mirrors the results of previous studies of the reading ability of older children with ASD (e.g., McIntyre, Solari, Grimm, et al., 2017; Nation et al., 2006).

The second study examined the relationship between an early literacy development and the severity of autism symptomology as a predictor of reading comprehension skills in children with ASD. Knight and Colleagues (2018) used a set of curriculum-based measurement (CBM) 
called AIMSweb, a CBM tool with validated norms that can be used as criterion-referenced measures to predict later reading success. The participants were 152 children diagnosed with ASD between the ages of 4-7 $(M=5.8)$ The participants were in enrolled in preschool through first grade and were assessed at two time points during one school year (i.e., fall, spring). The group designations were Pre-k $(N=64)$, Kindergarten $(N=49)$, First Grade $(N=39)$. The Autism Diagnostic Observation Schedule (ADOS) guidelines were used to determine the severity of autism symptomatology with scores of 2-5 considered mild to moderate and scores of 6 and above deemed severe.

The orally administered Comprehensive Assessment of Spoken Language (CASL) was used to measure oral language comprehension in the subscale categories: Pragmatic Judgment, Basic Skills, and Syntax. The individual subscales of the CASL were not reported, but the overall CASL performance scores were $(M=81.97$, Range 42-130). The Aimsweb measure included: Letter-naming fluency (LNF) used for preschoolers, kindergarteners, and first graders, and letter sound fluency (LSF), phoneme segmentation fluency (PSF), and nonsense word fluency (NWF) which were used only for first graders. The PSF measure was administered orally, and students were asked to provide all sounds in given words. On the NWF measure, students were given a page of nonsense words and were asked to sound them out.

The participants with ASD performed significantly lower than national norms on the PSF measure $(N=39) t(38)=(7.91, p<.001, d=-1.27)$. In addition to this lower performance, the PSF measure predicted unique variance in reading comprehension as its significance was noted at $(p<.05, d=1.3)$ between the moderate $(M=97.57)$ and severe $(M=79.00)$ groups. The Cohen's $d$ effect sizes were considered large. Some limitations to these findings include the 
CASL scores not correlated with the AIMSweb measures and the number of children in the mild/moderate group and the severe group was not reported.

The following study also assessed participants according to levels of autism severity by measuring Nonverbal Cognition (NVC). Westerveld and colleagues (2017) conducted an experimental group study which examined the relationship between emergent literacy skills and differences in nonverbal cognition (NVC). The participants were 57 children with ASD ages 4-5. The participants were grouped according to NVC with one group of participants $\mathrm{NVC}<70(N=$ $36)$ and the other group with $\mathrm{NVC} \geq 70(N=21)$. The study took place in clinical, home, and educational settings where researchers assessed children according to parent choice. The measures used were the ADOS, MSEL, Social Communication Questionnaire (SCQ), VABS-2, PALS, Peabody Picture Vocabulary Test-Fourth Edition (PPVT-4), and the Profile of Oral Narrative Ability (PONA).

Results showed that the higher nonverbal cognition group outperformed the lower nonverbal cognition group on all measures of the code related ability. Predictors of the coderelated ability score were analyzed through multiple regressions with SCQ, nonverbal cognition, VABS-2, and PPVT-4. Predictors of the comprehension ability score were analyzed through SCQ, NVC, and VABS-2 Spoken Communication and the orally administered Profile of Oral Narrative Ability (PONA). Effect sizes were calculated using eta squared.

Decoding related group differences which reached statistical significance were: Name writing $\left(p<.05, \eta^{2=.167}\right)$, Letter-sound knowledge $\left(p<.05 \eta^{20=.093}\right)$, and Print/Word Awareness $\left(p<.05 \eta^{2=.215}\right)$. Comprehension group differences were: PPVT Vocabulary: $\left(p<.001 \eta^{2=.255}\right)$, Oral narrative comprehension $\left(\mathrm{p}<.001 \eta^{2=.2390}\right)$, and Oral Narrative Quality $\left(p<.001 \eta^{2=.084}\right)$. Effect sizes were small to medium. This study did not include nonverbal children with ASD as 
they could not participate in the VABS-2 Spoken Communication or the Oral Narrative Quality subscale of PONA.

Westerveld and Roberts, (2017) extended the findings of the previous study by examining if performance on norm-referenced language tasks was related to the oral narrative comprehension and/or production abilities of verbal pre-school children with ASD in a correlational study. The participants were 29 children with ASD ages 4-5. The study took place in a clinical setting at a university. The measures used were VABS-2, PPVT-4, and PONA. The scores of the PPVT-4 and VABS-2 were correlated with scores from the PONA. The subsets of the PPVT-4 that reached statistical significance when correlated with the PONA scores were: Number of Different words $(p<.001)$, Oral Narrative Comprehension $(p<.001)$. The subsets of the VABS-2 that reached statistical significance when correlated with the PONA scores were: Grammatical Accuracy $(p<.05)$, Oral Narrative Comprehension $(p<.05)$. Effect sizes were not reported for this study.

In sum, the four studies demonstrated that higher language and cognitive skills resulted in an increased performance in decoding and comprehension measures. However, the disparity between decoding and comprehension was still present even in children with more advanced language and cognitive skills. This information parallels the comparison studies between children with ASD and TD children. Moreover, it further demonstrates the need for the implementation of effective and evidence-based interventions that can facilitate listening comprehension skills for students with ASD in early childhood that are effective and evidencebased. One intervention used to increase listening comprehension in children with ASD in early education settings is shared book reading which is discussed in the following section. 


\section{Shared Book Reading Interventions}

The studies that examined interventions to increase listening comprehension skills used adaptations to shared book reading where children participated in answering questions to stories or text read aloud while guided and supported by a teacher. The first study was a pretest-posttest pilot study; two were single-subject research designs, and one was an experimental group design (Hudson et al., 2017; Kimhi, Achtarzad, \& Tubul-Lavy 2018; Mucchetti, 2013; Whalon, Martinez, Shannon, Butcher, \& Hanline, 2015). Two of the studies used researcher developed question-answer strategies (Kimhi et al., 2018; Mucchetti, 2013) and two used dialogic reading strategies (Hudson et al., 2017; Whalon et al, 2015). The question-answer strategy studies and the dialogic reading strategy studies will be discussed in the sections that follow.

Question-Answer Strategies. The pilot study (Kimhi, Achtarzad, \& Tubul-Lavy, 2018) adapted a shared reading intervention from the Israeli standards-based national curriculum specifically for kindergarten children with ASD. The six-week study simplified and scaffolded the literacy curriculum by adding explicit, systematic, and focused instruction to accommodate children with ASD. The participants were five students with ASD ages 5-8 in a self-contained kindergarten class. The curriculum adaptations included: (a) use of visual aids; (b) inclusion of language supports, and (c) individualized modification of tasks to fit each child's verbal and cognitive level. Pre-test and post-test measures included: The Narration of Picture Series Scale of the Katzenberger Hebrew Language assessment (KHLA) and PPVT-IV. Four dependent variables were measured using these assessments during pretest and posttest assessments. Coderelated skills included: Alphabetical Knowledge and Phonological Awareness. Comprehension related skills included: Text Comprehension and Syntactic Development. 
Three books were read twice weekly for the six-week duration of the study. The books utilized the Hargrave and Senenchal (2000) standards for preschool book selection. The books were read during circle-time, and two types of comprehension questions (fact and inference) were asked during the story. Results for the decoding dependent variables follow: Alphabet Knowledge: Pretest $(M=23.00)$, Posttest $(M=27.00)$; Phonological Awareness: Pretest $(M=$ 5.20), Posttest $(M=16.20)$. Results of the comprehension dependent variables follow: Text Comprehension: Pretest $(M=.80)$, Posttest $(M=2.3)$; Syntax: Pretest $(M=.80)$, Posttest $(M=$ 2.00). A significance of $p<.05$ was found across all dependent variables; however, no effect sizes were calculated.

Secondly, Mucchetti (2013) developed a shared reading intervention for students with severe ASD. The single subject multiple baseline across participants study included four students, ages 6-8, diagnosed with ASD with minimal expressive language abilities. Students were assessed for language and cognition using the MSEL, and PPVT-4. All group scores were recorded in years and months. PPVT-4: Vocabulary $(M=2.7)$. MSEL: Non-verbal Cognition $(M$ =2.2), Receptive Language $(M=1.6)$, Expressive Language $(M=1.3)$. The shared reading intervention was adapted by choosing stories with simple storylines, familiar concepts, and simple realistic illustrations. Additionally, the books were adapted to include simplified text, visual supports, and tactile objects embedded in the book. The comprehension questions consisted of asking who, what, or where questions about the picture or text that had one correct answer. Students worked one on one with teachers and answered comprehension questions by pointing to pictures on a communication board. The dependent variables measured were story comprehension and activity engagement. Results for story comprehension were Baseline $(M=$ 1.5) correct answers and Intervention $(M=4.5)$ correct answers. The activity engagement results 
were Baseline $(M=46 \%)$ and Intervention $(M=93 \%)$. The points of non-overlapping data $(\mathrm{PND})$ results for story comprehension were $(\mathrm{PND}=100 \%)$ and activity engagement $(\mathrm{PND}=$ $95 \%)$

Dialogic Reading Interventions. The two remaining studies implemented dialogic reading interventions. Dialogic reading is a shared reading model that includes a series of prompts to engage children and encourage verbal interactions during book reading (Whitehurst et al., 1988). Dialogic reading utilizes the mnemonics 'PEER' and 'CROWD' to remember dialogic reading steps, and specific question prompts. PEER stands for prompt, evaluate, expand, and praise. CROWD stands for completion, recall, open-ended, wh-, and distancing (background knowledge). While reading aloud, the teacher periodically prompts a child to verbally participate in the reading.

Whalon et al. (2015) conducted a single-subject multiple baseline across participants study which adapted dialogic reading to an intervention named RECALL (Reading to Engage Children with Autism in Language and Learning). RECALL includes embedded evidence-based systematic instructional procedures and supports known to facilitate the learning of children with ASD such as use of a prompting hierarchy and visual supports. The participants were four students diagnosed with ASD, ages 4-5, in special education preschool classrooms. The BDI-2, TOPEL, and PLS-5 were utilized to ascertain language and developmental levels and were as follows: BDI-2: NVC ( $M=77.2)$; PLS-4: Auditory Comprehension $(M=75.7)$; Expressive Language $(M=66.5)$. The independent variable was RECALL, and the dependent variables were correct unprompted verbal responses to the CROWD comprehension questions.

The intervention took place in dyads with TD peers who acted as social models. Each book had three sets of questions used over three days. Stories were read aloud to a child with 
ASD, and a peer three days a week for approximately 2.5 months, using the PEER and CROWD protocol. Results indicated that all four participants decreased the frequency of incorrect responding and gradually improved their correct, spontaneous answers to fact and inferencebased questions on story content. Tau-U effect sizes were calculated and were as follows on the correct unprompted responses of the four participants. 1) $(T=.40), 2)(T=.77), 3)(T=.71), 4)$ $(T=.71)$. The Tau-U effect sizes were large for three of the four participants and moderate for the fourth.

Hudson et al. (2017) implemented three randomized controlled trials in a group design to investigate two literacy interventions for preschool children with ASD. The treatments were implemented every week for six months across 57 classrooms in eight districts with 133 participants ages 3-5. Children were randomized into three groups. The first group of children participated were randomized to interactive book reading intervention; (IBR; treatment) or business as usual (BAU; control). Group two participated in phonological awareness (PA; treatment) or BAU. In group three, children were randomly selected to IBR or PA (IBR, $n=47$; PA, $n=42$; BAU, $n=44$ ). Pre and posttest measures were PPVT-4 (expressive and receptive vocabulary), the Woodcock Johnson-III (Listening Comprehension), and the TOPEL (Phonological Awareness).

The IBR intervention consisted of shared book reading using the dialogic reading PEER Prompts and CROWD questions. Each group engaged with the same books in an order determined through random selection. The books were chosen from a toddler read-aloud collection. The books were read three to four times consecutively before a new book was started. The PA intervention consisted of 30 lessons composed of words, onset rime, syllables, and letter sounds. 
The results reported Cohen's d effect sizes with the IBR group showing significant pretest-posttest gains on Expressive Vocabulary (Pre-Test $M=86.87$; Posttest $M=94.54, d=$ .29 ) and Listening Comprehension (Pre-test $M=78.15$; Posttest $M=83.78, d=.30$ ). Significant gains were also seen in the PA group intervention. Both the IBR and PA groups improved in phonological awareness: IBR (Pre-test $M=75.21$; Posttest $M=83.23, d=.36$ ) PA group (PreTest $M=79.21$; Posttest $M=91.74, d=.39$ ). Only the children in IBR treatment improved in listening comprehension, and neither treatment resulted in effects for print knowledge or letterword reading, which were not the focus of the interventions. Additionally, the control group did not improve in any of the measures.

All four shared book reading interventions were successful in improving the language and comprehension skills with a wide range of students with ASD. All studies engaged in strategies listed by The National Professional Development Center on Autism Spectrum Disorders (NPDC) for children with ASD such as a prompting hierarchy, peer mediated instruction, and visual supports (NPDC, 2014). The question answering and dialogic reading strategies used in the studies are further discussed in the following section. Refer to Table 1 for a summary of the reviewed studies.

\section{The Question-Answer Relationship Strategy}

QAR is an evidence-based question- answering strategy endorsed by the National Reading Panel (2002). QAR classifies comprehension questions into four categories(a) Fact, (b) Search, (c) Inference, and (d) Connection and is taught sequentially as the categories increase in difficulty (Raphael, 1986). In QAR, students learn to identify whether answers are found in the book only or are also combined with their own background knowledge. Fact and Search questions are found in the text, while Inference and Connection questions require the reader to 
access background knowledge and apply it to the information in the text. Additionally, the QAR strategy is considered a metacognitive strategy which teaches children to apply background knowledge to answer a novel problem or question (Cummins, Streiff \& Ceprano, 2012; Raphael \& Au, 2005; Wilson \& Smetana, 2009).

Two of the shared book reading interventions (Kimhi et al., 2018; Mucchetti, 2013) used elements of QAR, but neither of the studies used the four categories of the intervention. The Kimhi et al. (2018) study incorporated Fact and Inference questions while Mucchetti (2013) used only the first category of Fact questions. The two studies which included the dialogic reading interventions (Hudson et al., 2017; Whalon et al., 2015) used the five categories of the CROWD comprehension questions but did not ask the questions sequentially or in a designated order. None of the studies taught strategies on how to answer the different categories of questions to facilitate the higher-level metacognitive skills needed for proficiency in developing reading comprehension (Hogan et al., 2011; Wilson \& Smetana, 2009).

\section{QAR Review of the Literature}

A second review of the literature was conducted to examine reading comprehension deficits in children with ASD and the efficacy of QAR to target the identified reading comprehension deficits as a shared book reading intervention for children with ASD. This review focused on three themes: 1) What reading comprehension deficits are the most prevalent in children with ASD? 2) Will the QAR strategy help to increase reading comprehension skills in children with ASD? 3) Can QAR be adapted for students with ASD in early education settings?

\section{QAR Inclusion and Exclusion Criteria}

The articles for the literature review were identified by conducting an electronic search of the educational databases: Education Research Information Center (ERIC), EBSCOhost, Scopus, 
APA PsychNet, and Psychological Information Database (PsycINFO). The keyword used in the search were: autism spectrum disorder, question, and answer relationship strategy, and reading comprehension. The criteria for inclusion consisted of (a) articles published in a peer reviewed journal, (b) studies published 2002 to the present time, (c) articles with a focus on reading comprehension for students with ASD and (d) studies that used QAR or a question answering comprehension strategy for individuals with ASD or related disorders. Excluded were articles that were not (a) from peer reviewed journals, including dissertations, (b) focused on the implementation of interventions other than QAR or question-answering comprehension strategies (c) the participants were English Learners (EL); (d) the authors conducted a review of the literature.

The information extracted from the articles was analyzed using a researcher developed coding form. From this analysis four themes emerged: 1) Reading profiles of students with ASD, 2) Cognitive-based theories exploring reading deficits in ASD, 3) Experimental studies of QAR or question answering comprehension strategies, 4) Adaptations of QAR with visual supports for young children with ASD and language impairments. A total of eleven studies were identified for review. This review will summarize the literature that address each of the four themes posed for the review.

\section{Reading Profiles in ASD Populations}

In a comparative study, McIntyre, Solari, Gonzales et al., (2017) examined differences between groups with ASD $(N=81)$, Attention Deficit Hyperactivity (ADHD) $(N=39)$, and TD students $(N=44)$. The results of the study found decoding and comprehension disparities specific to the ASD group with higher decoding and decreased comprehension skills. Moreover, the language impairments in ASD were found to predict reading comprehension difficulties with 
$p<.01$ and $p<.001$ levels of significance. The researchers extrapolated these data to identify subgroups from the ASD group $(N=81)$ in order to identify a more precise alignment of treatments and educational plans for students with ASD. Four profiles emerged from this analysis: Readers with Severe Global Disturbance $(M=14.38)$, which also had the highest level of ASD symptomatology, Readers with Comprehension Disturbance $(M=11.31)$ Readers with Global Disturbance $(M=10.15)$, and Average Readers $(M=9.98)$ (McIntyre, Solari, Grimm et al., 2017). The global disturbance profiles included difficulty with phonology, vocabulary, and comprehension. All groups, including the average group, had difficulty with average auditory reasoning/inference scales and open-ended questions which required the integration of background knowledge. This information corresponded to Nation et al. (2006) in which 65\% of a group of 41 students with ASD students were found to be below standardized norms for reading comprehension, while $78 \%$ of the sample had age level word reading ability.

\section{Cognitive-Based Theories of Reading Deficits in ASD Populations}

In order to further investigate reading comprehension with students with ASD, Roycroft (2015) examined a series of theories that sought to explain cognitive-based reasons for these impairments. Weak central coherence (WCC) theory refers to a core cognitive weakness in children with ASD that causes them to focus on the details in a text, rather than the global meaning. The inhibition deficit theory or Theory of Mind (ToM) hypothesis posits that pupils with ASD may struggle to filter out unnecessary parts of a text and often remember only the parts which interest them. The top down executive deficit theory (EDF) hypothesizes that executive function of top down semantic processing with students with ASD is impaired which cause problems with tasks that require synthesizing information in text to create meaning.

Nguyen, Leytham, Schaefer, Whitby, \& Gelfer (2015) explored how these three cognitive 
deficits in students with ASD affect the ability to comprehend text, and how educators can infuse evidence-based comprehension strategies for students with ASD into the inclusive classroom that benefits all students. They developed as series of guidelines to address these needs: 1) activate and build prior background knowledge, 2) provide visual supports, 3), search for information 4) make connections. This information is relevant as the QAR strategy can encompass all identified recommendations.

\section{The Use of QAR and Question-Answering Strategies for ASD Populations}

Asberg \& Dahlgren-Sandberg (2010) implemented the QAR strategy with a group of students with ASD $(N=11)$ ages 10-15 using a pre-test, post-test experimental design. The fourweek intervention resulted in a $p<.05$ significance and a small effect size $p=.02$ in comprehension skills utilizing a non-parametric Mann-Whitney test. The researchers also measured pre and post decoding skills in which no significant change was found.

Wahlberg and Magliano (2004) examined the use of prior knowledge to answer comprehension questions in adults with $\operatorname{ASD}(N=12)$ compared to matched control group $(N=$ 60). Results showed that the ASD participants did not use prior knowledge provided by title and primer information to answer comprehension questions $(p>.05)$, in contrast to the control group $(p<.05)$. While it is possible that the results could have been influenced by encoding or retrieval deficits, this study highlights the difficulty in answering comprehension questions without an explicit strategy or direct instruction for the ASD population.

Whalon \& Hanline (2008) investigated the effects in a reciprocal questioning strategy in a single subject multiple baseline design across participants. The intervention focused on the measurement of the rate of unprompted questions and responses between ASD participants $(N=$ 3) and peers $(N=9)$ ages seven and eight using visual supports of story elements and types of 
questions. The results indicated that the participants with ASD increased in unprompted questions and responses with peers using visual supports that cued the parts of story and classified different types of comprehension questions which are elements consistent with the QAR strategy. These experimental studies demonstrate the adaptability of question and answer strategies of multiple ages and varying grades in the ASD population.

\section{QAR Adaptations Using Visual Supports}

A benefit of QAR is the versatility with which it can be used across text, content, and grade levels. An additional quality is that it lends itself to the use of visual supports which is an evidence-based practice for students with ASD (NPDC, 2014). Visual supports also allow the strategy to be used with younger children to facilitate reading comprehension skills during critical years of literacy development. Cortese (2003) developed the use of pictures in the question and answer relationship (P-QAR) in which pictures were used in place of text to answer the categories of QAR questions. A case study of a student with a language-based learning disability using P-QAR to correctly answer comprehension questions was described. Similarly (Whalon, Hanline, and Woods, 2007) developed strategies for breaking stories down into visual elements using story cards, story maps, and question cards to supplement text and cue students to answer comprehension questions. Whalon \& Hart (2011) specifically adapted QAR questions into visual supports for young children with ASD and included guidelines for classroom implementation. Refer to Table 2 for a list of the reviewed studies.

\section{Summary of Empirical Gaps in the Literature.}

In summary, the review of the literature on listening comprehension, reading profiles, and QAR studies showed that children with ASD often present a disparity between decoding skills and comprehension skills. Moreover, the disparity between decoding skills and comprehension 
skills is linked to the language and communication deficits inherent in the disorder. Listening comprehension difficulties often present in early childhood and align with later reading comprehension difficulties in primary grades when formal reading instruction begins. However, the reviews demonstrated that there is a paucity of research in the implementation of evidencebased interventions for children with ASD in early education settings to facilitate the development of listening comprehension, a critical precursor to effective reading comprehension. Four of the reviewed studies implemented dialogic and question answering strategies during shared reading interventions. However, no studies implemented a complete, evidence-based question-answer strategy in an early education setting. None of the experimental studies included strategies that teach children how to answer different categories of comprehension questions to target effective listening comprehension and facilitate metacognitive thinking skills.

\section{Purpose of the Study}

The purpose of the study is to examine the effects of QAR and QAR cue cards as a shared book reading intervention package on the listening comprehension skills of children with ASD. The study will focus on children in pre-k children in an early education setting. Currently, WWC guidelines to facilitate comprehension skills for pre-k and kindergarten students include the core components of the QAR strategy including: asking meaning-focused questions before, during, and after reading, activating prior knowledge connections to text, summarizing content, inferencing, and reflecting on the story (WWC, 2016; WWC, 2017). Therefore, the proposed study has the potential to be included as an evidence-based intervention that can be embedded in the quality instruction of early education settings with children with ASD. The following research questions will be addressed by this study. 
1) Is there a functional relation between an adapted question-answer relationship strategy and visual support, shared book reading intervention package and an increase in the level of listening comprehension skills related to fact, search, inference, and connection questions for pre-k children with ASD?

2) What is the social validity of an adapted question-answer relationship strategy and visual support, shared book reading intervention package for pre-k children with ASD? 


\section{CHAPTER THREE}

\section{METHODOLOGY}

A six week pilot study was conducted during the summer of 2018 which preceded the methodology described in this chapter. The purpose of the pilot study was to investigate the effect of the QAR and QAR visual support, shared book reading intervention on the listening comprehension of children with ASD in primary grades. The pilot study provided information to evaluate and refine procedures, measures, and protocols for the present study. Additionally, the results of the pilot study provided preliminary data to determine the effect of the intervention to increase listening comprehension skills in children with ASD. The pilot study will be briefly summarized prior to describing the methodology of the current study.

\section{Pilot Study}

The children in the pilot study were a rising first grade male (PA) and a rising second grade male (PB), both diagnosed with ASD. The children were enrolled in public school inclusion classrooms at the time of the study. The setting was an Applied Behavioral Analysis (ABA) center where the present study also took place. The books read were the series Mittens by Lola Schaefer, and Biscuit by Alyssa Satin Capucilli.

The dependent variable was correct answers to comprehension questions in the QAR categories: Fact, Search, Inference, and Connection. In addition to the dependent variable the Dynamic Indicators of Basic Early Literacy Skills-6 ${ }^{\text {th }}$ Edition (DIBELS) was used as pretest and posttest measure. DIBELS is a set of standardized procedures and measures for assessing the acquisition of literacy skills in grades K-8 (Good and Kaminski, 2002). The study utilized the DIBELS Oral Reading Fluency (ORF) and Retell Fluency (RTF) subscales. The RTF measured reading fluency by words read per minute and the ORF measured comprehension by the number 
of words used to describe the reading passage. Typically, a student will use approximately half of the words per minute to retell a reading passage. For example, a student who reads 100 words per minute will have retell fluency of approximately 50 words. These subscales were chosen to determine if the children displayed a disparity between reading fluency and comprehension skills and if the intervention would show an increase in the posttest results of either subscale.

The results of the pilot study on the dependent variable for PA were: Fact Baseline $(M=$ $60 \%)$, Intervention, $(M=80 \%)$; Search Baseline $(M=30 \%)$, Intervention, $(M=60 \%)$; Inference Baseline $(M=30 \%)$, Intervention, $(M=90 \%)$; Connection Baseline $(M=30 \%)$, Intervention, $(M$ $=90 \%)$. The results of the pilot study of the dependent variable for PB were: Fact Baseline $(M=$ $87 \%)$, Intervention, $(M=92 \%)$; Search Baseline $(M=25 \%)$, Intervention, $(M=67 \%)$; Inference Baseline $(M=39 \%)$, Intervention, $(M=67 \%)$; Connection Baseline $(M=25 \%)$, Intervention, $(M$ $=75 \%$.

The results of the DIBELS pretest for PA were an ORF of 60 words per minute and an RTF score of 3 words. The results of the DIBELs posttest for PA were an ORF of 101 words per minute and an RTF of 17 words. PB's results for the DIBELs pretest and posttest showed an increase in the ORF subscale and the RTF subscale. The results of the DIBELS pretest for PB were an ORF of 105 words per minute and an RTF score of 3 words. The results of the DIBELS posttest for PB were an ORF of 107 words per minute and an RTF of 3 words. PB's results for the DIBELs pretest and posttest showed a slight increase in the RTF subscale and no increase in the ORF subscale. Both pretest and posttest RTF scores for PB consisted of reading the three word titles of the passages. Due to time constraints, a maintenance phase was not conducted in the pilot study. Overall, the results of the pilot study showed a promising effect on the listening comprehension of the two children. However, the short duration and of the study, and the small 
sample size of participants warranted further research. Refer to Figures 1 and 2, and Table 3 for a display of the pilot study results.

Figure 1. Baseline: Individual Mean of Correct Responses

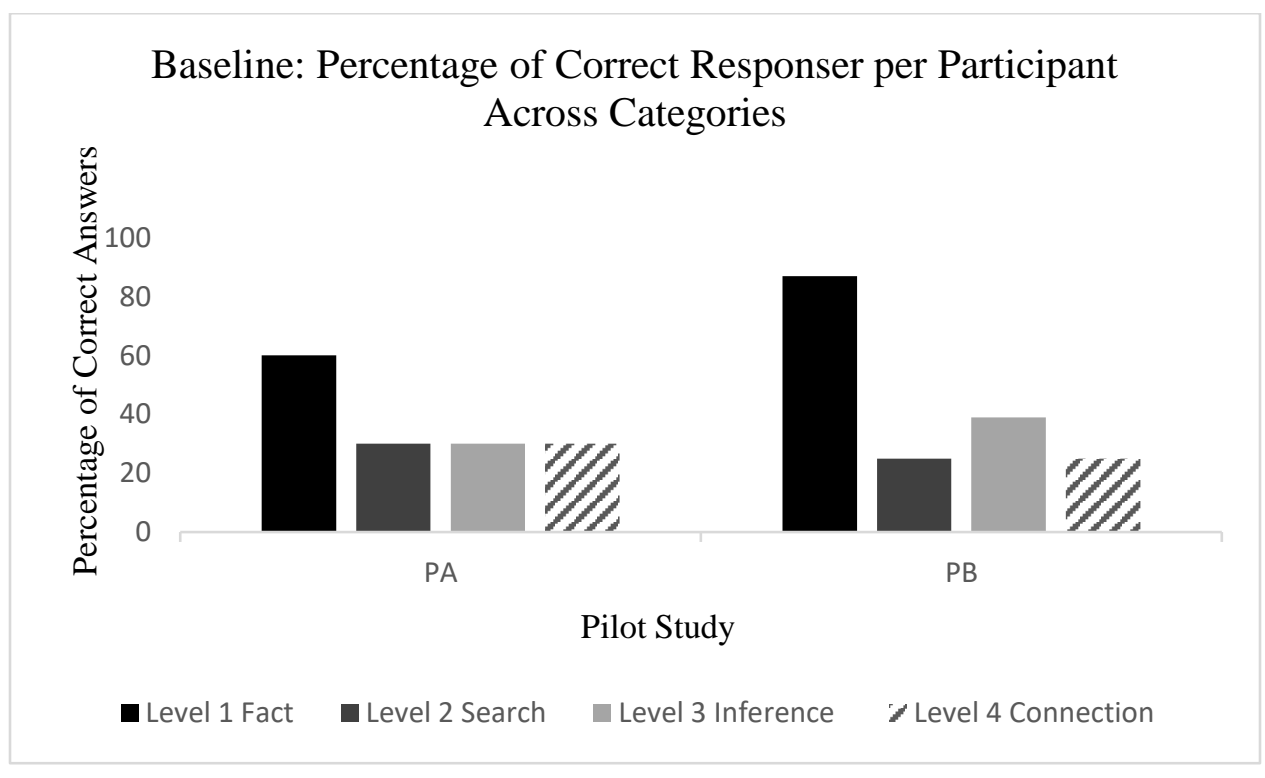

Figure 2. Intervention: Individual Mean of Correct Responses

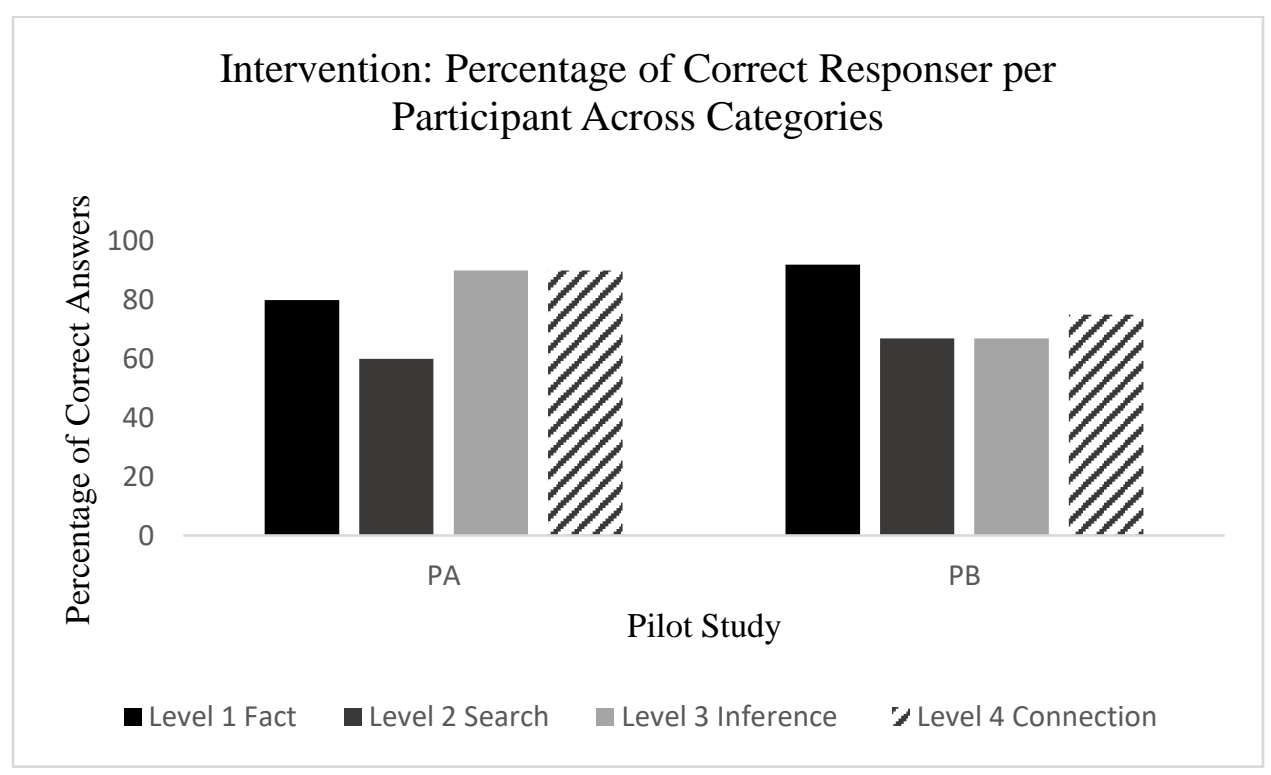


Table 3. Pilot Study DIBELS Oral Reading Fluency and Retell Fluency Scores

\begin{tabular}{lcccc}
\hline Child & ORF Pretest & ORF Posttest & RTF Pretest & RTF Posttest \\
\hline PA & 60 & 101 & 3 & 17 \\
PB & 105 & 107 & 3 & 3 \\
\hline
\end{tabular}

\section{Present Study}

The remainder of this chapter will present the methodology used to examine the effect of QAR and QAR cue cards as a visual support, shared book reading intervention package on the listening comprehension skills of preschool children with ASD. It will include the study framework, research questions, a description of the participants and setting, measurement of the independent and dependent variables, experimental design, research materials and procedures, data collection protocol, and data analysis. Additionally, this chapter will include the assessment of treatment fidelity, inter-observer agreement and social validity from the child and practitioners' perspectives.

\section{Present Study Framework}

The study was guided by the criteria that identifies evidence-based practices for reading interventions (NRP, 2000), visual supports, (NPDC, 2014), shared book reading interventions (WWC, 2015), and single subject research designs (Horner et al., 2005; Kratochwill et al., 2013; WWC, 2017).

QAR fulfills the National Reading Panel (NRP) criteria as an evidence-based practice in the category of question answering strategies within the NRP report. To be classified as an evidence-based practice the NRP used the following criteria: (a) relevant to instruction of reading or comprehension among normal readers, excluding studies on comprehension instruction in reasoning and mathematics problem solving, (b) published in a scientific journal, 
(c) an experimental design with treatment and control group or quasi-experimental variables with variations that serve as comparisons between treatments with random assignment of treatment and control groups (NRP, 2002).

The NPDC lists visual supports an evidence-based practice for students with ASD using the following criteria: (a) two high quality experimental or quasi-experimental design studies conducted by two different research groups, or (b) five high quality single case design studies conducted by three different research groups and involving a total of 20 participants across studies, or (c) a combination of research designs that must include at least one high quality experimental/quasi experimental design, three high quality single case designs, conducted by more than one researcher or research group (NPDC, 2014).

The WWC identified eight studies of shared book reading that meet WWC group design standards. Six studies meet WWC group design standards without reservations, and two studies meet WWC group design standards with reservations. Together, these studies included 791 children aged 3-6 years in 10 locations. The WWC found evidence of shared book reading outcomes in comprehension, alphabetics, general reading achievement and language devlopment. To be classified without reservations the study needed to meet the following criteria: (a) group membership was determined through a random process, (b) low overall and differential attrition, (c) equivalence was established at baseline for the groups in the analytic sample. If only criteria (a) and (c) are met the study is then classified as "with reservations". If criteria (a) and (c) are not met then the study did not meet WWG group design standards (WWC, 2017).

Additionally, the study utilized the quality indicators utilized by WWC (2017) for single subject research designs (Horner et al., 2005; Kratochwill et al., 2013). These include: (a) systematic manipulation of the independent variable or intervention, (b) meeting at least minimal 
standards of $20 \%$ of interrater agreement or reliability on each condition, (c) demonstration of the effect of the intervention over three points in time or over three phase repetitions, (d) at least five data points in each phase of the study. The use of single-subject research documents a causal or functional, relation between independent and dependent variables and is a rigorous, scientific methodology used to define basic principles of behavior and to establish evidence-based practices (Horner et al. 2005; Kratochwill et al., 2013).

\section{QAR Framework}

The QAR framework was adapted for early education students (Whalon \& Hart, 2011) and the categories in the study were covered in the following order and are described as levels: Level 1, (Fact), Level 2 (Search), Level 3 (Inference), and Level 4 (Connection). Adaptation of the four levels for early education children with ASD was as follows: (a) the Level 1, Fact category are questions that require one-word answers gleaned from the book cover and illustrations, that can be answered by who, what, and where (b) Level 2, Search questions require the child to look inside the book to locate a sequence or event. The Level 2, Search questions are limited to searching for answers from no further than one page before or after the page where the question is asked, (c) Level 3, Inference questions consist of local coherence inferences questions which require the child to integrate information that is not explicitly stated from within the text including sentences, pronouns, vocabulary, and illustrations, (d) Level 4, Connection questions ask the child to find a similarity or difference between themselves and a character, incident, or emotion in the story. Additionally, QAR cards (Appendix A) were utilized as visual supports to cue the child on the type of question being asked, to redirect focus and attention, and make abstract concepts more concrete. A think aloud script for each level accompanied the QAR 
card during instructional intervention sessions. Refer to Appendix B for an example of the think aloud scripts for each level.

\section{Research Questions}

The two research questions guiding this study were: 1) Is there a functional relation between an adapted question-answer relationship strategy and visual support, shared book reading intervention package and an increase in the level of listening comprehension skills related to fact, search, inference, and connection questions for pre-k children with ASD? and 2) What is the social validity of an adapted question-answer relationship strategy and visual support, shared reading intervention package for pre-k children with ASD?

\section{Participants}

Prior to the study, the site director of a center that was asked to recruit eligible participants met with the researcher who explained the recruitment process as follows: 1) Provide the site director with a list of the child inclusion criteria, 2) Explain each item of the inclusion criteria to the site director to develop a pool of eligible participants, 3) Ask site director to email the recruitment letter describing the study to the parents or guardians of the eligible participants (Appendix C). The researcher will collect the informed consent forms, the video recording consent forms after they are signed and turned in to the facility.

The inclusion criteria for participation in the study were: (a) a formal diagnosis of ASD defined by DSM-5 criteria or undergoing evaluations for an ASD diagnosis defined by DSM-V criteria, (b) no documented or identified intellectual disabilities (c) ages between 4-5 years, (d) expressive skills of at least 3-word utterances determined by the site director, (e) signed parental consent for participation in the study and permission to record sessions. A total of five children were found eligible to participate in the study. Each child was assigned a letter A-E 
for identity protection purposes. The following is an overview of each child, including Communication scores from the Vineland Adaptive Behavior Scales-Third Edition (VABS-3), (Sparrow, Cicchetti, and Saulnier, 2016). Refer to Table 4 for a display of the Child demographic information.

Table 4. Child Demographic Information

\begin{tabular}{|c|c|c|c|c|c|c|}
\hline Child & Age & Gender & Ethnicity & Diagnosis & $\begin{array}{l}\text { Co-Morbid } \\
\text { Diagnosis }\end{array}$ & $\begin{array}{c}\text { School } \\
\text { Experience }\end{array}$ \\
\hline A & 4 & Male & $\begin{array}{c}\text { African } \\
\text { American }\end{array}$ & SPD & Ataxia & N/A \\
\hline B & 4 & Male & Caucasian & ASD & ODD & $\begin{array}{c}\text { Private } \\
\text { Preschool }\end{array}$ \\
\hline $\mathrm{C}$ & 5 & Male & Caucasian & ASD & $\begin{array}{l}\text { Language } \\
\text { Impairment }\end{array}$ & N/A \\
\hline $\mathrm{D}$ & 4 & Male & Hispanic & ASD & N/A & $\begin{array}{c}\text { SPED } \\
\text { Preschool }\end{array}$ \\
\hline $\mathrm{E}$ & 4 & Male & $\begin{array}{c}\text { African } \\
\text { American }\end{array}$ & ASD & N/A & $\begin{array}{c}\text { SPED } \\
\text { Preschool }\end{array}$ \\
\hline
\end{tabular}

Note: $\mathrm{ADHD}=$ attention-deficit/hyperactivity disorder; ASD = autism spectrum disorder; ODD $=$ oppositional defiant disorder, $\mathrm{SPD}=$ sensory processing disorder; $\mathrm{SPED}=$ special education

Vineland Adaptive Behavior Scales-Third Edition. Each child was assessed at the center by the Board Certified Behavior Analyst (BCBA) assigned to the child prior to the study. The VABS-3 is a standardized, norm-referenced measure of adaptive behavior in three areas: Daily Living, Socialization, and Communication. The Communication domain is comprised of three subdomains Expressive, Receptive, and Written. The Expressive subdomain assesses the use of words and sentences expressed verbally. The Receptive subdomain score assesses attending, understanding, and responding appropriately to information from others. The Written subdomain score assesses reading and writing skills. The domain scores expressed as standard scores (SS) have a mean of 100 and standard deviation of 15. Percentile ranks for the VABS-3 are between 1-99 and correspond to the sum of raw scores from each domain. For the purposes of this study the scores for the Communication domain of the VABS-3 for each child was shared 
with the researcher and are reported along with additional pertinent information in the following sections. Refer to Table 5 for a display of the VABS-3 scores.

Table 5. Child VABS-3 Communication Domain Information

\begin{tabular}{ccccc}
\hline Child & $\begin{array}{c}\text { Expressive } \\
\text { Language } \\
\text { Raw Score }\end{array}$ & $\begin{array}{c}\text { Receptive } \\
\text { Language } \\
\text { Raw Score }\end{array}$ & $\begin{array}{c}\text { Written } \\
\text { Language } \\
\text { Raw Score }\end{array}$ & $\begin{array}{c}\text { Communication } \\
\text { Domain } \\
\text { Standard Score }\end{array}$ \\
\hline A & 55 & 42 & 7 & 76 \\
B & 82 & 58 & 14 & 89 \\
C & 48 & 46 & 11 & 66 \\
D & 70 & 62 & 26 & 93 \\
E & 31 & 33 & 8 & 81 \\
\hline
\end{tabular}

VABS-3= Vineland Adaptive Behavior Scales-Third Edition

Child A. Child A was a four-year-old African American male with a primary diagnosis of Sensory Processing Disorder (SPD) and a co-morbid diagnosis of ataxia. He qualified for Applied Behavior Analysis (ABA) services at the center while undergoing further evaluations for a possible ASD diagnosis. He was diagnosed with SPD at age 2. He did not attend public or private school at the time of the study and received all services from the ABA center. He received ABA services for communication, daily living, social, and behavioral goals. The VABS-3 Communication scores for Child A were below average. For Expressive, he had a raw score of 55 which is 25.5 raw points below the average for his age. The median raw score in the normative sample was 80 . For Receptive, he had a raw score of 42 which is 24 raw points below the average for his age. The median raw score in the normative sample was 66 . For Written, he had a raw score of 7 which is 6.5 raw points below the average for his age. The median raw score in the normative sample was 13.5. The Communication SS was 76 (with a $90 \%$ confidence interval of 72 to 80 ), which corresponds to a percentile rank of 5 and indicated significantly below average communication skills. 
Child B. Child B was a four-year-old Caucasian male with a primary diagnosis of ASD and a co-morbid diagnoses of Attention Deficit/Hyperactivity Disorder (ADHD) and Oppositional Defiant Disorder (ODD). He was diagnosed with ASD at age 4. He attended a half day private preschool program with typically developing peers. He received ABA services at the center for communication, daily living, social, and behavioral goals. The VABS-3

Communication scores for Child B were average. For Expressive, he had a raw score of 82 which is 6 raw points below the average for his age. The median raw score in the normative sample was 88 . For Receptive, he had a raw score of 58 which is 11 raw points below the average for his age. The median raw score in the normative sample was 69 . For Written, he had a raw score of 14 which is 1 raw point below the average for his age. The median raw score in the normative sample was 15 . The Communication SS was 89 (with a $90 \%$ confidence interval of 84 to 94), which corresponds to a percentile rank of 23 and indicated average communication skills.

Child C. Child C was a five-year old Caucasian male with a diagnosis of ASD and a comorbid diagnosis of a Language Impairment. He was diagnosed with ASD at age 2. He did not attend public or private school but was scheduled to begin Kindergarten in the fall.

He received $\mathrm{ABA}$ services at the center for communication, daily living, social, and behavioral goals. The VABS-3 Communication scores for Child $\mathrm{C}$ were below average. For Expressive, he had a raw score of 48 which is 44 raw points below the average for his age. The median raw score in the normative sample was 92 . For Receptive, he had a raw score of 46 which is 25 raw points below the average for his age. The median raw score in the normative sample was 71. For Written, he had a raw score of 11 which is 10 raw points below the average for his age. The median raw score in the normative sample was 21. The Communication SS was 66 (with a 90\% 
confidence interval of 61 to 71), which corresponds to a percentile rank of 1 and indicated significantly below average communication skills.

Child D. Child D was a four-year old Hispanic male with a diagnosis of ASD. He was diagnosed with ASD at age 2. He attended a half day special education preschool class through the public-school system at the time of the study. He received ABA services at the center for communication, daily living, social, and behavioral goals. The VABS-3 Communication scores for Child D were average. For Expressive, he had a raw score of 70 which is 14 raw points below the average for his age. The median raw score in the normative sample was 84. For Receptive, he had a raw score of 62 which is 5.5 raw points below the average for his age. The median raw score in the normative sample was 67.5. For Written, he had a raw score of 26 which is 9.5 raw points above the average for his age. The median raw score in the normative sample was 16.5. The Communication SS was 93 (with a 90\% confidence interval of 89 to 97), which corresponds to a percentile rank of 32 and indicated average communication skills.

Child E. Child E was a four-year old African American male with a diagnosis of ASD. He was diagnosed with ASD at age two. He attended a special education public school preschool program at the time of the study. He received ABA services at the center for communication, daily living, social, and behavioral goals. The VABS-3 Communication scores for Child E were below average. For Expressive, he had a raw score of 31 which is 29 raw points below the average for his age. The median raw score in the normative sample was 60 . For Receptive, he had a raw score of 33 which is 15.5 raw points below the average for his age. The median raw score in the normative sample was 48.5 . For Written, he had a raw score of 8 which is 10 raw points below the average for his age. The median raw score in the normative sample was 18 . The 
Communication SS was 81 (with a $90 \%$ confidence interval of 77 to 87 ), which corresponds to a percentile rank of 10 and indicated significantly below average communication skills.

\section{Setting}

The study was conducted in a series of therapy rooms at a center that provides behavioranalytic services to children with ASD in the southeastern region of the United States. Each room contained a table, chairs, and a shelf which contains books and learning materials. Each room had observation windows. The site was chosen because all children who received services at the center were diagnosed with ASD or a related disorder and had individualized programs which consisted of behavioral, communication, and social skills goals implemented by Registered Behavioral Technicians (RBT) and supervised by a BCBA. Each child was accompanied to the therapy room by their assigned RBT who advised and ascertained demand limits placed on the child in order to monitor sensory overload and behavioral outbursts.

The center ran a morning and afternoon program which consisted of circle time, group table activities, group sensory motor activities, snack time, outdoor recess, and one-on-one teacher time. The one-on-one teacher time was the allotted time when children worked on individual skills with their assigned RBT. The intervention sessions took place three times per week during the teacher time intervals during the morning session for one child and the afternoon session for the remaining four participants.

\section{Institutional Review Board and Consent Procedure}

Approval to implement the study was requested from the University Institutional Review Board (IRB) where the researcher is a doctoral student. Once approval for the study was received from IRB, the site director identified possible participants and emailed a recruitment letter. When a parent responded with intertest, the site director emailed an informed consent form and a video 
recording consent form. Once all the consent forms were collected, the researcher met individually with each child and read assent letters which contained emoji faces for the child to point to "yes" or "no". Each child pointed to yes and assented to the study. Refer to Appendix D to view the informed consent form, Appendix E for the video recording consent form, and Appendix F for the assent letter.

\section{Materials}

The books utilized for the study were a series of picture book stories at the pre-k or kindergarten level from the Read Together/ Talk Together program. Read Together/ Talk Together is a set of twenty books created for shared reading interventions in pre-k or kindergarten classrooms (Fleury \& Schwartz, 2017). This also increased the likelihood that the books were comparable in vocabulary, syntax, and semantic levels. Ten books were randomly selected using the Random.org integer generator for use in either baseline (five books), intervention (three books), or maintenance (two books). A list of questions and an answer key were prepared for each book. Refer to Appendix G for the list of books used in the study and Appendices H-Q for a sample of questions from each level and answer key for each book.

Additional materials included QAR cards which contained illustrations of each level, paired with the QAR think aloud scripts with specific directions on how to find answers, a board to display cards, a computer for recording sessions, and a stopwatch to time the latency between the presentation of a question and the child's response.

\section{Independent and Dependent Variables}

The main dependent variable was correct answers to comprehension questions. A correct answer was defined as the child answering the question correctly, beginning the answer within four to six seconds and with no prompting from the researcher. A response per-opportunity was 
used to collect data on the number of correct answers. The independent variable was the QAR strategy and QAR cards intervention package.

In addition to the main dependent variable, The CUBED Narrative Listening Measure (NLM) benchmark assessment (Petersen \& Spencer, 2016) was administered as a pre-test/posttest measure. The inter-rater agreement or reliability of NLM was 95\% (indicating that two independent examiners assigned the same scores to the same student responses). Concurrent validity was $>.70$ (very strong), and predictive validity was $.43 \mathrm{R}^{2}$ (meaningful) when compared to standardized assessments in language and reading and has been replicated through multiple studies (Petersen and Spencer, 2016).

During intervention sessions, correct unprompted, correct verbal prompted, correct verbal and gestural prompted, incorrect unprompted, incorrect verbal prompted, incorrect verbal and gestural prompted, and no response answers were recorded for instructional and programming purposes.

Prompt Definitions. The prompt definitions follow: (a) correct unprompted was defined as the child answers the question correctly beginning the answer within 4 to 6 seconds with no prompting from the researcher, (b) correct verbal prompted was defined as the researcher providing a verbal prompt (e.g., repeating question or providing a hint) if the child did not begin a response within 4 to 6 seconds and the child answered the question correctly, (c) correct verbal and gestural prompted was defined as the researcher providing a verbal and gestural prompt (i.e., pointing to picture) after 4 to 6 seconds if the child did not respond to the verbal prompt and the child answered the question correctly, (d) incorrect unprompted was defined as the child answering the question incorrectly beginning the answer within 4 to 6 seconds with no prompting from the researcher, (e) incorrect verbal prompted was defined as the researcher 
providing a verbal prompt (e.g., repeating question or providing a hint) if the child did not begin a response within four to six seconds and the child answers the question incorrectly, (f) incorrect verbal and gestural prompted was defined as the researcher providing a verbal and gestural prompt (i.e., pointing to picture) after 4 to 6 seconds if the child did not respond to the verbal prompt and the child answered the question incorrectly. No response was recorded if the child did not answer or said, "I don't know" after the prompting hierarchy has been employed. This information is not represented on the graph but was used to make programming or instructional decisions.

\section{Experimental Design}

A single-subject concurrent multiple-baseline design across participants with continuous acquisition probes was used to evaluate the effectiveness of the QAR strategy on the correct answers to the four levels of comprehension questions. In a concurrent multiple baseline design, the participants begin baseline at the same time and the intervention is staggered across participants. This design has been used successfully to identify effective educational interventions and has several advantages (Ledford \& Gast, 2018). One of the main assets of this design is that it does not require the withdrawal of a potentially effective intervention. Additionally, the sequential implementation of the independent variable aligns with the classroom practices of many teachers. Finally, the concurrent measurement of the independent variable allows for direct monitoring of intervention effects on the participants level of performance on the target behavior (Ledford \& Gast, 2018). Two of the four shared book reading studies in the first literature review (Mucchetti, 2013; Whalon et al., 2015) used the single subject multiple baseline across participants design. 


\section{Procedure}

Pretest/ Posttest. The NLM benchmark assessment was administered to each child prior to baseline and after the last intervention session at the conclusion of the study. The NLM benchmark assessments are comprised of nine passages divided into three per each in fall, winter, and springtime periods. Two of the same fall benchmark passages were used for the pretest session and posttest sessions. The NLM is administered utilizing scripts for examiners to follow in which a short story passage is read aloud, and questions are asked which correspond to the QAR categories. The NLM passages are accompanied by illustrations which the child follows along with as the passage is read aloud. The questions consist of "who" and "what" which correspond to QAR Fact questions, "where in the story" questions which corresponds to QAR Search questions, "why" questions and problem solving questions which correspond to the QAR Inference questions and a Personal Generation question in which the child is asked to relate a similar experience to the story which corresponds to the QAR Connection questions. The Story Question and Personal Generation sections of the NLM are scored and interpreted as criterion reference measures.

Baseline. Baseline sessions began with the RBT and the researcher accompanying the child to a therapy room. Next, the researcher asked the child to sit at the table and the researcher sat next to the participant. The RBT sat in chair across the room to monitor the session. The researcher read the designated book to the child and asked five questions from each level. In order to follow recommended guidelines to facilitate comprehension for pre-k and kindergarten students,' questions were asked before, during, and after the reading (Foorman, Beyler, Borradaile, Coyne, Denton, Dimino, \& Keating, 2016; Lonigan \& Shanahan, 2009; WWC 2016; WWC, 2017). The questions were asked in the following order: Level 1, Fact questions were 
asked before the story, but after the researcher stated the title and author of the story. Level 2, Search and Level 3, Inference questions were asked during the story and were embedded using adhesive tabs on the appropriate pages. Level 4 , Connection questions were asked after the story was completed. No prompts were used, and if no response had begun within 4 to 6 seconds the next question was asked. The children were praised for sitting, listening, and answering, but did not receive corrective feedback.

Once Child A achieved three to five stable baseline points, then intervention Level 1, Fact, began. Children B, C, D, and E began baseline for the first three sessions and then were probed periodically until Child A reached the first intervention criterion point in Level 1 (80\% unprompted correct answers to Level 1, Fact questions). If books were repeated during the baseline phase of the study, the Level 1 and Level 4 questions were randomized during their respective phases using the Random.org Sequence Generator. Level 2 questions were reversed from the page forward or the page back in repeated stories. Level 3 questions correspond to specific pages; therefore, this category was not randomized during repeated use of stories.

Probe Sessions. Prior to teaching the QAR level during intervention sessions, a probe was conducted using the book and five questions from the previous session chosen randomly by the Random.org Sequence Generator. Probes were conducted using the procedures in baseline. These probes were analyzed and graphed as the dependent variable.

The criterion to move from one level to the next was $80 \%$ of unprompted correct answers to questions for a total of three sessions. The criterion percentage of $80 \%$ was chosen as the ABA center uses this criterion to establish proficiency for similar tasks and considers a margin of error, given the young age of the children. 
Instructional Sessions. Following the probe, the QAR level was taught and modeled using a think aloud strategy with QAR cards and QAR level scripts. The researcher read the appropriate level script and modeled how to find an answer from the current book. One to three questions were modeled, depending upon the child's grasp of the concept. This process was repeated one to three times at each intervention session if the child scored less than $80 \%$ of correct answers during the probe.

Next, the researcher read the title and author of the next book and asked questions before, during, and after the story. If the child responded correctly within four to six seconds they were praised for the correct response. If the child emitted an incorrect response, they were given the correct response and praised for answering. If the child did not respond the prompting hierarchy was employed. The prompting hierarchy previously described was used.

Each intervention phase consisted of a story and 10 comprehension questions at the respective level. The three books that were used in the intervention sessions were assigned numbers one through three and randomly chosen using the Random.org Sequence Generator with no book being used more than twice consecutively. If the numbers generated a book being used more than twice consecutively, then a new sequence was run from Random.org. The sessions were approximately 20 minutes in duration and ran 3 days per week.

When Child A reached $80 \%$ criteria of correct answers for the first day in Level 1, Fact then Child B began intervention Level 1 if baseline data indicated stable levels of performance. This procedure was repeated until all participants entered the intervention phase of the study.

Maintenance. Two maintenance probes were conducted with five questions in each level. To conduct a maintenance probe, the researcher used the same procedures as in baseline. The maintenance sessions were conducted one week and two weeks after the conclusion of each 
child completing the four QAR levels. The baseline, intervention, and maintenance probes were tabulated, graphed, and analyzed. The answers and prompts in interventions sessions were recorded as supplemental information. Please see Appendix R, S, T and U for examples of the baseline, intervention probe, instructional intervention, and maintenance data sheets.

\section{Measures}

Interobserver Agreement. Two graduate students from the speech-language pathology program at Old Dominion University were trained as coders. Initial training in the observational codes and definitions was implemented prior to baseline using video tapes from the pilot study whose parents had signed consent forms for the videos to be used for training purposes. The training continued until the graduate students achieved a minimum of $85 \%$ agreement in the use of researcher questions and child responses. An additional training session was conducted when interobserver agreement fell below 85\%. The formula for interobserver agreement was calculated by the number of agreements divided by the total of agreements plus disagreements and multiplied by 100 . One graduate student was the primary recorder and the second graduate student was the reliability observer. The reliability observer coded $35 \%$ of the baseline, intervention, and maintenance sessions randomly selected by the Integer Generator on Random.org and reached a minimum of $85 \%$ accuracy with the primary recorder. The videotapes and data were stored in a password protected computer accessible only to the researcher and coders.

Procedural Fidelity. Procedural fidelity measures the degree to which all conditions of the study are consistently implemented as intended (Ledford \& Gast, 2018). This was assessed by the primary coder for each session using the Procedural Fidelity Checklist for either baseline, intervention, or maintenance sessions. In order to ensure procedures were consistently followed 
for each phase of the study $35 \%$ of sessions randomly selected by the Integer Generator on Random.org were assessed by the secondary coder. Refer to Appendix V to view the baseline or maintenance procedural fidelity checklist and Appendix W for the intervention procedural checklist.

Social Validity. Social validity is one of the quality indicators in single-subject research in which the socially important outcomes are considered for educational interventions (Horner et. al., 2005). A brief social validity questionnaire was administered to the children upon completion of the study. The questionnaire consisted of four questions that were read aloud to children to indicate their feelings about the study by circling happy, sad, or neutral emoji faces (Appendix $\mathrm{X}$. The questions asked the children if they thought that the strategy was helpful to answer questions, if they enjoyed the stories, and if they would like to use the intervention again. Additionally, a survey was prepared and given to each of the five RBTs who had observed and monitored the children during each phase of the study. The survey consisted of four demographic questions, ten Likert scale questions, and five open ended questions. The demographic questions focused on education and professional experience, the Likert scale questions focused on the effectiveness of the intervention, and their interest in learning the QAR strategy, the open- ended questions focused on what they considered to be the benefits of the study and how the study could have been improved. The survey was given to the RBTs one week before the study concluded. They were instructed to return the surveys to the office manager who kept them in a labeled envelope which was given to the researcher on the last day of the study. Refer to Appendix Y to view the RBT survey.

Data Analysis. The data sources for the study were the visual analysis of single-subject design data, and the pre/post NLM benchmark assessments. Data from baseline, intervention and 
maintenance sessions for each child was collected and graphed after each session for formative evaluation purposes of intervention effects. The formative evaluation included trend direction, variability, level change, changes in data patterns, immediacy of effect, and overlap of performance within and between phases. The trend refers to the slope and direction of data over time, variability refers to the fluctuation of one data point to the next, and the level refers to the mean of the data within a phase. The changes in data patterns examines the consistency of data when phases with similar conditions are associated with similar data. The immediacy of effect refers to the magnitude of change between phases. Overlap refers to the percentage of data from one phase that overlaps with the range of data from the previous phase. (Ledford \& Gast, 2018). Split middle analysis was used to identify the trend by examining whether the direction of the data path was flat, accelerating, or decelerating within each phase of the study and changes in trend between the baseline and intervention phases of the study. Stability envelope analysis estimated the stability and variability of levels and trends within each phase of the study. The immediacy of effect examined absolute or relative change between the baseline and intervention phases of the study. Tau-U statistical analysis was used to analyze the overlap of data between phases of the study. Tau-U is a quantitative approach for analyzing single subject research data. It combines nonoverlap between phases with intervention phase trend. It can correct for a baseline trend and provides an effect size to augment visual analysis in single subject research designs (Parker, Vannest, Davis \& Sauber, 2011).

Summative visual analysis was conducted on all factors at the conclusion of the study to determine if a functional relation occurred between the independent and dependent variables. Pre-test and post-test comparisons were also used to examine summative growth in answering comprehension questions to passages read aloud. 


\section{CHAPTER FOUR}

\section{RESULTS}

This study examined the effect of the four levels of comprehension questions in the QAR strategy to improve the listening comprehension of children with ASD. This chapter is organized in terms of the two specific research questions posed in Chapter 1. First, it examines whether participants' listening comprehnsion improved after learning the QAR strategy to answer comprehension questions. Secondly, it reports on the social validity of the QAR strategy for pre K children with ASD. The chapter presents results to both research questions and are discussed separately.

A single-subject concurrent multiple-baseline design across participants with continuous acquisition probes was used to evaluate the effect of the QAR strategy on increasing the correct answers to the four levels of comprehension questions. Baseline data were collected for each child until stable level of performance was noted. Intervention was then implemented and continued until each child reached criterion or if the level was discontinued. The results were examined through visual analysis and Tau-U statistical analysis. The Microsoft program Excel was used to construct graphs for each child, and for the levels of the comprehension questions.

Five aspects of data were analyzed in order to examine the types of functional relations that may have been established in the study (Horner et al., 2005). First, data were examined to determine changes in means and levels within and between phases. Second, the trend line in each phase was analyzed to determine the directionality of data points in a therapeutic or deteriorating direction. Trend line in each phase was determined to be accelerating, decelerating, or flat by split middle analysis. Third, the stability of levels and tends were inspected. For data to be considered stable, at least $80 \%$ of data had to fall within a $25 \%$ stability envelope. The stability 
envelope refers to the two lines drawn above and below the median points and/or trend lines within a $25 \%$ range of the median. When compared to the baseline phase, lower variability during the intervention could be a potential treatment effect of the intervention (Horner et al., 2005; Ledford \& Gast, 2018). Fourth, the immediacy of effect was analyzed to determine the magnitude of change by comparing the last data points in the baseline phase and the first data points in the intervention phase to determine absolute and relative change in level. Absolute change in level was calculated by finding the positive or negative difference between the last data point of the baseline phase and the first data point of the intervention phase. Relative change was calculated by finding the positive or negative difference between the medians of the last five data points and first five data points between the baseline and intervention phases (Horner \& Ferron, 2018; Ledford \& Gast, 2018).

The fifth method of analysis, Tau-U, was used to determine treatment effect size on the dependent variable for each child and for the overall effect of the intervention. An online calculator at http:// www.singlecaseresearch.org was used to compute the Tau-u effect size measures (Vannest, Parker, Gonen, \& Adiguzel, 2016). Raw data was entered into the online calculator for the baseline phase and intervention phase of the study for each participant. Baseline data is first calculated to determine if a corrected baseline formula is needed. The criteria to use the corrected baseline formula was a baseline trend over .20 (Vannest \& Ninci, 2015). Next the appropriate baseline and intervention data are chosen to calculate the effect size of each individual child and the effect size of the intervention. Tau-U effect sizes are .80 and above a very large effect size, .60 to .80 a large effect size, .20 to .60 a moderate effect size, .20 a small effect size, and below .20, no effect indicated (Vannest \& Ninci, 2015). 
Additionally, child and RBT satisfaction surveys were administered to collect and analyze data for the social validity of the QAR intervention.

The research took place over a four month period, which included recruiting participants, baseline, intervention, and maintenance phases of the study. Five pre-k children four with ASD and one with a related disorder participated in the study. They were randomly to assigned identifiers A, B, C, D, E which determined the order in which they would begin the baseline phase of the study and, subsequently, begin Level 1 of the intervention phase. As each Child reached criterion in Level 1, Fact questions, they progressed to the next level until each Child reached Level 4, Connection. Additionally, each Child was administered the Story Questions and Personal Generation section of the Narrative Listening Measure of the Cubed Language Dynamics assessment as a pre and posttest measure. Each research question is answered individually.

\section{Research Question 1}

Is there a functional relation between an adapted question-answer relationship strategy and visual support, shared book reading intervention package and an increase in the level of listening comprehension skills related to fact, search, inference, and connection questions for pre-k children with ASD?

\section{Visual Analyses of Data}

Baseline, intervention, and maintenance for each child are discussed, as well as a comparison of the QAR levels by each child individually and as a group during each phase of the study. Refer to Figure 3 for a graph of the results. Figures 4, 5, and 6 display the correct answers by each child in each category in the baseline, intervention, and maintenance phases. 
Child A. See the first graph of Figure 3 for the correct answers to comprehension questions for Child A. Child A completed five baseline sessions, 13 intervention sessions, and two maintenance sessions. Split middle analysis revealed an accelerating trend line in baseline and intervention phases with variability of $60 \%$ of data falling within a $25 \%$ stability envelope during baseline and a stable $92 \%$ of data falling within the stability envelope during intervention. Child A displayed a positive absolute level change of $45 \%(35 \%, 80 \%)$ and a relative level change of $35 \%(45 \%, 80 \%)$ between the baseline and intervention phases.

During the initial baseline, the answers to all four types of comprehension questions was variable, ranging from $35 \%$ to $65 \%,(M=48 \%)$. The mean percentage of correct answers by category can be seen on the first set of bar graphs on Figure 4 and were Level 1, Fact ( $M=75 \%$, range $=20 \%-100 \%)$, Level 2, Search $(M=18 \%$, range $=0-20 \%)$, Level 3, Inference $(M=56 \%$, range 10\%-80\%,), Level 4, Connection $(M=40 \%$, range $0-80 \%$,).

During the intervention phase, the correct answers to all four types of comprehension questions ranged from 20\% to $100 \%,(M=81 \%)$ During the intervention phase the Level 1, Fact category was $(M=87 \%$, range $=80 \%-100 \%$, Level 2, Search $(M=75 \%$, range $=20 \%-100 \%)$, Level 3, Inference $(M=80 \%$, range $=80 \%-80 \%)$, Level 4, Connection $(M=80 \%$, range $=80 \%$ $80 \%)$. The mean percentage of correct answers by category for the intervention phase can be seen on the first set of bar graphs on Figure 5.

During the maintenance phase, the correct answers to all four types of comprehension questions ranged from $60 \%$ to $100 \%,(M=80 \%)$. The mean percentage of correct answers by category can be seen on the first set of bar graphs on Figure 6 and were Level 1, Fact ( $M=$ $80 \%$, range $=80 \%-80 \%)$, Level 2, Search $(M=100 \%$, range 100\%-100\%, Level 3, Inference $(M=60 \%$. range $=60 \%-60 \%)$, Level 4, Connection $(M=80 \%)$, range $=80 \%-80 \%)$. 
Child B. See the second graph of Figure 3 for the correct answers to comprehension questions for Child B. Child B completed six baseline sessions, 13 intervention sessions, and two maintenance sessions. Split middle analysis revealed an accelerating trend line in the baseline phase and a flat trend line during the intervention phase with variability of $67 \%$ of data falling within a $25 \%$ stability envelope during baseline and a stable $93 \%$ of data falling within the stability envelope during intervention. Child B displayed a negative absolute level change of 5\% $(45 \%, 40 \%)$ and a relative level change of $35 \%(45 \%, 80 \%)$ between the baseline and intervention phases.

During the initial baseline phase, the answers to all four types of comprehension questions was variable, with a mean of $48 \%$ (range $=35 \%-60 \%$ ). The mean percentage of correct answers by category for the baseline phase can be seen on the second set of bar graphs on Figure 4 and were Level 1, Fact $(M=60 \%$, range $=20 \%-100 \%)$, Level 2 , Search $(M=20 \%$, range $=$ 10\%-20\%), Level 3, Inference $(M=43 \%$, range 20\%-60\%), Level 4, Connection $(M=67 \%$, range $20 \%-100 \%)$.

During the intervention phase, the correct answers to all four types of comprehension questions ranged from $40 \%$ to $100 \%,(M=85 \%)$. During the intervention phase the Level 1 , Fact category was $(M=75 \%$, range $=40 \%-100 \%)$, Level 2 , Search $(M=93 \%$, range $=80 \%-100 \%)$, Level 3, Inference $(M=93 \%$, range $=80 \%-100 \%)$, Level 4, Connection $(M=80 \%$, range $=$ $80 \%-80 \%)$. The mean percentage of correct answers by category for the intervention phase can be seen on the second set of bar graphs on Figure 5.

During the maintenance phase, the correct answers to all four types of comprehension questions ranged from $80 \%$ to $100 \%,(M=95 \%)$. The mean percentage of correct answers by category can be seen on the second set of bar graphs on Figure 6 and were Level 1, Fact (M 
$=100 \%$, range $=100 \%-100 \%)$, Level 2 , Search $(M=100 \%$, range 100\%-100\% $)$ Level 3, Inference $(M=80 \%$, range $=80 \%-80 \%)$, Level 4 , Connection $(M=100 \%$, range $=100 \%$ $100 \%)$.

Child C. See the third graph of Figure 3 for the correct answers to comprehension questions for Child C. Child C completed seven baseline sessions, 14 intervention sessions, and two maintenance sessions. Split middle analysis revealed a decelerating trend line in the baseline phase and the intervention phase with variability of $71 \%$ of data falling within a $25 \%$ stability envelope during baseline and a stable $100 \%$ of data falling within the stability envelope during intervention. Child C displayed a positive absolute level change of $60 \%(40 \%, 100 \%)$ and a relative level change of $60 \%(40 \%, 100 \%)$ between the baseline and intervention phases.

During the initial baseline phase, the answers to all four types of comprehension questions was variable, ranging from $20 \%$ to $65 \%(M=41 \%)$. The mean of percentage correct by category for the baseline phase can be on the third set of bar graphs on Figure 4 and were Level 1, Fact $(M=76 \%$, range $=20 \%-100 \%)$, Level 2, Search $(M=23 \%$, range $=10 \%-20 \%)$, Level 3, Inference $(M=29 \%$, range $20 \%-60 \%)$, Level 4, Connection $(M=34 \%$, range $20 \%$ $100 \%)$.

During the intervention phase, the correct answers to all four types of comprehension questions ranged from $60 \%$ to $100 \%(M=81 \%)$. During the intervention phase the Level 1, Fact category was $(M=90 \%$, range $=60 \%-100 \%)$, Level 2 , Search $(M=80 \%$, range $=80 \%-80 \%)$, Level 3, Inference $(M=75 \%$, range $=60 \%-100 \%)$, Level 4, Connection $(M=80 \%$, range $=$ $80 \%-80 \%)$. The mean percentage of correct answers by category for the intervention phase can be seen on the third set of bar graphs on Figure 5. 
During the maintenance phase, the correct answers to all four types of comprehension questions ranged from $60 \%$ to $100 \%(M=88 \%)$. The mean percentage of correct answers by category can be seen on the third set of bar graphs on Figure 6 and were Level 1, Fact ( $M$ $=100 \%$, range $=100 \%-100 \%)$, Level 2 , Search $(M=70 \%$, range 60\%-80\%), Level 3, Inference $(M=80$, range $=80 \%-80 \%)$, Level 4, Connection $(M=100 \%$, range $=100 \%-100 \%)$.

Child D. See the fourth graph of Figure 3 for the correct answers to comprehension questions for Child D. Child D are presented as the fourth graph of Figure 1. Child D completed eight baseline sessions, 12 intervention sessions, and one maintenance session. Split middle analysis revealed a flat trend line in the baseline phase and a decelerating trend line in the intervention phase with variability of $50 \%$ of data falling within a $25 \%$ stability envelope during baseline and a stable $100 \%$ of data falling within the stability envelope during intervention. Child D displayed a positive absolute level change of $45 \%(55 \%, 100 \%)$ and a relative level change of $70 \%(30 \%, 100 \%)$ between the baseline and intervention phases.

During the initial baseline phase, the answers to all four types of comprehension questions was variable, ranging from $20 \%$ to $55 \%(M=34 \%)$. The mean percentage of correct answers by category for the baseline phase can be on the fourth set of bar graphs on Figure 4 and were Level 1, Fact $(M=77 \%$, range $=20 \%-100 \%)$, Level 2, Search $(M=10 \%$, range $=$ 10\%-20\%), Level 3, Inference $(M=8 \%$, range 10\%-20\%), Level 4, Connection $(M=40 \%$, range $10 \%-60 \%)$.

During the intervention phase, the correct answers to all four types of comprehension questions was $(M=90 \%$, range $80 \%-100 \%)$. During the intervention phase Level 1, Fact category was $(M=100 \%)$, range $=100-\%-100 \%)$, Level 2 , Search $(M=93 \%$, range $=80 \%$ $100 \%)$, Level 3, Inference $(M=80 \%$, range $=80 \%-80 \%)$, Level 4, Connection $(M=87 \%$, range 
$=80 \%-100 \%)$. The mean percentage of correct answers by category for the intervention phase can be seen on the fourth set of bar graphs on Figure 5 .

During the maintenance phase, the correct answers to all four types of comprehension questions was $(M=85 \%$, range $60 \%-100 \%)$. The mean percentage of correct answers by category can be seen on the fourth set of bar graphs on Figure 6 and were Level 1, Fact ( $M$ $=100 \%$, range 100\%), Level 2, Search $(M=100 \%$, range $=100 \%)$, Level 3, Inference $(M=$ $60 \%$, range $=60 \%)$, Level 4, Connection $(M=80 \%$, range $=80 \%)$. Child D's baseline trend exceeded the .20 cut off value in the Tau-U analysis and thus the corrected baseline formula was employed on the online calculator.

Child E. See the fifth graph of Figure 3 for the correct answers to comprehension questions for Child E. Child E completed nine baseline sessions, 15 intervention sessions, and two maintenance sessions. Split middle analysis revealed a decelerating trend line in the baseline phase and the intervention phase with variability of $78 \%$ of data falling within a $25 \%$ stability envelope during baseline and a stable $80 \%$ of data falling within the stability envelope during intervention. Child E displayed a positive absolute level change of $40 \%(20 \%, 60 \%)$ and a relative level change of $60 \%(20 \%, 80 \%)$ between the baseline and intervention phases.

During the initial baseline phase, the answers to all four types of comprehension questions was variable, ranging from $10 \%$ to $45 \%(M=24 \%)$. The mean percentage of correct answers by category for the baseline phase can be on the fifth set of bar graphs on Figure 4 and were Level 1, Fact $(M=44 \%$, range $=0-100 \%)$, Level 2, Search $(M=9 \%$, range $=0 \%-10 \%)$, Level 3, Inference ( $M=22 \%$, range 0\%-60\%), Level 4, Connection ( $M=20 \%$, range 0\%-60\%). During the intervention phase, the correct answers to all four types of comprehension questions ranged from 20\%-100\% $(M=63 \%)$. During intervention the Level 1, Fact category 
was $(M=75 \%$, range $=40-\%-100 \%)$, Level 2 , Search $(M=75 \%$, range $=60 \%-80 \%)$, Level 3 , Inference $(M=75 \%$, range $=60 \%-80 \%)$, Level 4, Connection $(M=27$, range $=20 \%-40 \%)$.

Child E exhibited difficulty with the Level 4, Connection phase of the intervention thought to be due to the increased expressive language skills demands of the category. It was decided by his therapists to conclude Level 4 after three sessions due to frustration and signs of potential outbursts. The mean percentage of correct answers by category for the intervention phase can be seen on the fifth set of bar graphs on Figure 5.

During the maintenance phase, the correct answers to all four types of comprehension questions ranged from $60 \%-100 \%(M=68 \%)$. The mean percentage of correct answers by category can be seen on the fifth set of bar graphs on Figure 6 and were Level 1, Fact $(M=90 \%$, range $=80 \%-100)$, Level 2 , Search $(M=70 \%$, range $=60 \%-80 \%)$, Level 3, Inference $(M=$ $80 \%$, range $=60-100 \%)$, Level 4 , Connection $(M=30 \%$, range $=60 \%-60 \%)$. 
Figure 3. Percentage of Correct Responses to QAR Comprehension Questions

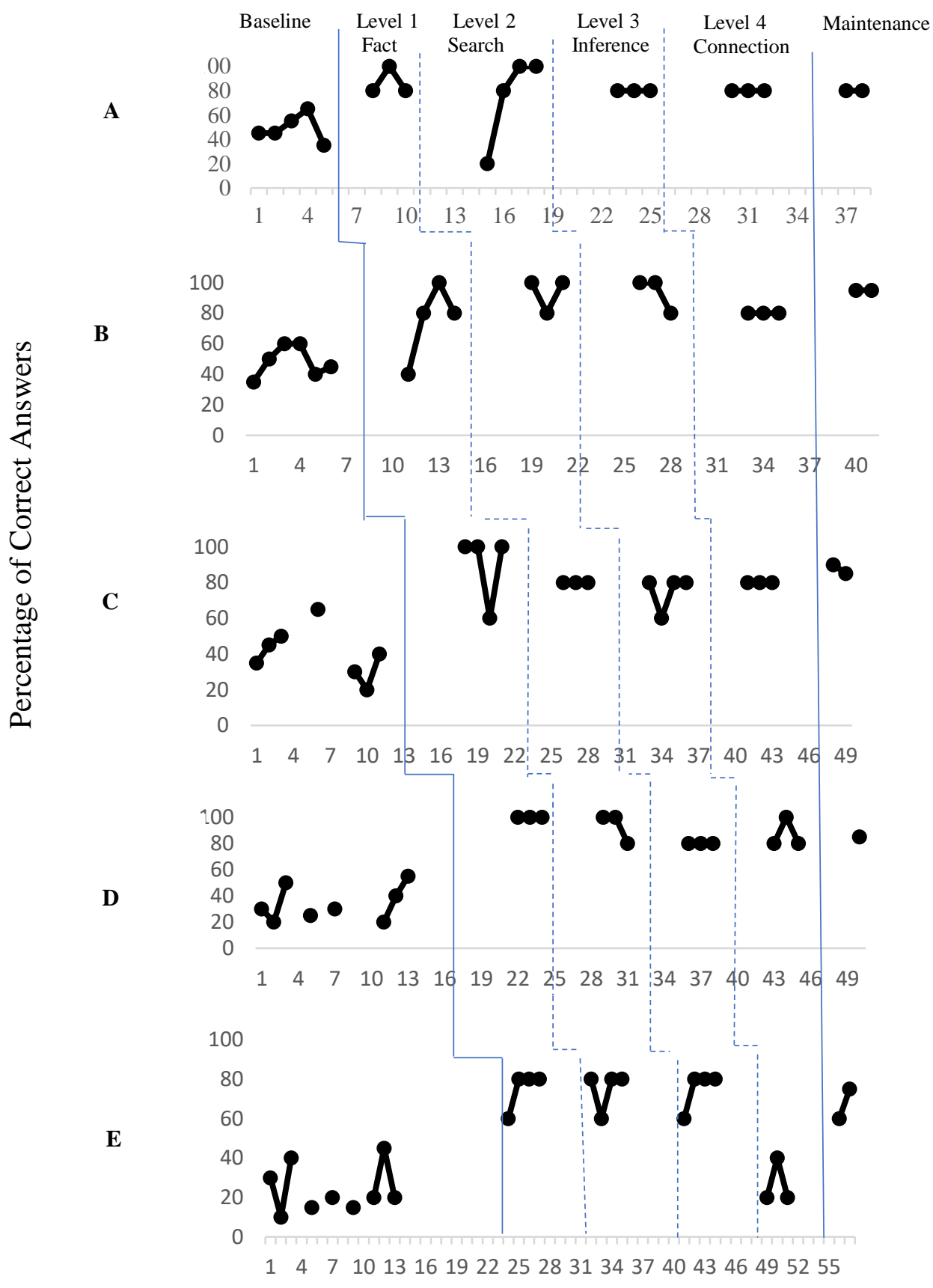

Sessions

\begin{tabular}{lll}
\hline Baseline: & Level Probes: & Maintenance: \\
5 books across baseline & 3 books across probes & 1 book per session $(2$ total $)$ \\
20 questions per book $(5$ per level $)$ & 5 questions per probe & 20 questions per book (5 per level) \\
\hline
\end{tabular}


Figure 4. Baseline: Individual Mean of Correct Responses

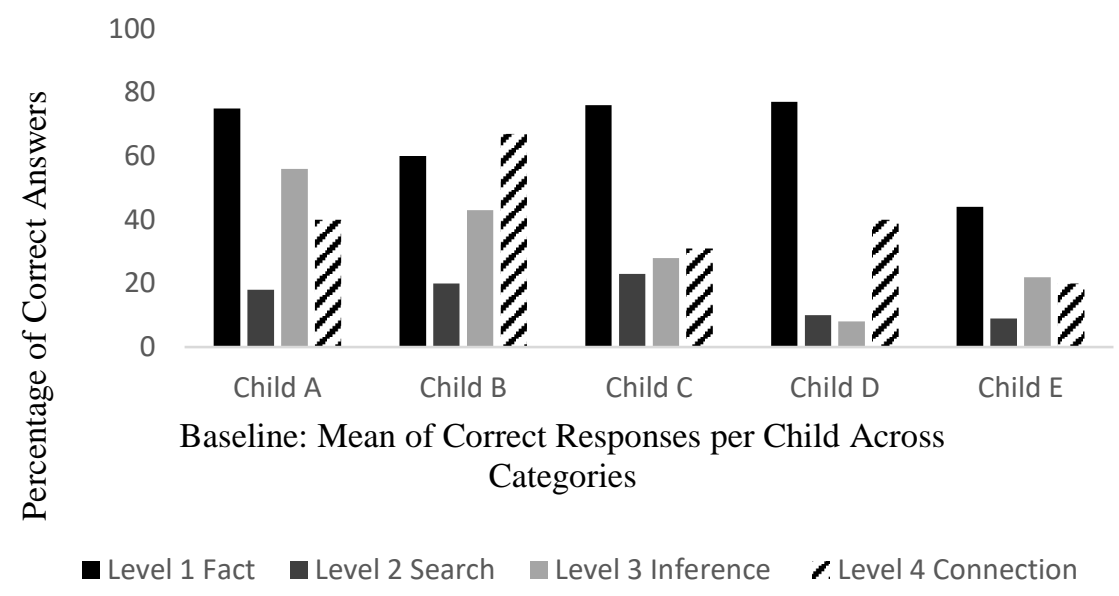

Figure 5. Intervention: Individual Mean of Correct Responses

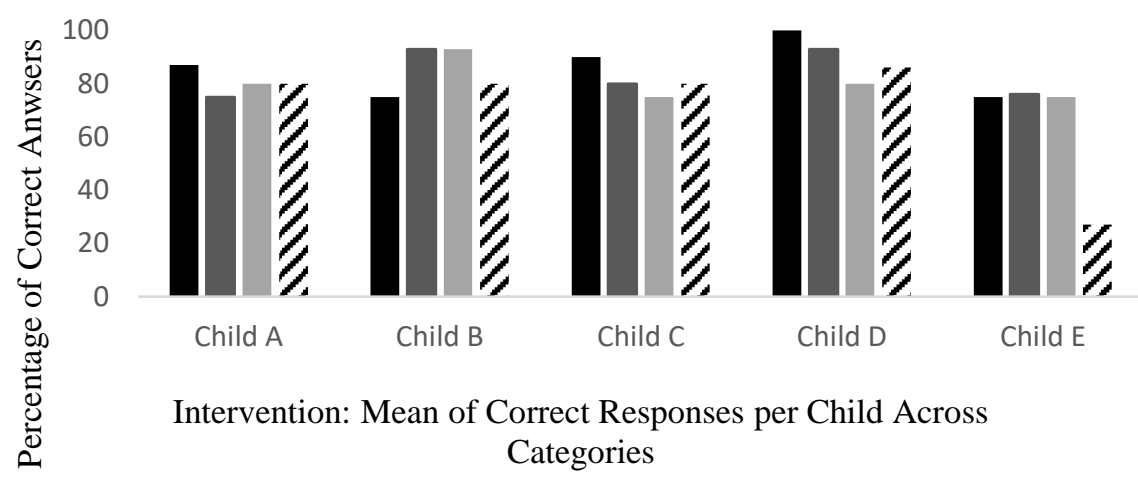

Figure 6. Maintenance: Individual Mean of Correct Responses

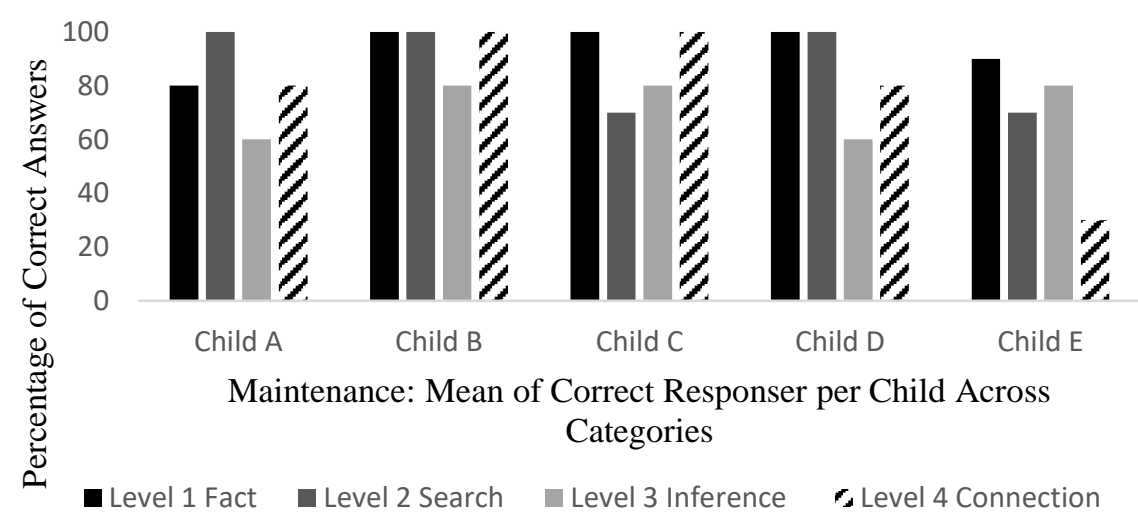


Percentage Means Combined per Category. Figure 7, 8, and 9 displays the percentage means of correct answers combined for all participants for baseline, intervention, and maintenance phase and places the categories in order of percentage correct in descending order.

Baseline. Figure 5 shows that during baseline the participants answered Level 1, Fact questions with the highest percentage correct $(M=66 \%$, range $=44 \%-77 \%)$, Level 4, Connection $(M=39 \%$, range $=20 \%-67 \%)$, Level 3, Inference $(M=31 \%$, range $=8 \%-56 \%)$, Level 2, Search $(M=16 \%$, range $=9 \%-23 \%)$.

Intervention. Figure 6 shows that during intervention the participants answered Level 1, Fact questions with the highest percentage correct $(M=85 \%$, range $=75 \%-100 \%)$, Level 2 , Search $(M=83 \%$, range $=75 \%-93 \%)$, Level 3, Inference $(M=80 \%$, range $=75 \%-93 \%)$, Level 4, Connection $(\mathrm{M}=70 \%$, range $=27 \%-86 \%)$.

Maintenance. Figure 7 shows that during maintenance the participants answered Level 1, Fact questions with the highest percentage correct $(M=94 \%$, range $=80 \%-100 \%)$, Level 2 , Search $(M=88 \%$, range $=70 \%-100 \%)$, Level 3, Connection $(M=78 \%$, range $=60 \%-80 \%)$, Level 3, Inference $(M=72 \%$, range $=30 \%-100 \%)$. 
Figure 7. Baseline: Combined Mean of Correct Responses

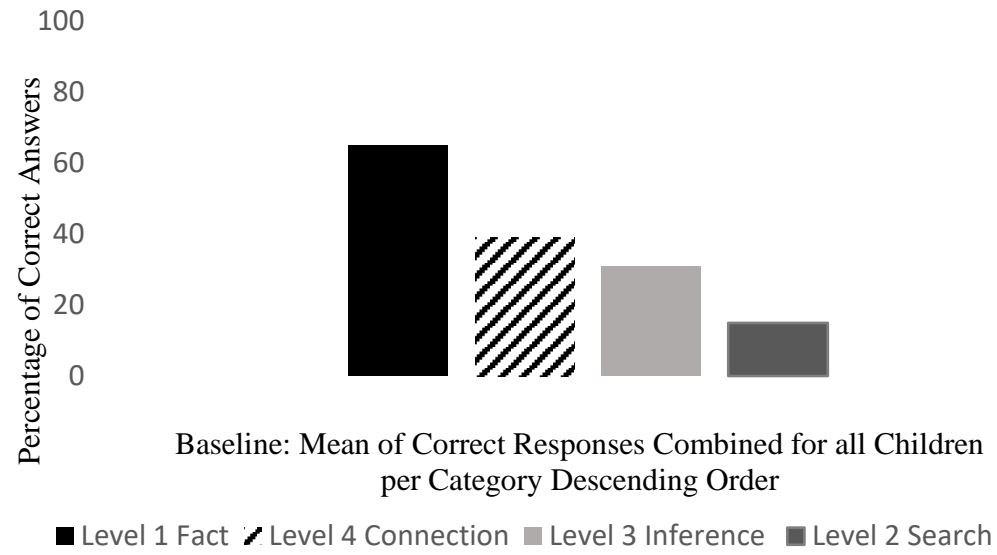

Figure 8. Intervention: Combined Mean of Correct Responses

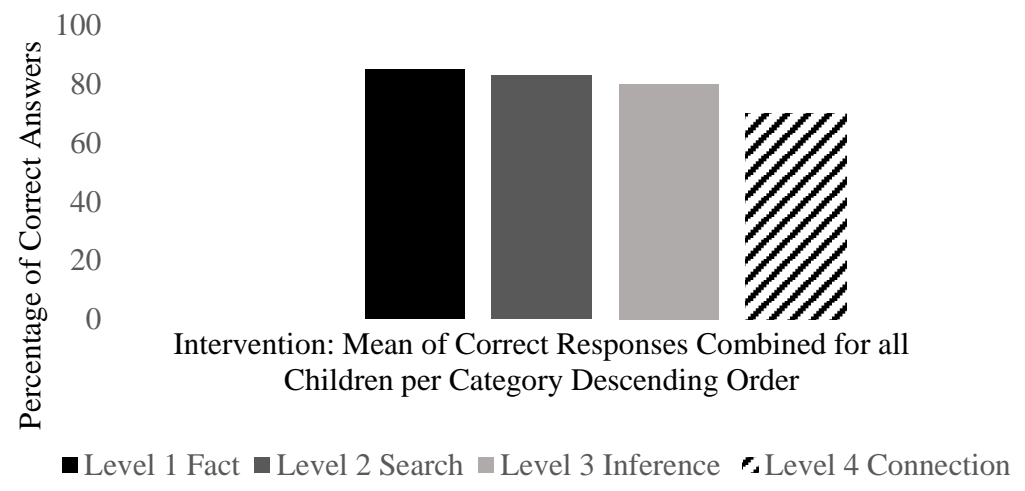

Figure 9. Maintenance: Combined Mean of Correct Responses

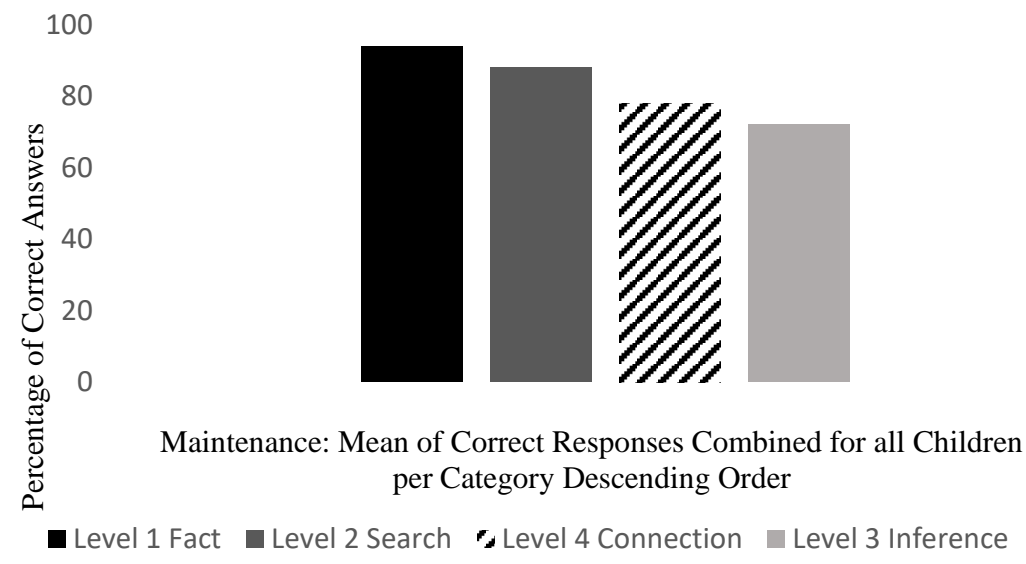


Tau-U Analysis. Tau-U is a method for measuring data non-overlap between baseline an intervention phases and provide the effect size of an intervention. It is a distribution free nonparametric technique with statistical power of $91 \%$ to $95 \%$ of ordinary least squares (OLS) linear regression when data conform to parametric assumptions. When data are non-conforming as is common in single subject research, then the power of Tau-U can exceed the parametric techniques to $115 \%$. Therefore, it is an appropriate index to use for small datasets often found in single subject research studies (Parker et al., 2011). Tau-U statistical analysis was conducted to calculate the individual and group effect sizes. The corrected baseline formula was employed for Child D to account for variations in baseline data (Parker et al., 2011). The Tau-U analysis for each individual child was: Child A $(\mathrm{T}=.84)$, Child $\mathrm{B}(\mathrm{T}=.88)$, Child $\mathrm{C}(\mathrm{T}=.96)$, Child $\mathrm{D}(\mathrm{T}=$ .92), Child $\mathrm{E}(\mathrm{T}=.85)$. The Tau $-\mathrm{U}$ analysis allowed for an effect size representative of the intervention based on combined data from all participants and was .89. All effect sizes were considered to be very large. Refer to Table 6 for a display of the Tau-U effect sizes.

Table 6. Tau-U Effect Sizes

\begin{tabular}{ll}
\hline Child & Effect Size \\
\hline A & .84 \\
B & .88 \\
C & .96 \\
D & .92 \\
E & .85 \\
Total & .89 \\
\hline
\end{tabular}

Pretest/Posttest NLM Results. Each child was administered the Story Questions and Personal Generation portion of the narrative listening measure (NLM) Cubed Language Dynamics. The NLM does not provide standardized norms for the Story Questions (SQ) and 
Personal Generation (PG) portions of the assessment; therefore, these scores are criterion referenced and evaluated to determine if children scores increased after the intervention in their ability to answer questions to passages and provide personal details relating to the passage. Table 7 displays the results of the Story Questions and Personal Generation scores. The Story Questions section consist of 6 comprehension questions with a total of 12 points possible. The Personal Generation section follows a story grammar flow chart and is scored by how many details are provided when asked to relate a similar experience to the story with a range from 1-23 points possible. Two of the same passages from the NLM Fall benchmark were read for pretest and posttest sessions. The results were: Child A Pretest $(\mathrm{SQ}=5,4, \mathrm{PG}=2,0)$, Posttest $(\mathrm{SQ}=9,7$, PG = 4,2); Child B Pretest ( $S Q=9,6, P G=3,4)$, Posttest ( $S Q=11,10, P G=8,10$ ); Child C Pretest ( $\mathrm{SQ}=7,6, \mathrm{PG}=2,2)$, Posttest ( $\mathrm{SQ}=6,8, \mathrm{PG}=3,2)$; Child D Pretest $(\mathrm{SQ}=1,0, \mathrm{PG}$ $=0,0)$, Posttest $(\mathrm{SQ}=8,9, \mathrm{PG}=2,2)$; Child E Pretest $(\mathrm{SQ}=1,2, \mathrm{PG}=0,0)$, Posttest $(\mathrm{SQ}=6,8 \mathrm{PG}$ $=2,2)$.

Table 7. NLM Story Question and Personal Generation Scores

\begin{tabular}{|l|l|l|l|l|l|l|l|l|}
\hline Child & \multicolumn{9}{|l}{$\begin{array}{l}\text { SQ } \\
\text { Scores }\end{array}$} & \multicolumn{2}{l|}{$\begin{array}{l}\text { PG } \\
\text { Scores }\end{array}$} \\
\hline & $\begin{array}{l}\text { Pretest } \\
\text { One }\end{array}$ & $\begin{array}{l}\text { Posttest } \\
\text { One }\end{array}$ & $\begin{array}{l}\text { Pretest } \\
\text { Two }\end{array}$ & $\begin{array}{l}\text { Posttest } \\
\text { Two }\end{array}$ & $\begin{array}{l}\text { Pretest } \\
\text { One }\end{array}$ & $\begin{array}{l}\text { Posttest } \\
\text { One }\end{array}$ & $\begin{array}{l}\text { Pretest } \\
\text { Two }\end{array}$ & $\begin{array}{l}\text { Posttest } \\
\text { Two }\end{array}$ \\
\hline A & 5 & 9 & 4 & 7 & 2 & 4 & 0 & 2 \\
\hline B & 9 & 11 & 6 & 10 & 3 & 8 & 4 & 10 \\
\hline C & 7 & 6 & 6 & 8 & 2 & 3 & 2 & 2 \\
\hline D & 1 & 8 & 0 & 9 & 0 & 2 & 0 & 2 \\
\hline E & 1 & 6 & 2 & 8 & 0 & 2 & 0 & 2 \\
\hline
\end{tabular}

Effects on Listening Comprehension. Overall, each child showed improvement in listening comprehension skills by correct answers to questions to stories read aloud, as evidenced by higher mean levels in the intervention and maintenance phases compared to the mean levels 
in the baseline phase of the intervention in each level of the QAR and QAR card intervention package. Although Child E was unable to reach criterion in the Level 4, Connection intervention phase, he was able to correctly answer 3/5 (60\%) of Level 4 questions in two maintenance phases.

The results reported for the remainder of this section refer to the children as a group. During baseline, the children answered the majority of correct answers in the Level 1, Fact category followed by Level 4, Connection, Level 3 Inference, and Level 2 Search. During intervention the children answered the majority of correct questions in sequential order Leve 1, Fact, Level 2, Search, Level 3, Inference, and Level 4, Connection. During maintenance, the children answered the majority of correct answers as Level 1, Fact, Level 2, Search, Level 4, Connection, and Level 3, Inference. The NLM pretest and post test showed that all children increased in the ability to answer comprehension questions and generate an answer with personal details.

\section{Research Question 2}

What is the social validity of an adapted question-answer relationship strategy and visual support, shared book reading intervention package for pre-k children with ASD?

Child Social Validity. At the end of the fourth level and before the posttest and maintenance phases of the study, each child was given a four question survey which consisted of emoji faces to circle for answers either yes, a little, or no. The surveys were read aloud to the children. The questions were: 1) I liked answering questions using the Look, Slow Down, Stop, and Story \& Me cards, 2) The cards helped me to answer questions in the book. 3) I liked the books that we read, and 4) I would like to use the cards again to answer questions in the book. 
Each Child circle the answer "yes" for each of the four questions with the exception of Child E who circled the answer "a little" to question 2.

RBT Survey. One week before completion of the study each RBT completed an anonymous survey consisting of four demographic questions, ten Likert scale questions, and five open ended questions. In the survey, the child participants are referred to as clients which is the term used at the ABA center. The RBTs were instructed to complete the survey and return it to the office manager at their convenience. The office manager was given a large manilla envelope in which the surveys were placed. The researcher was given the envelope on the last day of the study. Each question will be examined below. Refer to Tables 8, 9, and 10 for a display of the RBT responses to the demographic, Likert scale, and open-ended questions.

Demographic Information. All five of the RBTs were between 25-35 years of age. Three of the five RBTs were between 20-25 and two RBTs were between 25-35. All five held bachelor's degrees and had been working in the ABA field for 1-5 years. Three of the RBTs had teaching experience between 1-5 years, and two RBT had teaching experience between 5-10 years, one RBT had no teaching experience. All RBTs had undergone required certification to work as registered behavior technicians at the center.

Table 8. RBT Demographic Information

\begin{tabular}{lllll}
\hline RBT & Age & Education & $\begin{array}{c}\text { ABA } \\
\text { Experience }\end{array}$ & $\begin{array}{l}\text { Teaching } \\
\text { Experience }\end{array}$ \\
\hline 1 & $20-25$ & Bachelor's & $1-5$ years & $1-5$ years \\
2 & $20-25$ & Bachelor's & $1-5$ years & $1-5$ years \\
3 & $20-25$ & Bachelor's & $1-5$ years & None \\
4 & $25-25$ & Bachelor's & $1-5$ years & $5-10$ \\
5 & $25-35$ & Bachelor's & $1-5$ years & $5-10$ \\
\hline
\end{tabular}


Likert Scale Questions. The Likert scale used was as follows: 1-Strongly Agree, 2Agree, 3-Neutral, 4-Disagree, 5-Strongly Disagree. The questions asked were: 1) The QAR intervention helped my client to answer Level 1, Fact comprehension questions. 2)The QAR intervention helped my client to answer Level 2, Search comprehension questions. 3)The QAR intervention helped my client to answer Leve 3, Inference comprehension questions. 4) The QAR intervention helped my client to answer Level 4, Connection comprehension questions. 5)The use of the QAR intervention helped my client to facilitate expressive language skills. 6) I would be interested in learning the QAR strategy to use with my client. 7) The QAR strategy would be easy to implement in my client's program. 8)The QAR strategy would help my client achieve goals at the center. 9) The QAR strategy could help my client achieve academic goals at school. 10) The QAR sessions were a positive experience for my client. The RBTs responded favorably to all Likert scale questions with Strongly Agree or Agree, except for one who was neutral on questions seven and eight.

For question 1), four RBTs chose Strongly Agree and one chose Agree that the QAR intervention helped their client to answer level 1, Fact comprehension questions $(M=4.8)$ 2) Three RBTs chose Strongly Agree and two chose Agree that the QAR intervention helped their client to answer Level 2, Search comprehension question $(M=4.6)$. 3) Four RBTs chose Strongly Agree and one chose Agree that the QAR intervention helped their client to answer Level 3, Inference comprehension questions $(M=4.8)$. 4) Four RBTs chose Strongly Agree and one chose Agree that the QAR intervention helped their client to answer Level 4, Connection comprehension questions $(M=4.8)$. For question 5) Four RBTs chose Strongly Agree and one chose Agree that use of the QAR intervention helped their client to facilitate expressive language skills $(M=4.8) 6)$ All five RBTs chose Strongly Agree that they would be interested in learning 
the QAR strategy to use with their client $(M=5)$. 7) Three RBTs chose Strongly Agree, one chose Agree, and one was neutral that the QAR strategy would be easy to implement in their client's program $(M=4.6) .8)$ Three RBTs chose Strongly Agree, one chose Agree, and one was Neutral that the QAR strategy would help their client achieve goals at the center $(M=4.6) 9)$ All five RBTs chose Strongly Agree that the QAR strategy could help their client achieve academic goals at school $(M=5)$. 10) All five RBTs chose Strongly Agree that the QAR sessions were a positive experience for their client $(M=5)$. 
Table 9. Likert Scale Results

\begin{tabular}{|c|c|c|c|c|c|c|}
\hline Likert Scale Questions & $\begin{array}{c}5 \\
\text { Strongly } \\
\text { Agree }\end{array}$ & $\begin{array}{c}4 \\
\text { Agree }\end{array}$ & $\begin{array}{c}3 \\
\text { Neutral }\end{array}$ & $\begin{array}{c}2 \\
\text { Disagree }\end{array}$ & $\begin{array}{c}1 \\
\text { Strongly } \\
\text { Disagree }\end{array}$ & $\begin{array}{l}\text { Mean } \\
\text { Totals }\end{array}$ \\
\hline $\begin{array}{l}\text { 1)The QAR intervention helped my } \\
\text { client to answer Level, } 1 \text { Fact } \\
\text { Comprehension questions. }\end{array}$ & $\mathrm{XXXX}$ & $\mathrm{X}$ & & & & 4.8 \\
\hline $\begin{array}{l}\text { 2) The QAR intervention helped my } \\
\text { client to answer Level 2, Search } \\
\text { comprehension questions. }\end{array}$ & XXX & $X X$ & & & & 4.6 \\
\hline $\begin{array}{l}\text { 3) The QAR intervention helped my } \\
\text { client to answer Level 3, Inference } \\
\text { comprehension questions. }\end{array}$ & XXXX & $\mathrm{X}$ & & & & 4.8 \\
\hline $\begin{array}{l}\text { 4) The QAR intervention helped my } \\
\text { client to answer Level } 4 \text {, } \\
\text { Comprehension questions. }\end{array}$ & $\mathrm{XXXX}$ & $\mathrm{X}$ & & & & 4.8 \\
\hline $\begin{array}{l}\text { 5) The use of the QAR intervention } \\
\text { helped my client to facilitate } \\
\text { expressive language skills. }\end{array}$ & XXXX & $\mathrm{X}$ & & & & 4.8 \\
\hline $\begin{array}{l}\text { 6) I would be interested in learning } \\
\text { the QAR strategy to use with my } \\
\text { client. }\end{array}$ & XXXXX & & & & & 5 \\
\hline $\begin{array}{l}\text { 7) The QAR strategy would be easy } \\
\text { to implement in my client's program }\end{array}$ & XXX & $\mathrm{X}$ & $\mathrm{X}$ & & & 4.4 \\
\hline $\begin{array}{l}\text { 8) The QAR strategy would help my } \\
\text { client achieve goals at the center. }\end{array}$ & XXX & $\mathrm{X}$ & $\mathrm{X}$ & & & 4.4 \\
\hline $\begin{array}{l}\text { 9) The QAR strategy could help my } \\
\text { client achieve academic goals at } \\
\text { school }\end{array}$ & $\mathrm{XXXXX}$ & & & & & 5 \\
\hline $\begin{array}{l}\text { 10) The QAR sessions were a } \\
\text { positive experience for my client. }\end{array}$ & XXXXX & & & & & 5 \\
\hline
\end{tabular}


Open-ended Questions. The open-ended question questions were as follows: 1) What do you feel was the most helpful part of the QAR intervention. 2) What was the least helpful part of the QAR intervention? 3) How could the QAR intervention be improved? 4) Have you participated in a research study before? If yes, please briefly explain. 5) What do you consider the most important thing you learned during this study?

For question 1), all five RBTs stated that seeing client improvement in comprehension skills was the most helpful part of the QAR intervention. Specific aspects mentioned were modeling, visual supports, repeated exposure to the books, expressive language skills, helping to focus on the story, and the Story \& Me category. On question 2), three RBTs reported that the distraction with recording the sessions was the lease helpful part of the intervention, one RBT wanted to see data on the client progress through each phase of the study, one RBT stated that using the same books was repetitive. On question 3), three RBTs stated that the intervention could be improved by another method of recording where the participants were not aware of being recorded, one RBT stated the child being able choose books, one RBT stated corrective feedback during baseline /probes. On question 4), three RBTs had previously participated in research, one RBT had previously participated and conducted research, one RBT had not previously participated or conducted research. On question 5), three RBTs stated that the sequential teaching of the QAR levels was the most important thing that they learned, one RBT stated that having a better idea of client deficits and improvement, one RBT stated the learning the baseline, intervention and maintenance phases of the study. 
Table 10. RBT Open-Ended Question Responses

\begin{tabular}{|c|c|}
\hline Question & Responses \\
\hline $\begin{array}{l}\text { 1) What do you feel was the most helpful part } \\
\text { of the QAR intervention? }\end{array}$ & $\begin{array}{l}\text { 5/5 Responded: Client improvement in answering } \\
\text { comprehension question including: visual supports, } \\
\text { Story \& Me visual support, modeling, exposure to } \\
\text { books, expressive language skills, focus }\end{array}$ \\
\hline \multirow{3}{*}{$\begin{array}{l}\text { 2) What was the least helpful part of the QAR } \\
\text { intervention? }\end{array}$} & 3/5 Responded: Distracting recording sessions \\
\hline & 1/5 Responded: Books became repetitive \\
\hline & 1/5 Responded: Not seeing data in real time \\
\hline \multirow[t]{3}{*}{$\begin{array}{l}\text { 3) How could the QAR intervention be } \\
\text { improved? }\end{array}$} & $\begin{array}{l}\text { 3/5 Responded: Improve method of recording } \\
\text { sessions }\end{array}$ \\
\hline & 1/5 Responded: Book choice \\
\hline & 1/5 Responded: Corrective feedback during probes \\
\hline \multirow[t]{3}{*}{$\begin{array}{l}\text { 4) Have you participated in a research study } \\
\text { before? If yes, please briefly explain. }\end{array}$} & $\begin{array}{l}\text { 3/5 Responded: Previously participated in a } \\
\text { research study }\end{array}$ \\
\hline & $\begin{array}{l}\text { 1/5 Responded: Previously participated in and } \\
\text { conducted research }\end{array}$ \\
\hline & 1/5 Responded: No previous research experience \\
\hline \multirow{3}{*}{$\begin{array}{l}\text { 5) What do you consider the most important } \\
\text { thing you learned during this study? }\end{array}$} & 3/5 Responded: Sequential teaching of QAR levels \\
\hline & $\begin{array}{l}\text { 1/5 Responded: Better understanding of client } \\
\text { deficits/improvements }\end{array}$ \\
\hline & $\begin{array}{l}\text { 1/5 Responded: Learning the baseline, intervention, } \\
\text { and maintenance phases of the study. }\end{array}$ \\
\hline
\end{tabular}

\section{Social Validity Summary}

Overall, the results of the both the children and RBT social validity were positive. The children answered affirmatively to each of the four survey questions except for Child $\mathrm{E}$ who answered that the cards helped him a little with answering questions in the book. The majority of the RBT Likert responses were Strongly Agree or Agree with the exception of one RBT who had 
a neutral response to the QAR intervention helping the client to achieve goals at the center or if the intervention would be easy to implement in the client's program at the center. The opened ended questions provided feedback on positive elements of the study in the relation to the importance of learning to answer comprehension questions and improvements in the study included giving the children choices in book selection and devising a less distracting method to record sessions.

\section{Interobserver Agreement and Procedural Fidelity.}

Interobserver Agreement. The formula used to calculate interobserver agreement was calculated by the number of agreements divided by the total of agreements plus disagreements and multiplied by 100 . One graduate student was the primary recorder and the second graduate student was the reliability observer. The reliability observer coded $35 \%$ of the baseline and intervention sessions randomly selected by the Integer Generator on Random.org and reached $(M$ $=94 \%$, range $=88 \%-96 \%))$ accuracy with the primary recorder for baseline sessions and $(M=$ $98 \%$, range $=96 \%-99 \%)$ accuracy for intervention sessions The Combined score was $(M=96 \%$, range $=88 \%-99 \%$ ) for interobserver agreement. Refer to Table 11 for a display of the interobserver agreement scores for each child and phase of the study.

Table 11. Interobserver Agreement Means

\begin{tabular}{cccc}
\hline Child & $\begin{array}{c}\text { Baseline/ } \\
\text { Maintenance }\end{array}$ & Intervention & $\begin{array}{c}\text { Interobserver } \\
\text { Agreement } \\
\text { Combined Mean }\end{array}$ \\
\hline A & $88 \%$ & $98 \%$ & $93 \%$ \\
B & $96 \%$ & $96 \%$ & $96 \%$ \\
C & $95 \%$ & $98 \%$ & $97 \%$ \\
D & $93 \%$ & $99 \%$ & $96 \%$ \\
E & $96 \%$ & $97 \%$ & $97 \%$ \\
Mean Total & $\mathbf{9 4 \%}$ & $\mathbf{9 8 \%}$ & $\mathbf{9 6 \%}$ \\
\hline
\end{tabular}


Procedural Fidelity. Procedural Fidelity was assessed by the primary coder for each session using the Procedural Treatment Fidelity Checklist for either baseline/maintenance procedures or the Procedural Treatment Fidelity Checklist for intervention procedures. In order to ensure procedures were consistently followed for each phase of the study, $35 \%$ of sessions randomly selected by the Integer Generator on Random.org and were assessed by the secondary coder for baseline/maintenance and intervention phases. The procedural fidelity for baseline or maintenance sessions was $(M=97 \%$, range $=93 \%-100 \%)$. The procedural fidelity for intervention sessions was $(M=99 \%$, range $=96 \%-98 \%))$. The combined score was $(M=97 \%$, range $=93 \%-100 \%$ ) for both procedural fidelity checklists. Refer to Table 12 for a display of the procedural fidelity scores for each child and phase of the study.

Table 12. Procedural Fidelity Means

\begin{tabular}{cccc}
\hline Child & $\begin{array}{c}\text { Baseline/ } \\
\text { Maintenance }\end{array}$ & Intervention & $\begin{array}{c}\text { Procedural } \\
\text { Fidelity } \\
\text { Combined Mean }\end{array}$ \\
\hline A & $100 \%$ & $98 \%$ & $99 \%$ \\
B & $93 \%$ & $98 \%$ & $96 \%$ \\
C & $100 \%$ & $98 \%$ & $99 \%$ \\
D & $95 \%$ & $98 \%$ & $97 \%$ \\
E & $95 \%$ & $96 \%$ & $96 \%$ \\
Mean Totals & $\mathbf{9 7 \%}$ & $\mathbf{9 8 \%}$ & $\mathbf{9 7 \%}$ \\
\hline
\end{tabular}

Prompting Hierarchy. A prompting hierarchy was used during the instructional portion of the intervention sessions. The prompts were coded and recorded for instructional and programming purposes but were not included in the dependent variable analysis. During the instructional sessions, answers were coded as either: correct unprompted, correct verbal prompt correct, correct verbal and gestural prompt correct, incorrect unprompted, incorrect verbal 
prompt, incorrect verbal and gestural prompt, or no response. Tables 13, 14, 15, and 16 display the prompt information for each child and prompt totals for each QAR level.

Table 13. Level 1, Fact Prompt Totals

\begin{tabular}{lllllllll}
\hline Child & $\begin{array}{l}\text { Correct } \\
\text { No } \\
\text { Prompt }\end{array}$ & $\begin{array}{l}\text { Correct } \\
\text { Verbal }\end{array}$ & $\begin{array}{l}\text { Correct } \\
\text { Verbal } \\
+\end{array}$ & $\begin{array}{l}\text { Incorrect } \\
\text { No } \\
\text { Gestural }\end{array}$ & $\begin{array}{l}\text { Incorrect } \\
\text { Verbal }\end{array}$ & $\begin{array}{l}\text { Incorrect } \\
\text { Verbal } \\
+\end{array}$ & $\begin{array}{l}\text { No } \\
\text { Response }\end{array}$ \\
& & & 4 & 5 & 0 & 2 & 1 & \\
\hline A & 18 & 4 & 11 & 1 & 0 & 0 & 0 \\
B & 25 & 3 & 4 & 0 & 0 & 0 & 0 \\
C & 24 & 12 & 4 & 1 & 0 & 0 & 0 \\
D & 19 & 0 & 10 & 3 & 3 & 11 & 0 \\
E & 19 & 2 & 3 & & & & \\
Prompt & & & & $\mathbf{3 3}$ & $\mathbf{3}$ & $\mathbf{5}$ & $\mathbf{1 2}$ & $\mathbf{0}$ \\
Totals & $\mathbf{1 0 5}$ & $\mathbf{2 1}$ & $\mathbf{3 3}$ & & & & \\
\hline
\end{tabular}

Table 14. Level 2, Search Prompt Totals

\begin{tabular}{lllllllll}
\hline Child & $\begin{array}{l}\text { Correct } \\
\text { No } \\
\text { Prompt }\end{array}$ & $\begin{array}{l}\text { Correct } \\
\text { Verbal }\end{array}$ & $\begin{array}{l}\text { Correct } \\
\text { Verbal } \\
+\end{array}$ & $\begin{array}{l}\text { Incorrect } \\
\text { No } \\
\text { Prompt }\end{array}$ & $\begin{array}{l}\text { Incorrect } \\
\text { Verbal }\end{array}$ & $\begin{array}{l}\text { Incorrect } \\
\text { Verbal } \\
+\end{array}$ & $\begin{array}{l}\text { No } \\
\text { Response } \\
\text { Gestural }\end{array}$ \\
& & & 2 & 4 & 0 & 0 & 1 & \\
\hline A & 33 & 2 & 4 & 0 & 0 & 0 & 0 \\
B & 24 & 2 & 7 & 2 & 0 & 0 & 0 \\
C & 20 & 1 & 2 & 0 & 0 & 0 & 0 \\
D & 26 & 2 & 2 & 2 & 5 & 2 & 2 \\
E & 23 & 2 & 8 & & & & \\
Prompt & & & & $\mathbf{2 5}$ & $\mathbf{4}$ & $\mathbf{5}$ & $\mathbf{3}$ & $\mathbf{2}$ \\
Totals & $\mathbf{1 2 6}$ & $\mathbf{9}$ & $\mathbf{2 5}$ & & & & & \\
\hline
\end{tabular}


Table 15. Level 3, Inference Prompt Totals

\begin{tabular}{lllllllll}
\hline Child & $\begin{array}{l}\text { Correct } \\
\text { No } \\
\text { Prompt }\end{array}$ & $\begin{array}{l}\text { Correct } \\
\text { Verbal }\end{array}$ & $\begin{array}{l}\text { Correct } \\
\text { Verbal } \\
+\end{array}$ & $\begin{array}{l}\text { Incorrect } \\
\text { No } \\
\text { Prompt }\end{array}$ & $\begin{array}{l}\text { Incorrect } \\
\text { Verbal }\end{array}$ & $\begin{array}{l}\text { Incorrect } \\
\text { Verbal } \\
+\end{array}$ & $\begin{array}{l}\text { No } \\
\text { Response }\end{array}$ \\
& & & 3 & 2 & 0 & 2 & 3 & 0 \\
\hline A & 20 & 3 & 2 & 1 & 3 & 0 & 0 \\
B & 18 & 6 & 10 & 5 & 0 & 0 & 1 & 0 \\
C & 23 & 14 & 6 & 7 & 3 & 0 & 0 & 0 \\
D & 14 & 4 & 8 & 1 & 0 & 2 & 0 \\
E & 23 & & & & & & \\
Prompt & & $\mathbf{2 9}$ & $\mathbf{2 4}$ & $\mathbf{5}$ & $\mathbf{5}$ & $\mathbf{4}$ & $\mathbf{0}$ \\
Totals & $\mathbf{9 8}$ & $\mathbf{2 9}$ & & & & & & \\
\hline
\end{tabular}

Table 16. Level 4, Connection Prompt Totals

\begin{tabular}{|c|c|c|c|c|c|c|c|}
\hline Child & $\begin{array}{l}\text { Correct } \\
\text { No } \\
\text { Prompt }\end{array}$ & $\begin{array}{l}\text { Correct } \\
\text { Verbal }\end{array}$ & $\begin{array}{l}\text { Correct } \\
\text { Verbal } \\
+ \\
\text { Gestural }\end{array}$ & $\begin{array}{l}\text { Incorrect } \\
\text { No } \\
\text { Prompt }\end{array}$ & $\begin{array}{l}\text { Incorrect } \\
\text { Verbal }\end{array}$ & $\begin{array}{l}\text { Incorrect } \\
\text { Verbal } \\
+ \\
\text { Gestural }\end{array}$ & $\begin{array}{l}\text { No } \\
\text { Response }\end{array}$ \\
\hline A & 18 & 10 & 1 & 0 & 1 & 0 & 0 \\
\hline B & 22 & 6 & 1 & 0 & 0 & 0 & 1 \\
\hline $\mathrm{C}$ & 18 & 4 & 6 & 2 & 0 & 1 & 0 \\
\hline $\mathrm{D}$ & 20 & 7 & 1 & 0 & 1 & 1 & 0 \\
\hline $\mathrm{E}$ & 12 & 3 & 7 & 3 & 0 & 1 & 7 \\
\hline $\begin{array}{l}\text { Prompt } \\
\text { Totals }\end{array}$ & 90 & 30 & 16 & 5 & 2 & 3 & 8 \\
\hline
\end{tabular}




\section{CHAPTER 5}

\section{DISCUSSION}

The purpose of this section presents an overview of the findings. It is divided into four sections: (a) a discussion on the impact of children's co-morbid or mitigating conditions (b) a discussion of the results of the two research questions (c) the limitations of the study and (d) implications for future research and practice.

\section{Child Co-Morbid and Mitigating Conditions.}

Due to the heterogeneity of ASD characteristics and the co-morbid conditions of some of the children a description follows for each child on how these factors may have impacted response to intervention.

Child A. Child A was diagnosed with SPD and had a co-morbid diagnosis of ataxia, which affected intelligibility and clarity of speech. It was sometimes necessary to clarify his answers before moving on to questions. It is possible that even with attempts to clarify his answers, correct answers could have been missed when his sessions were reviewed and coded.

Child B. Child B had a co-morbid diagnosis of ODD, which could cause him to engage in non-compliant behavior. He would often try to renegotiate his reward system with the RBT before attending the intervention sessions or refuse to transition from a previous activity. He had the highest expressive language skills of the group and would sometimes prefer to ask rather than answer questions or engage in conversations unrelated to the stories. It is possible that these behaviors may have interfered with obtaining higher scores in the QAR levels.

Child C. Child C was diagnosed with a co-morbid language impairment. He often engaged in echolalia in which he would repeat dialogue he had heard in movies or television shows, seemingly triggered by a similarity in a story, which sometimes interfered with his ability 
to answer questions. He would often require cues to re-focus his attention to attend to the book and questions during instructional intervention sessions. During probes, his echolalic responses were coded as incorrect as re-focusing his attention after the question had been answered with an echolalic response was not compatible with the procedural fidelity of the sessions. For example, when asked what kind of animal was on the cover of the book Bunny Cakes in which the correct answer was a "bunny" or "rabbit", he would begin to recite from a cartoon version of Peter Rabbit. His ability to answer questions without engaging in echolalic responses improved throughout the course of the study.

Child D. Child D had high expressive and receptive language skills but also engaged in frequent echolalia. He would often recite the question back to the researcher which was counted as an incorrect answer during baseline sessions. Once instructional sessions began, he was cued that a question was going to be asked so that he was primed to answer instead of repeating the question. He was able to improve in his ability to answer questions during probe sessions. He was also considered to be a hyperlexic reader, he could decode with high skill, but had difficulty comprehending or recounting what he had read. In addition, he was unaccustomed to listening to stories and preferred to read aloud to others. During baseline he was rewarded with choosing a story to read to the researcher and RBT after the session was complete.

Child E. Child E struggled the most with the sessions. He had a history of tantrums and non-compliant behavior which were being addressed at the center. Child E also displayed difficulty with communication skills, particularly expressive language. He was able to complete levels 1-3; however, once level four started he had numerous behavioral outbursts. It was decided by the BCBA and RBT assigned to him to discontinue the level. It was hypothesized that the combination of cognitive and language demands of the level caused him to experience 
frustration, leading to the behavior. Level 4, Connection required the participants to answer the questions outside the scope of the story which may have been too high of an expressive language demand, especially to reach the $80 \%$ criteria for a total of three sessions.

In summary, the described co-morbid and mitigating conditions may have affected the participants' ability to give correct responses to the comprehension questions as operationally defined in the study.

\section{Discussion of Results.}

The study was designed to explore the effect of the QAR and QAR cue cards as a shared book reading intervention package on the listening comprehension skills of pre-K children with ASD. The following research questions were evaluated: 1) Is there a functional relation between an adapted question and answer relationship strategy and visual support, shared book reading intervention package and an increase in the level of listening comprehension skills related to fact, search, inference, and connection questions for pre-k children with ASD? 2) What is the social validity of an adapted question and answer relationship strategy and visual support intervention package for pre-k children with ASD? A discussion of each research question follows.

Research Question One. It was hypothesized that implementing the QAR and visual support intervention package with children with ASD would increase listening comprehension skills related to Fact, Search, Inference, and Connection questions. Through visual analysis and non-parametric statistical analysis, the data showed that all or some aspects of the intervention were effective for each of the five children in the study. These findings were consistent with previous research on listening comprehension for children with ASD (Hudson et al., 2017; Kimhi, Achtarzad, \& Tubul-Lavy 2018; Mucchetti, 2013; Whalon et al., 2018) and question answering strategies for individuals with ASD (Asberg \& Dahlgren-Sanberg, 2010; Whalon \& 
Hanline, 2008). All four of the shared reading interventions (Hudson et al., 2017; Kimhi, Achtarzad, \& Tubul-Lavy 2018; Mucchetti, 2013; Whalon et al., 2018) and the Whalon \& Hanline (2008) question-answering strategy in the literature reviews showed an increase in listening comprehension skills for pre-k and kindergarten children with ASD and also included visual supports and targeted prompts. The Asberg \& Dahlgren-Sanberg (2010) study resulted in an increased percentage of correct answers to comprehension questions for children and adolescents with ASD using the QAR strategy. The data analysis from each of the five children will be discussed in in the sections below.

Split middle trend analysis. For this study, success of the intervention would depend upon an increase in ordinate value over time. Accelerating trend lines in the intervention phase would be described as therapeutic as participants improved in the intervention. Decelerating trend lines in intervention would indicate a deteriorating effect. Therefore, in baseline the trend lines would be predicted to be decelerating or flat (Ledford and Gast, 2018). When examining the trend lines of the children, none fit the predicted profile of decelerating or flat trendlines in the baseline phase and accelerating trend lines in the intervention phase. Children $\mathrm{C}$ and $\mathrm{E}$ had decelerating trend lines in baseline while Child D was flat. However, all three children C, D, and E had decelerating trend lines is the intervention phase as well. Children A and B had accelerating trendlines in baseline. Although children A and B had the shortest baseline phases (Child $\mathrm{A}=5$, Child $\mathrm{B}=6$ ), it is possible that maturation contributed to the accelerating trend. Maturation refers to changes in behavior due to the passage of time (Ledford and Gast, 2018). Child A also had an accelerating trend line in the intervention phase, while Child B had a flat trend line in the intervention phase which determined neither an accelerating nor decelerating effect. It is difficult to pinpoint the potential sources in the trend lines going against the predicted 
direction. It is possible that the mitigating factors of the participants previously mentioned contributed to the variation in trend lines. The trend stability analysis revealed more consistent results with expected variability in the baseline phase and stability in the intervention phase discussed below.

Trend stability analysis. Further examination of trend stability showed that four of the participants had variability in baseline trend lines compared to stability during intervention with trend stability analysis within a $25 \%$ stability envelope. Child A showed variability in baseline with $2 / 5$ data points $(60 \%)$ falling outside of the $25 \%$ stability envelope compared to $92 \%$ stability in the intervention phase. Child B showed variability in baseline with 2/6 data points (67\%) falling outside of the stability envelope compared to $93 \%$ in intervention. Child C showed variability in baseline with $2 / 7$ data points $(71 \%)$ falling outside the stability envelope, compared to $100 \%$ stability in intervention. Child D showed variability in baseline with $4 / 8$ data points (50\%) falling outside the stability envelope compared to $100 \%$ stability in intervention. Child E showed the least variability in baseline with $2 / 9$ data point (78\%) falling outside of the stability envelope compared to $80 \%$ stability in intervention. These findings indicate that four of the five children achieved a stable trend during the intervention phase of the study compared to variability outside of the stability envelope in baseline. The stability analysis showed less variability in the intervention phase that the split middle analysis. Taken together, the split middle analysis and trend stability analysis show that there was a wide degree of variability in the baseline phase with possible maturation contributing to an accelerating trendline in Children A and B; the analyses during intervention showed greater stability in all children with decelerating trendlines for Children C, D and E and a flat trend line for Child B as the levels increased in difficulty. 
Immediacy of effect. All children showed positive absolute changes between the baseline and intervention phases with the exception of Child B who had a 5\% negative difference between the phases. However, all of the children had higher percentages in the intervention phase of the study when relative change was analyzed. This indicated that overall, the immediacy of the effect showed a functional relation between the intervention and an increase in correct answers to comprehension questions between the intervention and baseline phases of the study.

Overlap analysis. The significant evidence of the functional relation between the intervention and listening comprehension was observed for each child as indicated by Tau-U statistical analysis and for the overall intervention with effect sizes that were considered to be very large (Vannest, et al., 2011. The results of the Tau-U analysis in the study were comparable across children in determining the magnitude of the treatment effect. The corrected baseline formula was used for Child D as his baseline trend exceeded the .20 cut off value. It is possible that this trend occurred due to Child D having an extended baseline phase and also the variability within the baseline phase indicated by the trend stability analysis. The Tau-U findings should be interpreted with caution and viewed in totality with all other measures of data analysis.

Baseline. When examining the dependent variable of correct responses to comprehension questions in the baseline phase all children scored the highest during baseline in the Level 1, Fact category $(M=66 \%)$ and the lowest in the Level 2, Search category $(M=16 \%)$.

Level 1, Fact questions required one word answers while looking at the cover and title of the story. It was not surprising that this level resulted in the highest scores across children as this level required the least expressive and receptive language demands. Child A, B, C, and D scores ranged between $60 \%-77 \%$ while Child E scored $44 \%$. 
The Level 2, Search category yielded the lowest scores in the baseline phase. This level required the participants to turn the pages to locate the answer in the book. None of the participants turned pages to locate answers during the baseline phase of the study. Correct answers were due to the participants remembering the relevant part of the story with scores ranging between $9 \%-23 \%$.

Level 3, Inference consisted of local coherence inferences questions which required participants to integrate information not explicitly stated in the story from within the text, including sentences, pronouns, vocabulary, and illustrations. Difficulty with this level was expected as children with ASD historically have difficulty organizing, connecting, and monitoring the content of text in a manner that is conducive to comprehension of text (McIntyre, Solari, Gonzales, et al., 2017; Nguyen et al., 2015; Roycroft, 2015). The scores ranged widely from $8 \%-56 \%$.

Interestingly, the Level 4, Connection was the second highest scoring category in the baseline phase. This level required the children to find similarities or differences between themselves and a character, incident, or emotion in the story. It is the most difficult level as it requires the highest language demands and critical thinking skills. The scores ranged from $20 \%$ 67\%. The Level 3, Inference and Leve 4, Connection had the largest and most similar ranges $48 \%$ and $47 \%$ respectively which indicate the greatest variance in the children's scores and align with the levels requiring the highest cognitive and language skills.

Intervention. The intervention phase of the study yielded results in which all children improved in the four levels of the intervention once the QAR strategy was sequentially taught in conjunction with the QAR cue cards as visual supports with the most significant change from baseline in the Level 2, Search category, $(M=16 \%)$ to intervention, $(M=83 \%)$. The participants 
as a group were similar as most reached criterion in three to four sessions with the exception of Child E in Level 4, Connection.

The children learned Level 1, Fact with relative ease and improved with practice from the instructional sessions with scores ranging from 75\%-100\%.

Level 2, Search involved learning to turn pages one at time forwards or backwards to locate the section of the book that contained the answer. Therefore, this level included a specific motor skill which needed to be taught in order to answer the questions. Once the skill of searching for answers by turning pages was mastered the children excelled and enjoyed the instructional sessions, viewing it almost like a game and expressing excitement when they found the correct answer. The QAR cue card for the Search category displayed an illustration of a hand turning a page and this card was referred to independently by the children multiple times during the instructional sessions. The scores ranged from 76\%-93\%.

Level 3, Inference, used local coherence in which the context clues were within the text and illustrations and did not require global knowledge about the theme, main point, or moral of the story. These questions were embedded on specific pages and were not randomized as the other levels during repeated readings of the stories. Along with the direct teaching during instructional sessions, it is possible that the predictability of the questions could have contributed to high scores in the Level 3, Inference category, The ranges were 75\%-93\%, which was similar to the Level 2, Search category and may further illustrate the success of the level being attributed to explicit instruction and repeated exposure to the book and questions.

Level 4, Connection, which required children to relate to the story with personal details about themselves. Level 4, Connection required the most modeling during instructional sessions in order for the children to give original answers rather than the same answers as in previous 
stories or mimic answers from the story that did not apply to themselves. Therefore, this level required the highest expressive language and critical thinking skills of the four categories. Child D, who was prone to echolalic answers benefited greatly from the modeling and practice during the instructional sessions. Child E would become frustrated during the instructional sessions and the RBT and BCBA assigned to his case determined that the language demand of the level was too high, although it was thought that he possessed the cognitive skill, but could not coordinate the two functions which lead to frustration. The scores ranged from $27 \%-86 \%$ with Child E having the lowest score and the rest of the children all scoring between $80 \%-86 \%$.

Maintenance. The maintenance phase was conducted in two parts, one week and two weeks after each child had completed the four levels of the intervention. Child D was unable to complete the second maintenance session due to illness. The children stayed consistent with skills compared to intervention with the main difference being Level 3, Inference $(M=72 \%)$ having the lowest score compared to Level 4, Connection $(M=78 \%)$.

In Level 1, Fact the children scored higher in the maintenance phase $(M=94 \%)$ than the intervention phase $(M=85 \%)$ and increased $28 \%$ from baseline $(M=66 \%)$. In Level 2, Search the children scored higher in the maintenance phase $(M=88 \%)$ than the intervention phase $(M=$ $83 \%)$ and increased $72 \%$ from baseline $(M=16 \%)$. In Level 3, Inference the children scored lower in the maintenance phase $(M=72 \%)$ than the intervention phase $(M=80 \%)$ and increased $41 \%$ from baseline $(M=31 \%)$. In Level 4, Connection the children scored higher in the maintenance phase $(M=78 \%)$ than the intervention phase $(M=70 \%)$ and increased $42 \%$ from baseline $(M=39 \%)$.

Child E participated in both maintenance sessions. It was decided in advance that the Level 4, connection questions would be included and the BCBA and RBT would monitor his 
frustration level and discontinue the session if necessary. He was able to answer $3 / 5(M=30 \%)$ of the Connection questions in both sessions which was commensurate with his intervention sessions $(M=27 \%)$ and contributed to the overall low score of the group in that category. He displayed minimal frustration with connection questions during the maintenance phase.

NLM Pretest and Posttest. The same NLM passages were read for the pretest and posttest phases of the study and consisted of two of the fall benchmark stories. The first was a passage about a girl who was not feeling and went to the doctor for medicine. The second was about a boy who, while running indoors, tripped over some toys, and hurt himself. In the NLM story questions subtest, each child increased in their ability to answer comprehension questions about the passages read aloud, especially Child D whose highest pretest score was 1 point out of a possible 12 points and had post test scores ranging from 6-9 points. The personal generation portion of the subtest asked the children to relate a similar experience to the passage that had been read aloud to them. The child's personal generation story was scored using a story grammar flow chart in which points are given for details provided. A complete, detailed personal retell of the question would result in the 23 points possible. During the pretest Child D and Child E did not provide any response to the personal generation prompt, but on the posttest were able to provide simple details which consisted of a pronoun and a location (i.e., "I went to the doctor" for the first passage or "I fell outside" for the second passage). Child B scored the highest with a score of 10 on the second posttest. It was hoped that the NLM benchmark passages could serve as a generalization measure of the dependent variable of correct answers to comprehension questions in Fact, Search, Inference, and Connection categories. While the NLM questions were not labeled with these exact terms the types of questions asked in the passages aligned with the QAR categories and are consistent with comprehension questions that children will be asked 
during reading assessments and instruction commensurate with their developmental level (Petersen and Spencer, 2016). The NLM posttest results demonstrated that the children improved in their ability to answer comprehension questions about stories outside of those used in the intervention.

Research Question One Summary. Overall, the children improved and maintained skills in the Level 1, Fact and Level 2, Search categories through each phase of the study. It is reasonable to say that the children improved in the Level 1, Fact category with practice and repeated exposure to the books during both baseline and instructional phases. Once the children understood the process of turning pages to locate answers in the Level 2, Search category they steadily improved through each phase of the study. The Level 3, Inference and Level 4, Connection categories were closely aligned in group scores through each phase of the study. However, the Level 4, Connection questions improved in maintenance compared to Level 3, Inference which decreased in the maintenance phase. These levels involved higher level cognitive and expressive language skills required to construct answers using the ability to infer, compare, and contrast information from the book and integrate it with their own background knowledge. The maintenance phase consisted of two books not previously used in the baseline or intervention phases and included novel questions without the benefit of prior practice or exposure. Since the Level, 3 Inference was the only category lower in the maintenance phase than in the intervention phase in can be reasonably asserted that this category may be the most difficult for this group of children with ASD.

The theories in the second literature review examined the comprehension challenges found in children with ASD. These theories may help to explain the barriers that the inference and connection questions may present to those with ASD in developing the metacognitive skills 
necessary to answer higher level questions. In the present study, the participants displayed challenges in their ability to integrate existing knowledge of events with information described in the stories. The weak central coherence (WCC) theory refers to a core cognitive deficit that causes individual to focus on the details in a text, rather than the global meaning (Nyguyen et al., 2015; Roycroft, 2015). An example of strong central coherence would be the ability to see a forest when observing a wide span of trees in the wilderness. Conversely, an individual with weak central coherence would be see only the individual trees. The top down executive deficit theory (EDF) is similar in that it hypothesizes that executive function of top down semantic processing in children with ASD is impaired which inhibits the ability to synthesize information in text to create meaning (Nyguyen et al., 2015; Roycroft, 2015). The inhibition deficit theory or Theory of Mind (ToM) hypothesis posits that children with ASD may have difficulty filtering out unnecessary parts of a text and focus on parts which interest them or are familiar to them (Nyguyen et al., 2015; Roycroft, 2015). Researchers in neuroscience have replicated studies showing that children with ASD use different neurological functions compared to typically developing peers when processing information. One such example is the activation of ventral occipitotemporal regions in children with ASD versus activation of the prefrontal working memory regions in typically developing children (Manjaly et al., 2007; Nuske, \& Bavin, 2011; Ring et al., 1999). This may point to the strengths in visual processing that children with ASD often display (McIntyre, Solari, Gonzales, et al., 2017; McIntyre, Solari, Grimm, et al., 2017; Nation, Clarke, Wright, \& Williams, 2006; Whalen \& Hart, 2011). A common thread in all theories is that the neurological impairments in ASD may impede the ability to integrate the details of text in a variety of ways and require interventions that include explicit instruction in 
how to synthesize and organize information while recognizing the differences they may present in processing the information.

An interesting development in the study was that during the instructional sessions the children began to initiate and generate their own questions. While this was not a targeted skill it was consistent with the reviewed Whalon and Hart (2008) study in which children with ASD increased in unprompted questions and responses using visual supports that cued the parts of story and classified different types of comprehension questions. The comprehension questions in the Whalon and Hart (2008) study included setting, characters, events, problem, and solution which are consistent with the QAR comprehension questions. The ability to generate questions also allowed the children to play an active role in instructional goals by seeking additional information (Whalon and Hart, 2011).

When examining the results of the pilot study and the present study, similarities were present in both. The pilot study children scored similarly in the baseline phase of the study. The Level 1, Fact category was the highest scoring category in both the baseline and intervention phase of the pilot study as in the present study. Another similarity was that the older children in the pilot study did not independently turn pages to locate answers during the baseline phase during the Level 2, Search category and required direct instruction to master the skill efficiently in the intervention phase of the study. The older children in the pilot study also made sequential gains across levels in the intervention phase with substantial increases in the higher level Inference and Connection categories compared to baseline scores.

The pilot study pretest and posttest compare to the present study in that all children were able to improve in their ability to add details when generating personal details or retelling a passage with the exception of PB in the pilot study. PB was susceptible to changes in his routine 
and could require extra time when transitioning between activities. It is also possible that that the time limit on the RTF subscale of the DIBELS assessment was not commensurate with the processing time he required for the task.

The pretest and post test scores of the pilot study children display the pattern found in both literature reviews in which a disparity exists between decoding and comprehension skills in children with ASD, also known as the poor comprehender profile in the simple view of reading theory. The Davidson and Weismer, (2014) study in the first literature review which compared the cognitive and language heterogeneity among children with ASD found that $62 \%$ of their sample of children with ASD ages 2-5 had the poor comprehender profile of normal to average decoding skills compared to below average comprehension skills. This mirrored the Nation et al., (2006) study which found $65 \%$ of their sample of children with ASD ages 6-15 to have had the same disparity or poor comprehender profile. Moreover, the language and cognitive heterogeneity within ASD study (Knight and Blancher, 2018), and the studies which compared children with ASD to TD children (Dynia et al., 2016; Fleury and Lease, 2018) also aligned with previous studies (McIntyre, Solari, Gonzales, et al., 2017; McIntyre, Solari, Grimm, et al., 2017) which found the disparity between decoding skills and comprehension skills in children with ASD. Thus, a pattern emerges of preschool aged children with ASD presenting at an early age with similar comprehension deficits as school aged children with ASD.

The present study focused on the comprehension component of the simple view of reading theory in preschool aged children. The children in the study presented with low comprehension skills in the baseline phase of the study and the NLM pretest measures which both increased after intervention. This provides a further rationale for the implementation of interventions which address listening comprehension in early education settings. The results of 
the present study extend the literature by demonstrating that a targeted intervention may improve listening comprehension skills in some preschool aged children with ASD.

Research Question Two. The social validity of an intervention is an important consideration and includes the feasibility of the intervention as it applies to those who will implement and receive the treatment as well as its social importance (Horner et al., 2005). When implementing educational interventions evaluating whether the treatment outcomes are acceptable, socially relevant, and useful to children, teachers, and practitioners is necessary to understand the intervention's impact. Moreover, interventions with a focus on emergent literacy skills such as listening comprehension during early childhood are of critical importance for children with ASD as they are at risk for continued language difficulties and future reading problems (McIntyre, Solari, Gonzales, et al., 2017; McIntyre, Solari, Grimm, et al., 2017; Nation, Clarke, Wright, \& Williams, 2006; Whalen \& Hart, 2011). Because of the continued increase in the number of young children identified with ASD, it is crucial to identify strategies that specifically targeting the core language and communication impairment challenges of children with ASD that are socially valid. Therefore, the social validity of the study was examined.

Child Social Validity. Overall, the participants enjoyed the sessions and would react positively when it was time for sessions. Children B and E would sometimes have difficulty transiting from a previous activity to the sessions and Child E also had displayed frustration with the final level as previously reported. The RBTs and BCBAs shared comments that the participants would look forward to the sessions when they saw it displayed on their schedules. The children frequently referred to the QAR cue card during instructional sessions and Children 
A, C and D would position the cards which were displayed on a small board where they could more easily see the appropriate card for the level being taught.

The children responded favorably to the books which were read during the baseline, intervention, and maintenance sessions. The three books used for the intervention phase Alexander and the Wind-Up Mouse, Duck on a Bike, and Whistle for Willie could become a bit repetitive as this phase of the study lasted the longest. The books were chosen randomly from the Read Together/Talk Together program however, it was fortuitous that three of the books The Snowy Day, Whistle for Willie, and Corduroy featured African American characters as the participants were ethnically diverse. It would be a consideration to be mindful that books are chosen with diverse characters that are representative of the study population.

It is acknowledged that the participants who circled the "yes" emojis may have done so because they preferred the smiling face or green color, as opposed to the yellow neutral emoji or the red no emoji. It is also possible that the survey reflected their feelings in the moment and not the entirety of the study.

RBT Social Validity. The demographic information revealed that the RBTs skewed towards a younger age bracket with none above 35 years old. They were equally educated with bachelor's degrees and RBT certification. No RBT had been in the ABA field longer that five years and two had teaching experience longer than five years, with one having no teaching experience. Therefore, the demographic information shows a group that was very similar in terms of age, education, and experience which may account for the consensus of many of their answers to the survey questions.

The survey requested feedback on how the study could have been improved and what was the most helpful part of the intervention. Improvements mentioned were giving the children 
a choice in the books that were read or having a wider variety of books. Also mentioned was that recording the sessions could be distracting, and a lack of corrective feedback during probe sessions. Positive aspects of the study included the improvements in client ability to answer comprehension questions, having a clearer sense of the client's strengths and deficits, the sequential levels that increased in difficulty and built confidence in answering questions, and knowledge of different levels on comprehension questions and how this relates to reading success. The improvements that the RBTs listed and the positive aspects of the study will be discussed in the sections below.

Improvements to the Intervention. The most frequently mentioned improvement to the study was the process in which the sessions were recorded. The sessions were recorded on a Lenovo ThinkPad computer. The therapy rooms were quite small and had no high shelving to place the computer, so it was usually placed at eye level to the participants. At first, they were able to see themselves on the screen, which was very distracting. Through trial and error, a way to position the computer and minimize the video function was achieved which did improve the quality of the sessions and became less distracting to the participants.

Before the study began all operational definitions and treatment fidelity procedures were explained. RBTs and BCBAs were given data sheets and procedural fidelity checklists to review. However, it was important to explain that the participants did not receive corrective feedback during probes to protect the experimental control of the study. Incorporating a check for understanding of procedures into the procedural fidelity checklist may be helpful in future studies. It is acknowledged that giving the participants a choice in which books to read would have been desirable but using the same books for each child also supported experimental control of the study. 
Positive Aspects of the Intervention. All five of the RBTs felt that the intervention helped their clients to answer the four levels of comprehension questions and was a positive experience for their client. Specifically, modeling, visual supports, repeated exposure to the books, facilitating expressive language skills, helping to focus on story, and the Story \& Me card (Level 4, Connection) category were mentioned as being the most helpful part of the intervention. The sequential teaching of the QAR levels and the relation to reading success was considered by the majority of RBTs (3/5) to be the most important thing that they learned during the study. It is worth noting that all five RBTs strongly agreed that they would be interested in learning the strategy and that the intervention would help their client to achieve academic goals at school. The answers were more mixed when asked if the intervention would be easy to implement at the center or achieve goals with two RBTs choosing "agree" or neutral responses, as opposed to strongly agree. It can be concluded that although they had strong interest in learning the intervention and recognized the possible academic significance, integrating the intervention into client goals at the center garnered a more ambivalent response.

\section{Limitations}

This research study was subject to limitations which will be discussed below. First, all children made gains, but performance was variable for Child E in the Level 4, Connection phase of the intervention. Also, as with all intervention research on children with ASD, the study represented a highly heterogeneous group with co-morbid conditions and one child did not have a definitive diagnosis of ASD. Therefore, it is difficult to determine if these findings will generalize to all children with ASD. The sample size of five children could also be considered to be small. Maturation in which changes are attributed to the passage of time could have been a threat to the internal validity of the study. Additionally, QAR is an educational intervention and 
ideally would be implemented in an early childhood classroom setting. The results of an intervention may not translate when research is conducted outside of the environment in which it is to be implemented. The one-to-one ratio in which the study was conducted may also make implementation to a classroom difficult. All intervention sessions were conducted by the researcher; therefore, researcher bias could be considered a threat to the validity of the study. The social validity survey for children devised of circling emoji faces may not have accurately represented the feelings of the children and was administered by the researcher, so a desire to please the researcher should be taken into consideration. The RBTs who completed the social validity survey had limited teaching experience and their evaluation of the intervention may not reflect those of educators in early childhood classrooms. The use of non-standardized, researcher developed testing instruments for the baseline, intervention, and maintenance probes was susceptible to researcher and coding errors. The study did not include the prompting information from the instructional sessions into the final data analysis. The intervention phase of the study was implemented immediately after the last baseline session for all five children. However, Figure 3, which displayed the data of all five participants could be interpreted as a delay in sessions occurring between baseline and intervention, making it difficult to know if any changes in child behaviors occurred immediately before intervention. Finally, the study was limited in scope to comprehension and did not measure any other areas of early literacy skill development.

\section{Implications for Future Research and Practice}

Given both the findings and limitations of this study, it is suggested that the QAR intervention and QAR card intervention package has the potential to improve listening comprehension for some children with ASD by increasing the ability to answer four levels of comprehension questions, Fact, Search, Inference, Connection. Although these outcomes are 
positive, they are limited. Improvement in other areas of early literacy skill development, such as expressive vocabulary, question generation, and print awareness were not measured in the present study. Future studies that examine the effectiveness of shared reading interventions for children with ASD should include a broader range of early literacy outcome measures. Furthermore, longitudinal studies have been conducted which demonstrate the link between early listening comprehension and later reading comprehension of TD children and children with language impairments (e.g., Bishop \& Edmundson, 1987; Tunmer et al. 2006; Bishop \& Edmundson, 1987; Catts, Bridges, Little, \& Tomblin, 2008; NICHD, 2005). Thus, it would be valuable to conduct longitudinal studies with children with ASD as well. Future research studies should also examine effective standardized listening comprehension measures. Tests designed to measure listening comprehension vary in the degree that they measure the constructs and processes of vocabulary, inferencing, semantics, syntax, and background knowledge and use a variety of different terms (i.e., text comprehension, narrative comprehension). Considering the preliminary outcomes in this study, it is hopeful that the QAR intervention techniques may be a promising practice that can be incorporated in early intervention programming for children with ASD pending further studies that replicate and extend these findings.

\section{Conclusion}

In summary, it is important for educators to emphasize explicit listening comprehension skills in early childhood programming to maximize student success in academic achievement (e.g., Fleury \& Lease, 2018; NELP, 2008; NICHD, 2005). Children with ASD who do not receive explicit listening comprehension instruction in early childhood may still be able to decode efficiently enough to read on grade level once they reach primary grades, but lack the skills needed for effective comprehension of text (McIntyre, Solari, Gonzales, et al., 2017; 
Ricketts et al., 2013; Whalon et al., 2009). Research indicates that there is a probable link between the language and communication impairments in the disorder and the listening and reading comprehension deficits of children with ASD (McIntyre, Solari, Gonzales, et al., 2017; Nation et al., 2006; Norbury \& Nation, 2011). As the number of children identified with ASD continues to increase, there is a need to identify effective interventions for improving the academic achievement of students with ASD by addressing their unique challenges with listening comprehension. Research has shown that for some children with ASD deficits in listening comprehension during early childhood correspond with reading comprehension difficulties in primary and elementary grades. The high prevalence rate and heterogeneity of ASD emphasize the need for evidence-based interventions that can meet to meet the needs of this diverse population during early child development. Facilitating listening comprehension during the emergent literacy period has the potential to positively impact academic and long-term outcomes for children with ASD. 


\section{References}

Åsberg, J., \& Sandberg, A. D. (2010). Discourse comprehension intervention for high functioning students with autism spectrum disorders: preliminary findings from a school-based study. Journal of Research in Special Educational Needs, 10, 9198. doi:10.1111/j.1471-3802.2010.01147.x

Centers for Disease Control and Prevention (2018) autism spectrum disorder (ASD) data and statistics. Retrieved from: https://www.dcd.gov/ncbddd/autism/data.html

Chiang, H., Walsh, E., Shanahan, T., Gentile, C., Maccarone, A., Waits, T., \& Rikoon, S. (2017). An exploration of instructional practices that foster language development and comprehension: Evidence from prekindergarten through grade 3 in title I schools. NCEE 2017-4024. National Center for Education Evaluation and Regional Assistance. Retrieved from: http://ies.ed.gov/ncee/pubs/20174024/

Cortese, E.E., (2004). The application of the question-answer relationship to pictures. The Reading Teacher, 57, 374-280. Retrieved from: https://jstor.org./stable/20205372

Coyne, M. D., Simmons, D. C., \& Kame'enui, E. J. (2004). Vocabulary instruction for young children at risk of experiencing reading difficulties: Teaching word meanings during shared storybook readings. Exceptionality, 12, 145-162. doi:

$10.1207 / \mathrm{s} 15327035 \mathrm{ex} 1203 \_3$

Cummins, S., Streiff, M., \& Ceprano, M. (2012). Understanding and applying the qar strategy to improve test scores. Journal of Inquiry and Action in Education, 4, 18-26. Retrieved from: https://digitalcommons.buffalostate.edu/jiae/vol4/iss3/2/

Davidson, M. M., \& Weismer, S. E. (2014). Characterization and prediction of early reading abilities in children on the autism spectrum. Journal of Autism and Developmental Disorders, 44, 828. doi: 10.1007/s10803-013-1936-2 
Dynia, J., Brock, M., Logan, J., Justice, L., \& Kaderavek, J. (2016). Comparing children with asd and their peers' growth in print knowledge. Journal of Autism \& Developmental Disorders, 46, 2490-2500. doi:10.1007/s10803-016-2790-9

Finnegan, E., \& Mazin, A. L. (2016). Strategies for increasing reading comprehension skills in students with autism spectrum disorder: A review of the literature. Education and Treatment of Children, 39, 187-219.

Fleury, V. P., \& Lease, E. M. (2018). Early indication of reading difficulty? A descriptive analysis of emergent literacy skills in children with autism spectrum disorder. Topics in Early Childhood Special Education, 38, 82-93. doi:10.1177/0271121417751626.

Fleury, V., Herriott Miramontez, S., Hudson, R., \& Schwartz, I. (2014). Promoting active participation in book reading for preschoolers with autism spectrum disorder: A preliminary study. Child Language Teaching and Therapy, 30, 273-288. doi:10.1177/0265659013514069

Fleury, V. P., \& Schwartz, I. S. (2017). A modified dialogic reading intervention for preschool children with autism spectrum disorder. Topics in Early Childhood Special Education, 37, 16-28. doi:10.1177/0271121416637597

Foorman, B., Beyler, N., Borradaile, K., Coyne, M., Denton, C. A., Dimino, J., \& Keating, B. (2016). Foundational skills to support reading for understanding in kindergarten through 3rd grade. educator's practice guide. NCEE 2016-4008. National Center for Education Evaluation and Regional Assistance. Retrieved from: http://ies.ed.gov/ncee/wwc

Good, R. H., \& Kaminski, R. A. (2002). Dynamic indicators of basic early literacy skills (6th ed.). Eugene, OR: Institute for the Development of Educational Achievement. Retrieved from: http://dibels.uoregon.edu/. 
Hargrave, A. C., \& Sénéchal, M. (2000). A book reading intervention with preschool children who have limited vocabularies: The benefits of regular reading and dialogic reading. Early Childhood Research Quarterly, 15, 75-90. doi: 10.1016/S0885-2006(99)00038-1

Henry, A. R., \& Solari, E. J. (2020). Targeting oral language and listening comprehension development for students with autism spectrum disorder: A school-based pilot study. Journal of Autism and Developmental Disorders, 1-14. doi: 10.1007\%2Fs10803-02004434-2

Hogan, T. P., Bridges, M. S., Justice, L. M., \& Cain, K. (2011). Increasing higher level language skills to improve reading comprehension. Focus on Exceptional Children, 44, 1-20. Retrieved from http://digitalcommons.unl.edu/specedfacpub/79

Hogan, T. P., Adlof, S. M., \& Alonzo, C. N. (2014). On the importance of listening comprehension. International Journal of Speech-Language Pathology, 16, 199-207. doi:10.3109/17549507.2014.904441

Horner, R. H., Carr, E. G., Halle, J., McGee, G., Odom, S., \& Wolery, M. (2005). The use of single-subject research to identify evidence-based practice in special education. Exceptional children, 71, 165-179. doi: 10.1177/001440290507100203

Horner, R. H., Ferron, J. (2018). Single-case intervention design and analysis. IES Summer Research Institute. Retrieved from: https://www.slideserve.com/dmalek/ies-summerresearch-institute-single-case-design-and-analysis-powerpoint-ppt-presentation

Kim, Y.-S. G., \& Pilcher, H. (2016). What is listening comprehension and what does it take to improve listening comprehension? In R. Schiff \& M. Joshi (Eds.), Handbook of interventions in learning disabilities (pp. 159-174). New York: Springer. doi: 10.1007/978-3-319-31234-4_1 
Kimhi, Y., Achtarzad, M., \& Tubul-Lavy, G. (2018). Emergent literacy skills for five kindergartners with autism spectrum disorder. Journal of Research in Special Educational Needs, 18, 211-221. doi: 10.1111/14.71-3802.12406

Kinniburgh, L. H., \& Prew, S. S. (2010). Question answer relationships (QAR) in the primary grades: Laying the foundation for reading comprehension. International Journal of Early Childhood Special Education, 2, 31-44. Retrieved from: https://dergipark.org.tr/en/download/article-file/91510

Knight, E., Blacher, J., \& Eisenhower, A. (2018). Predicting reading comprehension in young children with autism spectrum disorder. School Psychology, 34, 168-177. doi: $10.1037 /$ spq0000277

Kratochwill, T. R., Hitchcock, J. H., Horner, R. H., Levin, J. R., Odom, S. L., Rindskopf, D. M., \& Shadish, W. R. (2013). Single-case intervention research design standards. Remedial and Special Education, 34, 26-38. doi: 10.1177/0741932512452794

Language and Reading Research Consortium, \& Chiu, Y. D. (2018). The simple view of reading across development: Prediction of grade 3 reading comprehension from prekindergarten skills. Remedial and Special Education, 39, 289-303. doi:10.1177/0741932518762055

Lanter, E., Watson, L. R., Erickson, K. A., \& Freeman, D. (2012). Emergent literacy in children with autism: An exploration of developmental and contextual dynamic processes. Language, Speech, and Hearing Services in Schools, 43, 308-324 doi: 10.1044/0161$1461(2012 / 10-0083)$

Ledford, J. R., \& Gast, D. L. (2018). Single case research methodology: Applications in special education and behavioral sciences. New York: Routledge. 
Lonigan, C. J., Anthony, J. L., Bloomfield, B. G., Dyer, S. M., \& Samwel, C. S. (1999). Effects of two shared-reading interventions on emergent literacy skills of at-risk preschoolers. Journal of Early Intervention, 22, 306-322. doi: 10.1177/105381519902200406

Lonigan, C. J., \& Shanahan, T. (2009). Developing early literacy: Report of the National Early Literacy Panel. Executive Search. A Scientific synthesis of early literacy development and implications for intervention. National Institute for Literacy. Retrieved from: https://files.eric.ed.gov/fulltext/ED508381.pdf

Ma, H. (2006). An alternative method for quantitative synthesis of single-subject researchers: Percentage of data points exceeding the median. Behavior Modification, 30, 598-617. doi: $10.1177 / 0145445504272974$

Manjaly, Z. M., Bruning, N., Neufang, S., Stephan, K. E., Brieber, S., Marshall, J. C., ... \& Fink, G. R. (2007). Neurophysiological correlates of relatively enhanced local visual search in autistic adolescents. Neuroimage, 35, 283-291. doi: 10.1016/j.neuroimage.2006.11.036

McCauley, R. J., Fey, M. E., \& Gillam, R. B. (Eds.). (2006). Treatment of language disorders in children. Baltimore, MD: Paul H. Brookes Publishing Co.

McIntyre, N. S., Solari, E. J., Gonzales, J. E., Solomon, M., Lerro, L. E., Novotny, S., Oswald, T. M., \& Mundy, P. C. (2017). The Scope and Nature of Reading Comprehension Impairments in School-Aged Children with Higher-Functioning Autism Spectrum Disorder. Journal of Autism and Developmental Disorders, 47, 2838-2860. doi:10.1007/s10803-017-3209-y

McIntyre, N. S., Solari, E. J., Grimm, R. P., Lerro, L. E., Gonzales, J. E., \& Mundy, P. C. (2017). A comprehensive examination of reading heterogeneity in students with high functioning Autism: Distinct reading profiles and their relation to autism symptom severity. Journal 
of Autism and Developmental Disorders, 47, 1086-1101. doi:10.1007/s10803-017-3029

Mucchetti, C. A. (2013). Adapted shared reading at school for minimally verbal students with autism. Autism, 17, 358-372. doi:10.1177/1362361312470495

Nation, K., Clarke, P., Wright, B., \& Williams, C. (2006). Patterns of reading ability in children with autism spectrum disorder. Journal of Autism and Developmental Disorders, 36, 911. doi: 10.1007/s10803-006-0130-1

National Early Literacy Panel. (2008). Developing early literacy: Report of the National Early Literacy Panel. Washington, DC: National Institute for Literacy. Retrieved from https://files.eric.ed.gov//fulltext/ED5085381.pdf

National Institute of Health and Human Development Early Child Care Research Network, (2005). Pathways to reading: The role of oral language in the transition to reading. Developmental Psychology, 41, 428-442. doi: 10.1037/0012-1649.41.2.428

National Reading Panel (U.S.), \& National Institute of Child Health and Human Development (U.S.). (2000). Report of the National Reading Panel: Teaching children to read: an evidence-based assessment of the scientific research literature on reading and its implications for reading instruction: reports of the subgroups. Washington, D.C.: National Institute of Child Health and Human Development, National Institutes of Health. Retrieved from https://www.nichd.gov/sites/default/files/publication/pubs/nrp/ Documents/report.pdf

National Research Council. (1998). Preventing reading difficulties in young children. Washington, DC: National Academies Press. doi: 10.17226/6023

No Child Left Behind (NCLB) Act of 2001, Publ. L. No. 107-110,§ 115, Stat.1425 (2002). Retrieved from https://www2.ed.gov/policy/elsec/leg/esea02/107-110.pdf 
Nguyen, N. N., Leytham, P., Schaefer Whitby, P., \& Gelfer, J. I. (2015). Reading comprehension and autism in the primary general education classroom. The Reading Teacher, 69, 7176.doi:10.1002/trtr.1367

Nuske, H. J., \& Bavin, E. L. (2015). Narrative comprehension in 4-7-year-old children with autism: testing the weak central coherence account. International Journal of Language \& Communication Disorders, 1-12. doi:10.310913681822.2010484847

Petersen, D. B., \& Spencer, T. D. (2016). Cubed. Laramie, WY: Language Dynamics Group. Retrieved from: https://www.languagedynamicsgroup.com/products/cubed/cubed_download/

Parker, R. I., \& Hagan-Burke, S. (2007). Useful effect size interpretations for single case research. Behavior Therapy, 38, 95-105. doi:10.1016/j.beth.2006.05.002

Parker, R. I., Vannest, K. J., Davis, J. L., \& Sauber, S. B. (2011). Combining nonoverlap and trend for single-case research: Tau-U. Behavior Therapy, 42, 284-299. doi: 10.1016/j.beth.2010.08.006

Paynter, J., Westerveld, M. F., \& Trembath, D. (2016). Reading assessment in children with autism spectrum disorder. Journal of Psychologists and Counsellors in Schools, 26, 205-217. doi: 10.1017/jgc.2016.15

Piasta, S. B., Justice, L. M., McGinty, A. S., \& Kaderavek, J. N. (2012). Increasing young children's contact with print during shared reading: Longitudinal effects on literacy achievement. Child Development, 83, 810-820. doi:10.1111/j.1467-8624.2012.01754.x

Pollard-Durodola, S. D., Gonzalez, J. E., Simmons, D. C., Kwok, O., Taylor, A. B., Davis, M. J., ... \& Simmons, L. (2011). The effects of an intensive shared book-reading intervention for preschool children at risk for vocabulary delay. Exceptional Children, 77, 161-183. 
doi: $10.1177 / 001440291107700202$

Raphael, T. E. (1986). Teaching question answer relationships, revisited. The Reading Teacher, 39(6), 516-522. Retrieved from: https://www.jstor.org/stable/20199149

Raphael, T. E., \& Au, K. H. (2005). QAR: Enhancing comprehension and test taking across grades and content areas. The Reading Teacher, 59, 206-221. doi: 10.1598/RT.59.3.1

Ricketts, J., Jones, C. R., Happé, F., \& Charman, T. (2013). Reading comprehension in autism spectrum disorders: The role of oral language and social functioning. Journal of Autism and Developmental Disorders, 43, 807-816. doi: 10.1007/s10803-012-1619-4

Ring, H. A., Baron-Cohen, S., Wheelwright, S., Williams, S. C., Brammer, M., Andrew, C., \& Bullmore, E. T. (1999). Cerebral correlates of preserved cognitive skills in autism: a functional MRI study of embedded figures task performance. Brain, 122, 1305-1315. doi:10.1093/brain/12

Roycroft, H. (2015). Autism Spectrum Disorder and Reading Comprehension: Challenges and Implications in the Primary School. Reach, 29, (1) Retrieved from: https://web.b.ebscohost.com/

Schwartz I., \& Hackett, J. (2017). Effects of emergent literacy interventions for preschoolers with autism spectrum disorder. Exceptional Children, 84, 55-75. doi: $10.1177 / 0014402917705855$

Scruggs, T. E., \& Mastropieri, M. A. (1994). The utility of the PND statistic: A reply to Allison and Gorman. Behaviour Research and Therapy, 32(8), 879-883.

Sparrow, S. S., Cicchetti, D. V., \& Saulnier, C. A. (2016). Vineland adaptive behavior scales, (Vineland-3). Antonio: Psychological Corporation. Retrieved from: 
https://jvrafricagroup.co.za/downloads/vinelandii/Product\%20Description/Product \%20Description\%20_\%20Vineland-3.pdf

Tunmer, W. E., Chapman, J. W., \& Prochnow, J. E. (2006). Literate cultural capital at school entry predicts later reading achievement: A seven-year longitudinal study. New Zealand Journal of Educational Studies, 41, 183-204. Retrieved from: https://www.researchgate.net/profile/Jane_Prochnow/publication/289861171

US Department of Education, Institute of Education Sciences, \& What Works Clearinghouse. (2017). What works clearinghouse: Standards handbook (Version 4.0). Washington, DC.

Vannest, K. J., \& Ninci, J. (2015). Evaluating intervention effects in single-case research designs. Journal of Counseling \& Development, 93, 403-411. doi: $10.1002 /$ jcad. 12038

Vannest, K. J., Parker, R. I., Gonen, O., \& Adiguzel, T. (2016). Single case research: web based calculators for SCR analysis. (Version 2.0) [Web-based application]. College Station, TX: Texas A\&M University. Retrieved from: www.singlecaseresearch.org/

Wahlberg, T., \& Magliano, J. P. (2004). The ability of high function individuals with autism to comprehend written discourse. Discourse Processes, 38, 119-144. doi: 10.1207/s15326950dp3801_5

Westerveld, M. F., Paynter, J., Trembath, D., Webster, A. A., Hodge, A. M., \& Roberts, J. (2017). The emergent literacy skills of preschool children with autism spectrum disorder. Journal of Autism and Developmental Disorders, 47, 424-438. doi:10.1007/s10803-016-2964-5

Westerveld, M. F., \& Roberts, J. M. A. (2017). The oral narrative comprehension and production 
abilities of verbal preschoolers on the autism spectrum. Language, Speech \& Hearing Services in Schools, 48, 260-272. doi:10.1044/2017

Westerveld, M. F., Trembath, D., Shellshear, L., \& Paynter, J. (2016). A systematic review of the literature on emergent literacy skills of preschool children with autism spectrum disorder. The Journal of Special Education, 50, 37-48. doi:10.1177/0022466915613593

Whalon, K., \& Hanline, M. F. (2008). Effects of a reciprocal questioning intervention on the question generation and responding of children with autism spectrum disorder. Education and Training in Developmental Disabilities, 43, 367-387. Retrieved from: https://www.jstor.org/stable/23879798

Whalon, K., Delano, M., \& Hanline, M. F. (2013). A rationale and strategy for adapting dialogic reading for children with autism spectrum disorder: RECALL. Preventing School Failure: Alternative Education for Children and Youth, 57, 93-101. doi: 10.1080/1045988X.2012.672347

Whalon K., Hart J. E. (2011). Adapting an evidence-based reading comprehension strategy for learners with autism spectrum disorder. Intervention in School and Clinic, 46, 195 - 203. doi:10.1177/1053451210389036

Whalon, K., Martinez, J. R., Shannon, D., Butcher, C., \& Hanline, M. F. (2015). The impact of reading to engage children with autism in language and learning (RECALL). Topics in Early Childhood Special Education, 35, 102-115. doi:10.1177/0271121414565515

What Works Clearinghouse, W. W. (2017). Standards handbook (version 4.0). Washington, DC: Institute of Education Sciences. Retrieved from: https://ies.ed.gov/ncee/wwc/Docs/referenceresources/wwc_standards_handbook_v4.pdf 
What Works Clearinghouse. (2015). WWC intervention report: Shared book reading.

Washington, DC: Institute of Education Sciences, U.S. Department of Education.

Retrieved from http://ies.ed.gov/ncee/wwc/pdf/intervention_reports/wwc_ sharedbook_041415.pdf

What Works Clearinghouse. (2010). WWC Intervention report: Early childhood education interventions for children with disabilities: Dialogic reading. Washington, DC: Institute of Education Sciences, U.S. Department of Education. Retrieved from http://ies.ed.gov/ncee/wwc/reports/ece_cd/ dialogic_reading/

Wilson, N. S., \& Smetana, L. (2009). Questioning as thinking: A metacognitive framework. Middle School Journal, 4, 20-28. doi:10.1080/00940771.2009.11461709 
Table 1. Listening Comprehension Studies

\begin{tabular}{|c|c|c|c|c|c|c|}
\hline \multirow[t]{2}{*}{ Study } & \multirow{2}{*}{ Purpose } & \multirow{2}{*}{$\begin{array}{l}\text { Participants/ } \\
\text { Setting }\end{array}$} & \multirow{2}{*}{ Design } & \multicolumn{2}{|c|}{ Oral Language Comprehension } & \multirow[t]{2}{*}{ Limitations } \\
\hline & & & & Measure & Outcome & \\
\hline $\begin{array}{l}\text { Davidson \& } \\
\text { Weismer, } \\
2014\end{array}$ & $\begin{array}{l}\text { Heterogeneity: } \\
\text { reading ability } \\
\text { predictors early } \\
\text { reading profiles } \\
\text { in ASD }\end{array}$ & $\begin{array}{l}\text { ASD } \\
(N=101) \\
\text { Ages 2-5 } \\
M=2.5 \\
M=5.5 \\
\text { University } \\
\text { Setting }\end{array}$ & $\begin{array}{l}\text { Longitudinal } \\
2 \text { time points } \\
\text { across } 3 \text { years }\end{array}$ & $\begin{array}{l}\text { TERA-3 RQ } \\
\text { Correlate } \\
\text { to PLS-4 } \\
\text { Auditory } \\
\text { Comprehension } \\
\text { Profile } 2 \& 3 \\
\text { Low } \\
\text { Comprehension }\end{array}$ & $\begin{array}{l}\text { Time One: } \\
\text { Range } \\
\text { Severely } \\
\text { Impaired to } \\
\text { Average } \\
\text { 50-117 } \\
\text { Time Two: } \\
\text { Severely } \\
\text { Impaired to } \\
\text { Average } \\
\text { 50-129 }\end{array}$ & $\begin{array}{l}\text { Did not } \\
\text { report effect } \\
\text { sizes } \\
\text { for predictors } \\
\text { or correlates }\end{array}$ \\
\hline
\end{tabular}

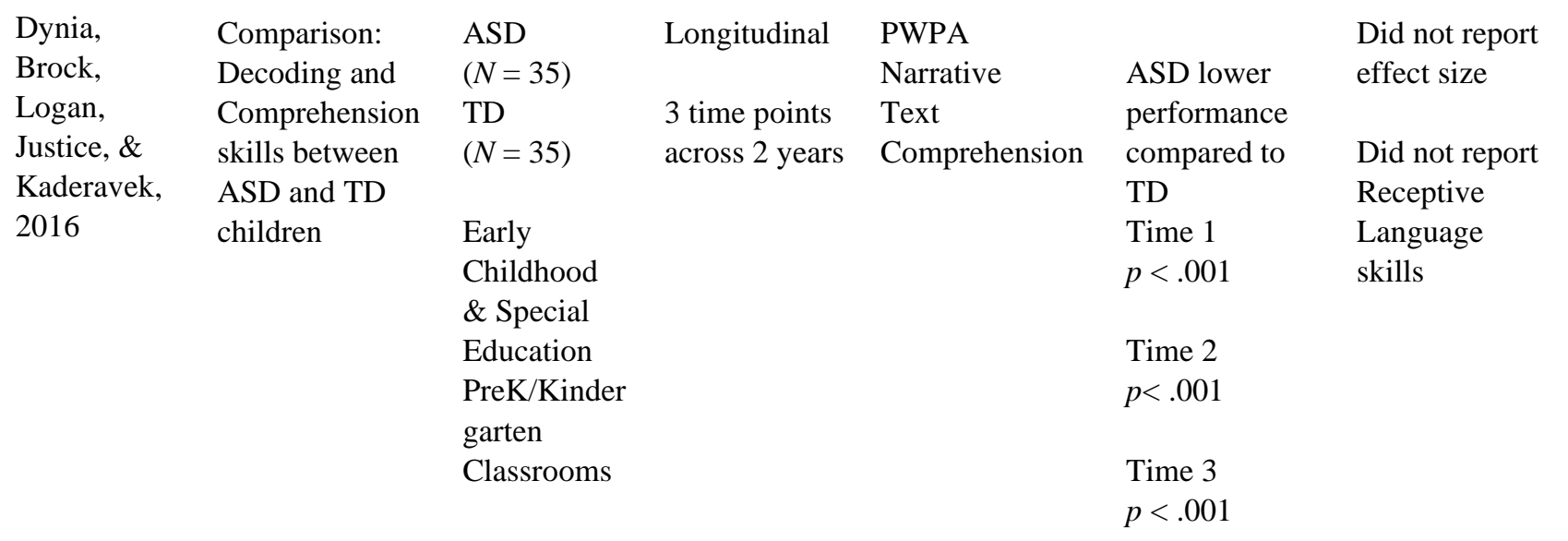




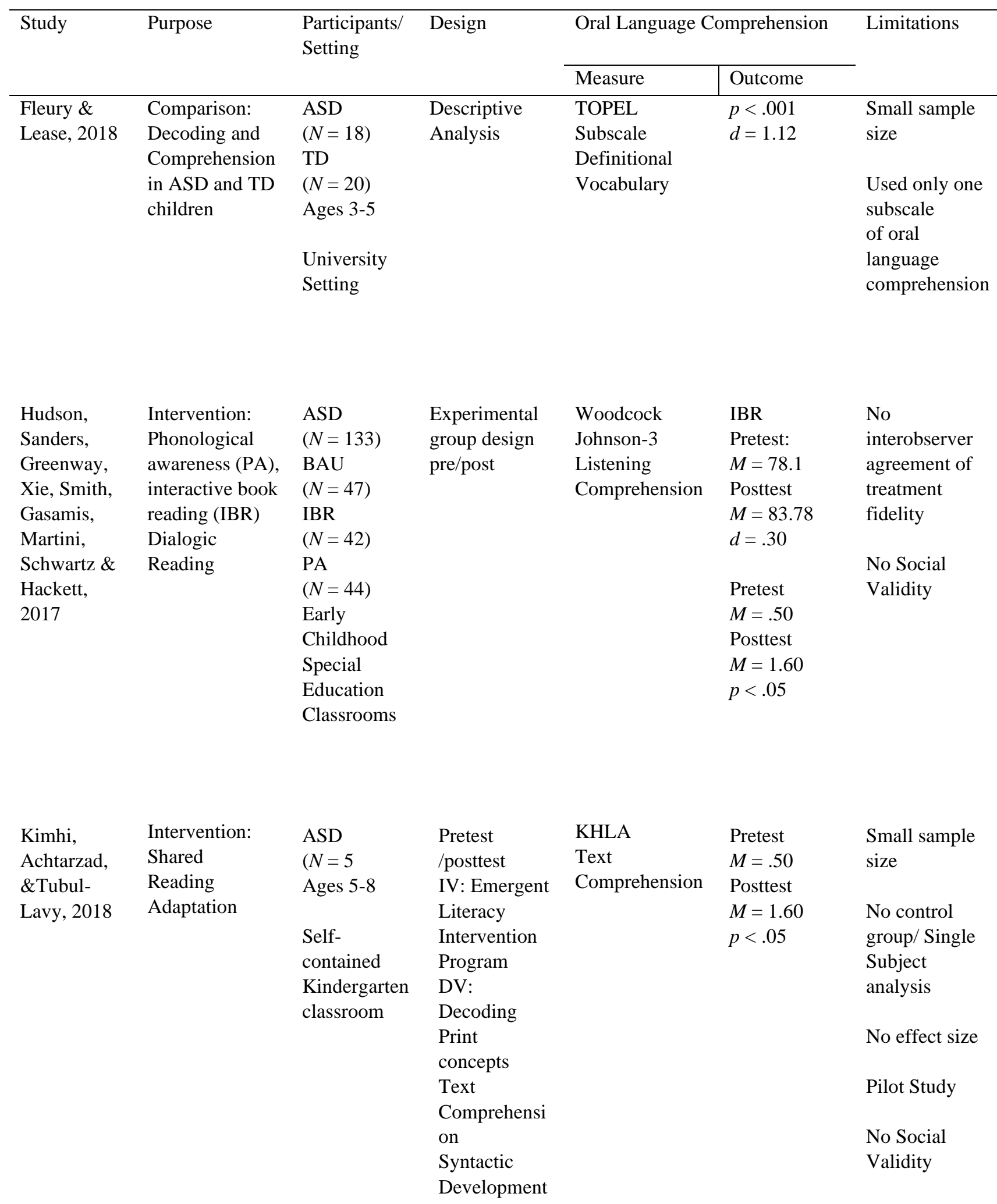




\begin{tabular}{|c|c|c|c|c|c|c|}
\hline \multirow[t]{2}{*}{ Study } & \multirow[t]{2}{*}{ Purpose } & \multirow{2}{*}{$\begin{array}{l}\text { Participants/ } \\
\text { Setting }\end{array}$} & \multirow[t]{2}{*}{ Design } & \multicolumn{2}{|c|}{ Oral Language Comprehension } & \multirow[t]{2}{*}{ Limitations } \\
\hline & & & & Measure & Outcome & \\
\hline $\begin{array}{l}\text { Knight \& } \\
\text { Blancher, } \\
2018\end{array}$ & $\begin{array}{l}\text { Heterogeneity: } \\
\text { ADOS severity } \\
\text { In ASD and } \\
\text { AimsWeb } \\
\text { performance }\end{array}$ & $\begin{array}{l}\text { ASD } \\
(N=157) \\
\text { Ages 5-7 } \\
(M=5.8) \\
\text { Pre-K } \\
(N=69) \\
\text { K } \\
(N=49) \\
\text { Grade } 1 \\
(N=40)\end{array}$ & $\begin{array}{l}\text { Longitudinal } \\
2 \text { time points } \\
\text { across } 1 \text { year }\end{array}$ & $\begin{array}{l}\text { CASL } \\
\text { Oral Language } \\
\text { Comprehension }\end{array}$ & $\begin{array}{l}\text { Range } \\
42-130 \\
M=81.97\end{array}$ & $\begin{array}{l}\text { Did not } \\
\text { Correlate } \\
\text { CASL } \\
\text { with } \\
\text { AimsWeb } \\
\text { Did not } \\
\text { report } N \\
\text { of moderate/ } \\
\text { severe } \\
\text { group }\end{array}$ \\
\hline $\begin{array}{l}\text { Mucchetti, } \\
2013\end{array}$ & $\begin{array}{l}\text { Intervention: } \\
\text { Shared Reading } \\
\text { Adaptation } \\
\text { Severe } \\
\text { ASD }\end{array}$ & $\begin{array}{l}\text { ASD } \\
(N=4) \\
\text { Ages 6-8 }\end{array}$ & $\begin{array}{l}\text { Single Subject } \\
\text { Multiple } \\
\text { Baseline Across } \\
\text { Participants } \\
\text { IV: } \\
\text { Shared Reading } \\
\text { DV: } \\
\text { Story } \\
\text { Comprehension } \\
\text { Activity } \\
\text { Engagement }\end{array}$ & $\begin{array}{l}\text { Text } \\
\text { Comprehension }\end{array}$ & $\begin{array}{l}\text { Baseline } \\
1.5 \text { Correct } \\
\text { Intervention } \\
4.5 \text { Correct } \\
\text { PND } 100 \%\end{array}$ & $\begin{array}{l}\text { Small sample } \\
\text { Size } \\
\text { No effect } \\
\text { Size } \\
\text { No Social } \\
\text { Validity } \\
\text { No } \\
\text { standardized } \\
\text { pretest/ } \\
\text { posttest }\end{array}$ \\
\hline $\begin{array}{l}\text { Westerveld, } \\
\text { Paynter, } \\
\text { Trembath, } \\
\text { Webster, } \\
\text { Hodge, \& } \\
\text { Roberts, } \\
2017\end{array}$ & $\begin{array}{l}\text { Heterogeneity: } \\
\text { Nonverbal } \\
\text { cognition } \\
\text { (NVC) in } \\
\text { ASD }\end{array}$ & $\begin{array}{l}\text { ASD } \\
(N=57) \\
\text { NVC }<70 \\
(N=36) \\
\text { NVC } \geq 70 \\
(N=21) \\
\text { Age } 4 \\
\text { Clinical } \\
\text { Educational } \\
\text { Home }\end{array}$ & $\begin{array}{l}\text { Experimental } \\
\text { group design }\end{array}$ & $\begin{array}{l}\text { Profile of Oral } \\
\text { Narrative } \\
\text { Ability }\end{array}$ & $\begin{array}{l}\text { Oral narrative } \\
\text { comprehension } \\
p<.001 \\
\eta^{2}=.239 \\
\text { Oral narrative } \\
\text { quality } \\
p<.001 \\
\eta^{2}=.084\end{array}$ & $\begin{array}{l}\text { Only verbal } \\
\text { children were } \\
\text { eligible for } \\
\text { study }\end{array}$ \\
\hline $\begin{array}{l}\text { Westerveld, } \\
\text { \& Roberts, } \\
2017\end{array}$ & $\begin{array}{l}\text { Heterogeneity: } \\
\text { In ASD and } \\
\text { language test } \\
\text { performance in } \\
\text { ASD }\end{array}$ & $\begin{array}{l}\text { ASD } \\
(N=29) \\
\text { Ages 4-5 } \\
\text { Clinical }\end{array}$ & $\begin{array}{l}\text { Experimental } \\
\text { Correlational }\end{array}$ & $\begin{array}{l}\text { Profile of Oral } \\
\text { Narrative } \\
\text { Ability }\end{array}$ & $\begin{array}{l}\text { PPVT-IV } \\
\text { Oral narrative } \\
\text { comprehension } \\
p<.001 \\
\text { VABS-II } \\
\text { Oral narrative } \\
\text { comprehension }\end{array}$ & $\begin{array}{l}\text { Small sample } \\
\text { size } \\
\text { Used only one } \\
\text { subscale } \\
\text { of oral } \\
\text { language } \\
\text { comprehension }\end{array}$ \\
\hline
\end{tabular}


$p<.05$

\begin{tabular}{lllll|ll}
\hline Study & Purpose & Participants/ & Design & \multicolumn{2}{l}{ Oral Language Comprehension } & Limitations \\
\cline { 5 - 6 } & & Setting & & Measure & Outcome & \\
\hline Whalon, & Intervention: & ASD & Single Subject & RECALL & Tau-U Effect & Small Sample \\
Martinez, & RECALL & $(N=4)$ & Multiple & IV: RECALL & Sizes: & size \\
Shannon, & With Dialogic & Ages 4-5 & Baseline Across & DV: & 1) $T=.40$ & \\
Butcher, \& & Reading & special & Participants & Unprompted & 2) $T=.77$ & No \\
Hanline, & & education & & Correct & 3) $T=.71$ & standardized \\
2015 & preschool & & Responses & 4) $T=.71$ & pretest/ \\
& & & & & posttest \\
& & classrooms & & & \\
& Dyad (ASD & & & &
\end{tabular}

ADOS= Autism Diagnostic Observation Schedule; ASD=Autism Spectrum Disorder; BDI-II -Battelle Developmental Inventory, second edition; $\mathrm{CASL}=$ Comprehensive Assessment of Spoken Language; ELP =Emergent Literacy Profile; KHLA-=The Narration of Picture Series Scale of the Katzenberger Hebrew Language assessment; MSEL= Mullen Scales of Early Learning; PALS= Phonological Awareness Literacy Screening; PONA=Profile of Oral Narrative Ability; PPVT-4=Peabody Picture Vocabulary Test-IV; PLS-4 Preschool Language Scale, Fourth Edition; PWPA=Preschool Word and Print Awareness; RECALL = Reading to Engage Children with Autism with Language and Learning; TERA-3=-Test of Early Reading Ability; TOPEL=Test of Preschool Early Literacy; VABS-II =Vineland Adaptive Behavior Scales-Second Edition 
Table 2. QAR Reading Comprehension Studies

\begin{tabular}{|c|c|c|c|c|c|c|}
\hline Study & Purpose & $\begin{array}{l}\text { Participants/ } \\
\text { Setting }\end{array}$ & Measures & Design & Outcome & Limitations \\
\hline $\begin{array}{l}\text { Asberg \& } \\
\text { Dahlgren- } \\
\text { Sandberg, } \\
2010\end{array}$ & $\begin{array}{l}\text { Test effectiveness } \\
\text { of discourse } \\
\text { comprehension } \\
\text { (QAR translated } \\
\text { into Swedish) }\end{array}$ & $\begin{array}{l}N=11 \text { ASD } \\
\text { Ages } 10-15 \\
\text { ASD School }\end{array}$ & $\begin{array}{l}\text { Pretest } \\
\text { WASI } \\
\text { PPVT } \\
\text { DCT }\end{array}$ & $\begin{array}{l}\text { Pretest } \\
\text { Post test } \\
\text { Experimental } \\
\text { Design }\end{array}$ & $\begin{array}{l}p<.05 \\
\text { Small effect size } \\
p=.02 \\
\text { Comprehension } \\
\text { No significance } \\
\text { Decoding }\end{array}$ & $\begin{array}{l}\text { No Control } \\
\text { group }\end{array}$ \\
\hline $\begin{array}{l}\text { Cortese, } \\
2004\end{array}$ & $\begin{array}{l}\text { Adapting QAR to } \\
\text { pictures (p-QAR) } \\
\text { 1. practice task } \\
\text { demands } \\
\text { 2. Facilitate } \\
\text { metacognitive } \\
\text { awareness }\end{array}$ & $\begin{array}{l}N=1 \mathrm{LD} \\
\text { Age } 8 \\
\text { Elementary } \\
\text { Classroom }\end{array}$ & $\begin{array}{l}\text { Responses to P- } \\
\text { QAR questions }\end{array}$ & $\begin{array}{l}\text { Intervention } \\
\text { Protocol }\end{array}$ & $\begin{array}{l}\text { P-QAR 1: 4/4 } \\
\text { P-QAR:2 } 2 / 2 \\
\text { P-QAR 3: 2/2 } \\
\text { P-QAR 4: 1/1 } \\
\text { (\# of } \\
\text { Questions/Correct } \\
\text { Responses) }\end{array}$ & $\begin{array}{l}\text { Imprecise } \\
\text { taxonomic } \\
\text { definitions, } \\
\text { potential } \\
\text { overlap of } \\
\text { categories, } \\
\text { ambiguity of } \\
\text { prior } \\
\text { knowledge }\end{array}$ \\
\hline $\begin{array}{l}\text { McIntyre et } \\
\text { al., } 2017\end{array}$ & $\begin{array}{l}\text { Test the } \\
\text { hypothesis that } \\
\text { reading } \\
\text { comprehension } \\
\text { impairments in } \\
\text { ASD w/o ID are } \\
\text { social } \\
\text { communication } \\
\text { phenotype }\end{array}$ & $\begin{array}{l}N=81 \\
\text { ASD } \\
N=39 \\
\text { ADHD } \\
N=\text { TD } 44 \\
\text { Ages 8-16 } \\
\text { University } \\
\text { Child } \\
\text { Assessment } \\
\text { Center }\end{array}$ & $\begin{array}{l}\text { WASI-2 } \\
\text { QRI-5 } \\
\text { GORT-5 } \\
\text { TOWRE } \\
\text { CTOPP } \\
\text { ADOS } \\
\text { Oral Language } \\
\text { Subtests }\end{array}$ & Longitudinal & $\begin{array}{l}\text { Reading } \\
\text { comprehension } \\
\text { Problems specific } \\
\text { to ASD. } \\
\text { Language problems } \\
\text { predict } \\
\text { reading } \\
\text { comprehension } \\
\text { difficulty (ASD) } \\
p<.01 \\
p<.001\end{array}$ & $\begin{array}{l}\text { Heterogeneity } \\
\text { in ASD require } \\
\text { larger sample } \\
\text { size } \\
\text { Only } \\
\text { concurrent data } \\
\text { reported }\end{array}$ \\
\hline $\begin{array}{l}\text { McIntyre et } \\
\text { al., } 2017\end{array}$ & $\begin{array}{l}\text { Identify reading } \\
\text { profiles in ASD }\end{array}$ & $\begin{array}{l}N=81 \\
\text { ASD }\end{array}$ & $\begin{array}{l}\text { WASI-2 } \\
\text { QRI-5 } \\
\text { GORT-5 } \\
\text { TOWRE } \\
\text { CTOPP } \\
\text { ADOS } \\
\text { Oral Language } \\
\text { Subtests }\end{array}$ & Not Reported & $\begin{array}{l}\text { 4 Profiles: Readers } \\
\text { with Severe Global } \\
\text { Disturbance } \\
(M=14.38) \text { had } \\
\text { the highest level of } \\
\text { ASD } \\
\text { symptomatology } \\
\text { Comprehension } \\
\text { Disturbance } \\
(M=11.31), \\
\text { Global Disturbance } \\
(M=10.15), \\
\text { Average Readers, } \\
(M=9.98)\end{array}$ & $\begin{array}{l}\text { Extensive } \\
\text { developmental } \\
\text { span between } \\
\text { elementary and } \\
\text { secondary } \\
\text { students }\end{array}$ \\
\hline
\end{tabular}




\begin{tabular}{|c|c|c|c|c|c|c|}
\hline Study & Purpose & $\begin{array}{l}\text { Participants/ } \\
\text { Setting }\end{array}$ & Measures & Design & Outcome & Limitations \\
\hline $\begin{array}{l}\text { Nation et } \\
\text { al., } 2006\end{array}$ & $\begin{array}{l}\text { Examine } \\
\text { heterogeneous } \\
\text { reading skills in } \\
\text { ASD }\end{array}$ & $\begin{array}{l}N=41 \text { ASD } \\
\text { Home and } \\
\text { School } \\
\text { Ages 6-15 }\end{array}$ & $\begin{array}{l}\text { The Graded } \\
\text { Nonword } \\
\text { Reading Test } \\
\text { BAS-II } \\
\text { NARA-II } \\
\text { BPVS-II } \\
\text { WISC-III }\end{array}$ & Not Reported & $\begin{array}{l}65 \% \text { of sample } \\
1 \text { SD below norms } \\
\text { reading } \\
\text { comprehension } \\
32 / 41 \text { of sample } \\
\text { had measurable } \\
\text { word } \\
\text { reading skills, } \\
\text { showed average- } \\
\text { for-age word } \\
\text { reading ability }\end{array}$ & $\begin{array}{l}\text { Did not } \\
\text { measure } \\
\text { phonological } \\
\text { processing }\end{array}$ \\
\hline $\begin{array}{l}\text { Nguyen et } \\
\text { al., } 2015\end{array}$ & $\begin{array}{l}\text { Strategies to } \\
\text { increase reading } \\
\text { comprehension in } \\
\text { ASD/ primary } \\
\text { grades }\end{array}$ & N/A & N/A & N/A & $\begin{array}{l}\text { 1. Activate and } \\
\text { build prior } \\
\text { knowledge } \\
\text { 2. Provide } \\
\text { visual supports } \\
\text { 3. Make } \\
\text { Connections } \\
\text { 4. Engage in } \\
\text { consistent } \\
\text { discussions } \\
\text { 5. Search } \\
\text { understanding }\end{array}$ & N/A \\
\hline $\begin{array}{l}\text { Roycroft, } \\
2015\end{array}$ & $\begin{array}{l}\text { Examines } \\
\text { variability in } \\
\text { reading } \\
\text { comprehension } \\
\text { impairments in } \\
\text { ASD }\end{array}$ & N/A & N/A & $\begin{array}{l}\text { Literature } \\
\text { Review }\end{array}$ & $\begin{array}{l}\text { Describes reading } \\
\text { comprehension } \\
\text { theories and } \\
\text { interventions } \\
\text { including QAR }\end{array}$ & N/A \\
\hline $\begin{array}{l}\text { Wahlberg } \\
\& \\
\text { Magliano, } \\
2004\end{array}$ & $\begin{array}{l}\text { Investigated } \\
\text { Using prior } \\
\text { knowledge to } \\
\text { answer } \\
\text { comprehension } \\
\text { questions in ASD }\end{array}$ & $\begin{array}{l}N=12 \text { ASD } \\
N=60 \\
\text { Control } \\
\text { Age } 18-27\end{array}$ & $\begin{array}{l}\text { K-BIT } \\
\text { K-TEA } \\
\text { Stanford Binet } \\
\text { Intelligence } \\
\text { Scale }\end{array}$ & $\begin{array}{l}\text { Quantitative } \\
\text { Experimental } \\
\text { Design }\end{array}$ & $\begin{array}{l}\text { No significance } \\
\text { with ASD } \\
\text { participants in } \\
\text { primer and title } \\
\text { cues } \\
p>.05 \\
\text { Control } p<.05\end{array}$ & $\begin{array}{l}\text { Results could } \\
\text { have been } \\
\text { influenced by } \\
\text { encoding, } \\
\text { retrieval } \\
\text { deficits }\end{array}$ \\
\hline
\end{tabular}




\begin{tabular}{|c|c|c|c|c|c|c|}
\hline Study & Purpose & $\begin{array}{l}\text { Participants/ } \\
\text { Setting }\end{array}$ & Measures & Design & Outcome & Limitations \\
\hline $\begin{array}{l}\text { Whalon, } \\
\text { Hanline \& } \\
\text { Woods, } \\
2007\end{array}$ & $\begin{array}{l}\text { Using visual } \\
\text { supports for story } \\
\text { elements and } \\
\text { comprehension } \\
\text { questions for } \\
\text { students with } \\
\text { ASD }\end{array}$ & $\begin{array}{l}\text { Primary } \\
\text { Grades K-3 }\end{array}$ & N/A & $\begin{array}{l}\text { Reading } \\
\text { Comprehension } \\
\text { Adaptation }\end{array}$ & $\begin{array}{l}\text { Story Cards } \\
\text { Story Map } \\
\text { Question Cards }\end{array}$ & N/A \\
\hline $\begin{array}{l}\text { Whalon \& } \\
\text { Hanline, } \\
2008\end{array}$ & $\begin{array}{l}\text { Investigate the } \\
\text { effects of } \\
\text { reciprocal } \\
\text { questioning } \\
\text { strategy }\end{array}$ & $\begin{array}{l}N=3 \text { ASD } \\
\text { Ages7-8 } \\
\text { Self-contained } \\
\text { Special } \\
\text { Education } \\
\text { Classroom }\end{array}$ & $\begin{array}{l}\text { PPVT-III } \\
\text { EOWVT } \\
\text { DIBELS } \\
\text { (ORF, RF) }\end{array}$ & $\begin{array}{l}\text { Multiple Baseline } \\
\text { Across } \\
\text { participants }\end{array}$ & $\begin{array}{l}\text { All three } \\
\text { participants } \\
\text { Increased in } \\
\text { unprompted } \\
\text { question generation } \\
\text { and responding }\end{array}$ & $\begin{array}{l}\text { Small sample } \\
\text { size } \\
\text { Lack of random } \\
\text { selection }\end{array}$ \\
\hline $\begin{array}{l}\text { Whalon \& } \\
\text { Hart, } 2011\end{array}$ & $\begin{array}{l}\text { Adapt question } \\
\text { generation } \\
\text { strategy QAR }\end{array}$ & $\begin{array}{l}\text { Primary } \\
\text { Grades } \\
\text { ASD }\end{array}$ & N/A & $\begin{array}{l}\text { Reading } \\
\text { Comprehension } \\
\text { Adaptation }\end{array}$ & Visual supports & N/A \\
\hline
\end{tabular}

ADOS=Autism Diagnostic Observation Schedule; BAS 11=-British Ability Reading Test Scales; BPVS-II=British Picture Vocabulary Scale II; CTOPP=Comprehensive Test of Phonological Processing; DCT=Discourse Comprehension Test; DIBELSDynamic Indicators of Basic Early Literacy; EOWVT=Expressive One Word Vocabulary Test; GORT=Gray's Oral Reading Tests; K-BIT=Kaufman Brief Intelligence test; K-TEA=Kaufman Test of Educational Achievement; NARA-II=Neale Analysis of Reading Ability-II; PPVT-Peabody Picture Vocabulary Test; PPVT-Peabody Picture Vocabulary Test; QRI=5-Qualiative Reading Inventory; TOWRE=Test of Word Reading Efficiency; WASI=Wechsler Abbreviated Scales of Intelligence Scale; 
Appendix A QAR Cards

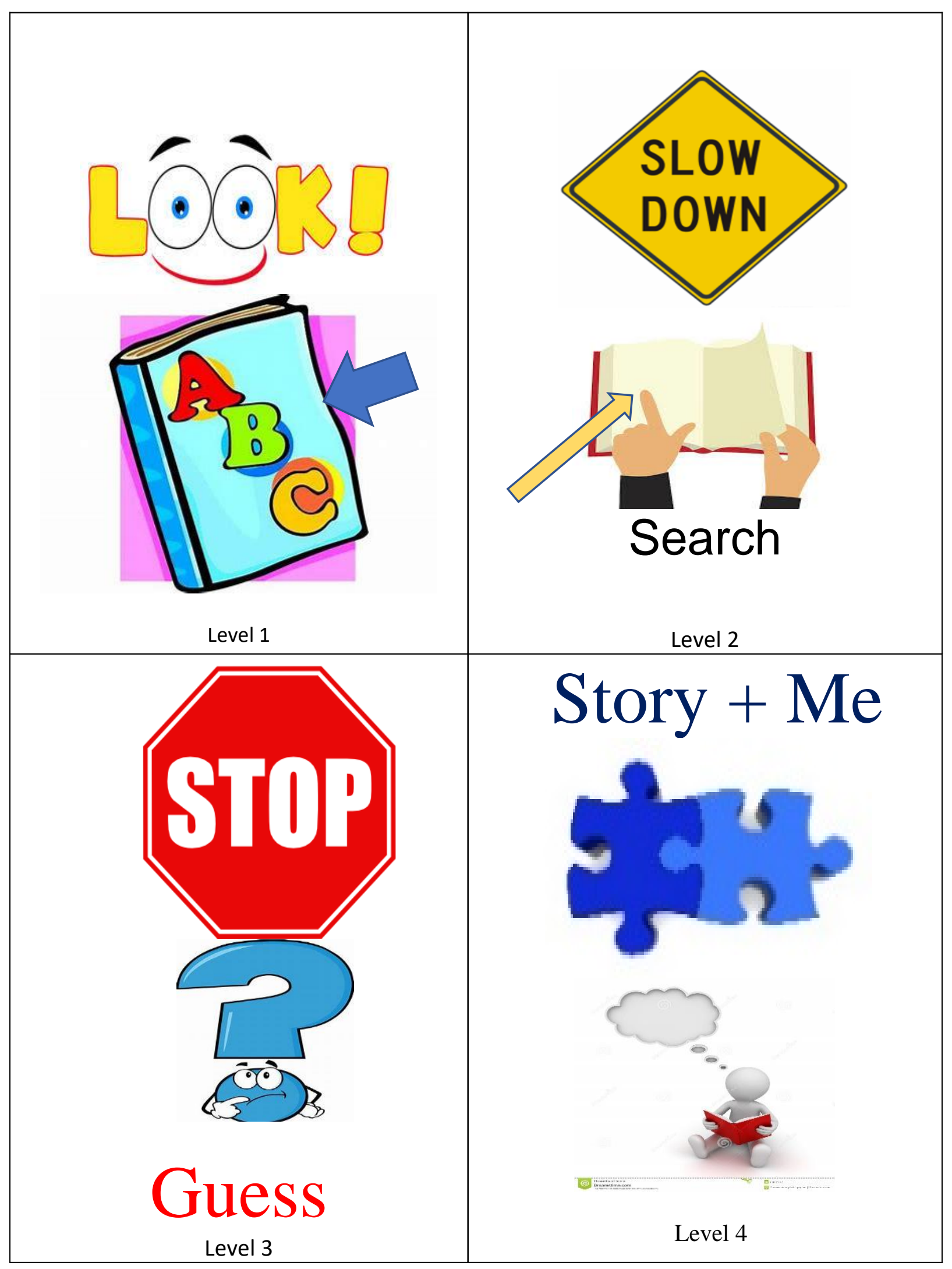


Appendix B

QAR Level Scripts

\section{Level 1}

The card says "Look" because we will look right at the cover and the pictures in the book for the answer. We can look at the cover and the pictures in the book to find out what the story is about.

I'm going to show you how to do it.

Watch me answer a question.

(Refer to Level 1 question)

The question is: (recite question)

I can look right here and get the answer

(Point to answer and recite answer)

\section{Level 2}

The card says "Slow Down" because we will slow down and search in our book for the answer. I'm going to show you how to do it.

Watch me answer a question.

(Refer to Level 2 question)

The question is: (recite question)

I'm going to slow down and turn pages one at a time to find the answer.

Say "I found the answer"

(Point to answer and recite answer)

\section{Level 3}

The card says "Stop" because we will stop, think, and make a guess. Sometimes the answer to a question is not in the book. Instead we have to stop and think about things that happen in the story and guess the answer.

I'm going to show you how to it.

Watch me answer a question.

(Refer to Level 3 question)

The question is: (recite question)

I'm going to stop and think about what happened in the story.

Say "I think the answer is (recite answer)"

\section{Level 4}

The card says "Story \& Me" because we will think about something that is the same or different about you and the story for the answer. We are going to think about the story and me. I'm going to show you how to do it.

Watch me answer a question.

(Refer to Level 4 question)

The question is: (recite question)

I'm going to think about the story and me.

Say "I think the answer is (recite answer)" 
Appendix C

Dear Parents,

I am a doctoral student at Old Dominion University conducting a study to help increase listening comprehension skills in children with Autism Spectrum Disorder (ASD). I am a special education teacher with a specialization in autism. I also taught at Autism Consulting and Therapy (ACT) before seeking higher education.

The intervention is called the Question and Answer Relationship strategy (QAR) which an evidence-based practice endorsed by the National Reading Panel. QAR helps students to answer comprehension questions by learning how to classify different types of questions and methods for finding answers. This study utilizes QAR cards as visual supports to cue students in identifying the four types of comprehension questions which are: 1. Facts 2. Summarize 3. Inference 4. Connections. Please see the attached example of the QAR cards.

To conduct this study, I am looking for participants diagnosed with ASD without intellectual disabilities, ages 4-6 in pre-k/kindergarten, with expressive skills of at least 3 -word phrases and who receive services at ACT. The attached "Informed Consent Document" form describes the study and asks your permission for your child to participate. Please carefully read this form. It provides important information for you and your child. If you have any questions pertaining to the attached form or research study, please feel free to contact Lisa Phalen at the number below or my advisor Dr. Peggy Hester at (757) 683-3226.

After reviewing the attached information, please return a signed copy of the "Informed Consent Document" to Autism Consulting and Therapy if you are willing to allow your child to participate in the study. Also, I would like to meet with you to further explain the study and answer any questions that you may have. Keep the additional copy of the form for your records.

Even when you give consent, your child will be able to participate only if he/she is willing to do so. Thank you in advance for taking the time to consider your child's participation in this study.

Sincerely,

Lisa Phalen

Doctoral Student

Lpha1001@odu.edu

(757) 376-0826 


\title{
Appendix D \\ INFORMED CONSENT DOCUMENT OLD DOMINION UNIVERSITY
}

\begin{abstract}
PROJECT TITLE Early Education QAR Strategy for Children with Autism Spectrum Disorder INTRODUCTION

The purposes of this form are to give you information that may affect your decision whether to say YES or NO to participation in this research, and to record the consent of those who say YES. The research study will be on the effect of the Question and Answer Relationship Strategy (QAR) on the oral language comprehension of students with autism spectrum disorder. The study will be conducted in a therapy room at Autism Consulting and Therapy (ACT) beginning in the summer semester, 2019.
\end{abstract}

\author{
RESEARCHERS \\ Responsible Project Investigator: \\ Dr. Peggy Hester \\ Darden College of Education \\ Department of Communication Disorders \& Special Education \\ Old Dominion University \\ Investigator: \\ Lisa Phalen, Doctoral Student \\ Darden College of Education \\ Department of Communication Disorders \& Special Education \\ Old Dominion University \\ Graduate Assistant: \\ Jennifer Wolff, Graduate Student \\ Darden College of Education \\ Department of Communication Disorders \& Special Education \\ Old Dominion University
}

\section{DESCRIPTION OF RESEARCH STUDY}

This study will teach an intervention called the Question and Answer Relationship Strategy (QAR) to help students with autism spectrum disorder answer oral comprehension questions. If you decide to permit your child to participate in this study, he/she will be asked to answer comprehension questions in an age appropriate leveled reading series. This study will take 12 weeks in duration, 20 minutes $3 x$ per week with one 20-minute maintenance session two weeks following the intervention for a total of 740 minutes. The intervention will take place in a therapy room at Autism Consulting \& Therapy (ACT). There will be up to10 children participating in the study. The sessions will be video recorded for research purposes only.

\section{INCLUSIONARY CRITERIA}

Your child is diagnosed with ASD without intellectual disabilities; is between the ages 4-6 in Pre-KKindergarten; receive services at Autism Consulting and Therapy (ACT); and has expressive verbal skills of at least 3-word phrases.

\section{RISKS AND BENEFITS}

RISKS: Risks to your child will be minimized by implementing a strategy that is evidence-based. The project investigator will monitor the intervention implementation and fidelity to reduce any potential risks to participants. Your child may face a minimal risk of becoming bored or frustrated. The child's therapist will be present to assess boredom, frustration or any form of distress. The investigator will use the therapist's assessment to help determine if a subject should be withdrawn from the study due to distress. Project investigators will continue to monitor your child for adverse effects to reduce potential risk to your child's boredom, or frustration. Ongoing formative observational data will provide another means of ascertaining any adverse effects of research activities. 
BENEFITS: While we acknowledge that there might be no direct benefits, we anticipate because of the intervention your child may learn a strategy for answering reading comprehension questions. A

summary of your child's participation and overall study results will be made available to parents and to ACT clinical director. Upon your consent, you will receive a brief description of study procedures.

\section{COSTS AND PAYMENTS}

The researchers want your decision about participating in this study to be absolutely voluntary. Yet they recognize that your participation may pose some inconvenience.

\section{NEW INFORMATION}

If the researchers find new information during this study that would reasonably change your decision about participating, then they will give it to you.

\section{CONFIDENTIALITY}

This study is confidential. The records of this study will be kept strictly confidential. Research records will be kept in a locked file, and all electronic information will be coded and secured using a password protected file including video recordings. Participants will be assigned a code number and only researchers in involved in the study will have access to data sheets. A form will be included which links the child's name with their assigned code number. All data and participation information will be kept in a locked and secure location. We will not include any information in any report we may publish that would make it possible to identify your child. The videotapes and copies of raw data will be stored in a secure server and will be destroyed one year after all data have been coded, analyzed, and/or the results have been published in professional publications.

\section{WITHDRAWAL PRIVILEGE}

Your child's participation in this study is voluntary. Your child may decline to participate or to withdraw from participation at any time. Withdrawal or refusing to participate will not affect their relationship with Autism Consulting and Therapy in any way. You can agree to allow your child to be in the study now and change your mind later without any penalty.

\section{COMPENSATION FOR ILLNESS AND INJURY}

If you say YES, then your consent in this document does not waive any of your legal rights. However, in the event of harm arising from this study, neither Old Dominion University nor the researchers are able to give you any money, insurance coverage, free medical care, or any other compensation for such injury. In the event that you suffer injury as a result of participation in any research project, you may contact Dr. Peggy Hester at 757-683-3226, Lisa Phalen at 757-376-0826, or Dr. Tancy Vandecar-Burdin at, 6833802 at Old Dominion University, or the Old Dominion University Office of Research at 757-683-3460 who will be glad to review the matter with you.

\section{VOLUNTARY CONSENT}

By signing this form, you are saying several things. You are saying that you have read this form or have had it read to you, that you are satisfied that you understand this form, the research study, and its risks and benefits. The researchers should have answered any questions you may have had about the research. If you have any questions later on, then the researchers should be able to answer them:

Lisa Phalen

(757) 376-0826

Email: Lphal001@odu.edu

If at any time you feel pressured to participate, or if you have any questions about your rights or this form, then you should call Dr. Tancy Vandecar-Burdin, the current IRB chair, at 757-683-3802 or the Old Dominion University Office of Research, at 757-683-3460. 
And importantly, by signing below, you are telling the researcher YES, that you agree to participate in this study. The researcher should give you a copy of this form for your records.

\begin{tabular}{|l|l|}
\hline & \\
Child's Printed Name & Date \\
\hline & \\
\hline Parent / Legally Authorized Representative's Printed Name \& Signature & Date \\
\hline
\end{tabular}

\section{INVESTIGATOR'S STATEMENT}

I certify that I have explained to this subject the nature and purpose of this research, including benefits, risks, costs, and any experimental procedures. I have described the rights and protections afforded to human subjects and have done nothing to pressure, coerce, or falsely entice this subject into participating. I am aware of my obligations under state and federal laws and promise compliance. I have answered the subject's questions and have encouraged him/her to ask additional questions at any time during the course of this study. I have witnessed the above signature(s) on this consent form. 


\section{Appendix E \\ INFORMED CONSENT \\ PHOTO/VIDEO MATERIALS}

STUDY TITLE: Early Education QAR Strategy for Children with Autism Spectrum Disorder

\section{DESCRIPTION}

The researchers would like to take photographs or videotapes of your child participating in the intervention in order to illustrate the research in teaching, presentations, and/or or publications.

\section{CONFIDENTIALITY}

Your child would not be identified by name in any use of the photographs or videotapes. Even if you agree to be in the study, no photographs or videotapes will be taken of you unless you specifically agree to this consent. All photographs or videotapes will be destroyed within one-year after the study analysis ends.

\section{VOLUNTARY CONSENT}

By signing below you are granting to the researchers the right to use your child's likeness, image, appearance and performance - whether recorded on or transferred to videotape, film, slides, photographs for presenting, training purposes or publishing this research. No use of photos or video images will be made other than for professional presentations, training, or publications. The researchers are unable to provide any monetary compensation for use of these materials. You can withdraw your voluntary consent at any time.

If you have any questions please call Lisa Phalen at 757-376-0826 or Dr. Peggy Hester at 757--683-3226. If at any time you feel pressured to participate, or if you have any question about your rights or this form, then you should call Dr. Tancy Vandecar-Burdin, the current IRB chair, at 757-683-3802.

Printed Name of Child

$\overline{\text { Printed Name of Parent(s) or Legal Guardian }}$

Signature of Parent(s) or Legal Guardian

Date 
Appendix F

Name

Child Assent Procedure

The researcher reads aloud:

My name is Lisa Phalen. I am a student at Old Dominion University.

I am asking if you would like to help me to learn how to teach children to answer questions about stories you read in school. It is called a study.

If you agree, you will be asked to work with me at ACT where we will read stories and answer questions about the story. I will show you question and answer cards to learn about different kinds of questions and how to answer them. Each session will last about 20 minutes and will be videotaped. You will be asked to take some tests, so that I know if the question and answer strategy helps you learn. When I write about the work we do, I will not use your real name.

You do not have to be in this study. No one will be mad at you if you decide not to do this study. If you agree to be in the study, you may stop being in the study at any time.

You can:

Say "yes: or "no"

Nod your head yes or no

or point to the Yes (smiley face) or No (sad face)

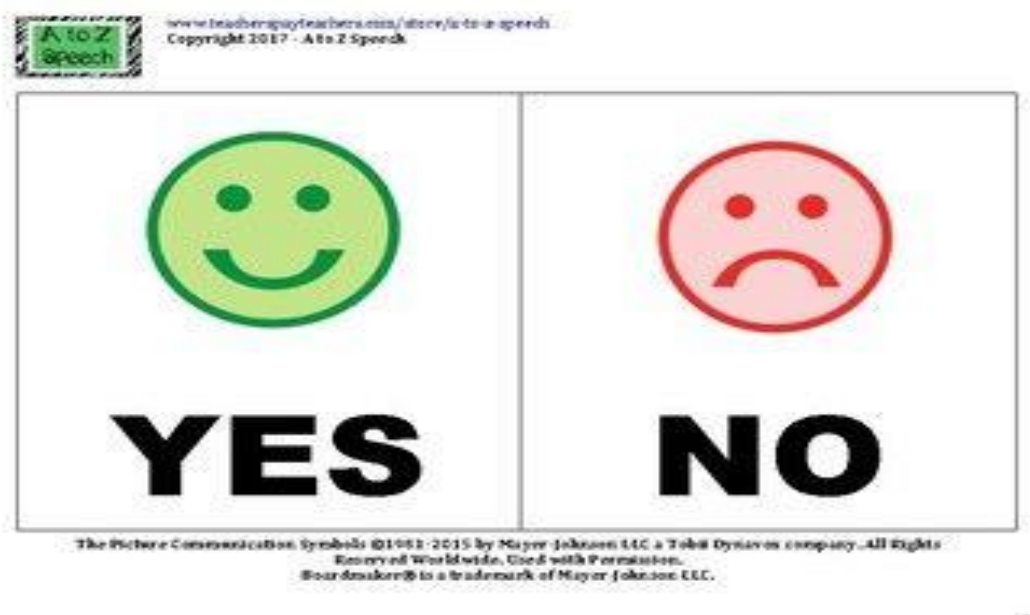


Appendix G

\section{Book List: QAR Study}

\section{Baseline Phase:}

1. The Snowy Day by Ezra Jack Keats

2. Harry the Dirty Dog by Gene Zion

3. Corduroy by Don Freeman

4. Bunny Cakes by Rosemary Wells

5. I Took My Frog to the Library by Eric A. Kimmel

\section{Intervention Phase:}

6. Whistle for Willie by Ezra Jack Keats

7. Alexander and The Wind-Up Mouse by Leo Lionni

8. Duck on a Bike by David Shannon

Maintenance Phase:

9. The Wolf's Chicken Stew by Keiko Kasza

10. The Adventures of Taxi Dog by Debra and Sal Barracca 


\section{Appendix $\mathrm{H}$ \\ The Snowy Day \\ by Ezra Jack Keats}

\section{Level 1-Fact:}

1.. What is the boy walking in?

2. What color is his coat?

3. What color are the letters?

4. Does the story take place in the day or night?

5. What is the boy looking at?

\section{Level 2-Search:}

6. Can you find in the story where Peter drags his feet slowly?

7. Can you find in the story where Peter finds something sticking out of the snow?

8. Can you find in the story where snow falls on top of Peter's head?

9. Can you find in the story where Peter makes an angel?

10. Can you find in the story where Peter looks for his snowball?

\section{Level 3-Inference:}

11. What covered everything as far as Peter's eye could see?

12. Who is throwing snowballs?

13. What is Peter thinking about?

14. What happened to Peter's snowball?

15. Why is Peter smiling?

\section{Level 4-Connection:}

16. How are you the same as Peter?

17. How are you different than Peter?

18. Peter likes to play in the snow. What is something you like to play?

19. Peter was sad his snowball melted. What is something that makes you sad?

20. Peter is happy to see new snow. What is something that makes you happy? 


\section{The Snowy Day}

\section{Answer Key}

\section{Level 1: Fact}

1. Snow

2. Red

3. White

4. Day

5. Footprints

\section{Level 2: Search}

6. Page where peter makes tracks.

7. Page with a stick stuck in the snow.

8. Page where snow is on top of Peter's head.

9. Page where Peter is laying on the ground.

10. Page where Peter looks in his pocket.

\section{Level 3: Inference}

11. Snow.

12. Big boys.

13. His adventures. Also, acceptable reference to playing in the snow.

14. It melted or any reference to melting.

15. New snow is falling or any reference to snow.

\section{Level 4: Connection}

16. Answers will vary: Answer must involve similar attribute(s) to Peter.

17. Answers will vary: Answer must involve contrasting attribute(s) to Peter.

18. Answers will vary: Answer must involve a game, toy, or recreational activity.

19. Answers will vary: Answer must involve a person event, or item.

20. Answers will vary: Answer must involve a person, event, or item. 


\section{Appendix I \\ Harry the Dirty Dog \\ by Gene Zion}

\section{Level 1-Fact:}

1.. Who is the story about?

2. What kind of animal is Harry?

3. What color are the spots on the first dog?

4. What color are the spots on the second dog?

5. What are the dogs looking at?

\section{Level 2-Search:}

6. Can you find in the story where Harry buries the scrub brush?

7. Can you find in the story where Harry plays with other dogs?

8. Can you find in the story where Harry is the dirtiest of all?

9. Can you find in the story when Harry finds the scrub brush?

10. Can you find in the story when the family knows it is Harry?

\section{Level 3-Inference:}

11. What is Harry scared of?

12. Where is Harry going?

13. What is making Harry dirty?

14. What is Harry looking for?

15. How does the family know it is Harry?

\section{Level 4-Connection:}

16. How are you different from Harry?

17. What is the name of a dog that you know?

18. Harry likes to play tag and run. What do you like to play?

19. Harry doesn't like taking baths. What is something you don't like?

20. The family is happy to see Harry. What is something that makes you happy? 


\section{Harry the Dirty Dog}

\section{Answer Key}

\section{Level 1: Fact}
1. Harry
2. Dog
3. Black
4. White
5. Each other. Also, acceptable reference to a dog.

\section{Level 2: Search}
6. Page where Harry is in the backyard.
7. Page where harry is running around with dogs.
8. Page where harry goes down the coal chute.
9. Page where Harry runs in house with the scrub brush.
10. Page where the family hugs Harry.

\section{Level 3: Inference}

11. Taking a bath.

12. Answer must reference Harry leaving home.

13. Answer must reference playing in the street, hole, or puddle.

14. The scrub brush.

15. Answer must reference after a bath or getting cleaned up.

\section{Level 4: Connection}

16. Answer will vary: Answer must involve contrasting attribute(s) to Harry.

17. Answers will vary: Answer must involve a name.

18. Answers will vary: Answer must involve a game, toy, or recreational activity.

19. Answers will vary: Answer must involve a person event, or item.

20. Answers will vary: Answer must involve a person, event, or item. 
Level 1-Fact:

\section{Appendix $\mathbf{J}$ \\ Corduroy \\ by Don Freeman}

1.. Who is the story about?

2. What kind of animal is Corduroy?

3. What color is his fur?

4. What color are his clothes?

5. What is he picking up?

\section{Level 2-Search:}

6. Can you find in the story where Corduroy goes to look for his button?

7. Can you find in the story where Corduroy falls?

8. Can you find in the story where Corduroy hides?

9. Can you find in the story where Lisa buys Corduroy?

10. Can you find in the story where Corduroy goes home with Lisa?

\section{Level 3-Inference:}

11. Who is a small bear in green overalls?

12. Where are Lisa and her mom going?

13. What does Corduroy think is a mountain?

14. Why is Corduroy covering his ears?

15. What are Corduroy and the other toys doing?

\section{Level 4-Connection:}

16. How are you the same as Lisa?

17. How are you different from Lisa?

18. How are you different from Corduroy?

19. What is the name of a stuffed animal you know?

20. Corduroy makes Lisa happy. What makes is something that makes you happy? 


\section{Corduroy}

\section{Answer Key}

\section{Level 1: Fact}

1. Corduroy

2. Bear

3. Brown

4. Green

5. A button

\section{Level 2: Search}

6. Page where Corduroy gets down from shelf.

7. Page where Corduroy falls trying to pick up a button.

8. Page where Corduroy is under the covers in bed.

9. Page where Lisa is at store counter.

10. Page where Lisa is running up the stairs with Corduroy.

\section{Level 3: Inference}

11. Corduroy

12. Home or any reference to leaving store.

13. Escalator: also, acceptable stairs.

14. Answer must reference a noise or crash.

15. Answer must reference sleeping.

\section{Level 4: Connection}

16. Answer will vary: Answer must include similar attribute(s) to Lisa.

17. Answers will vary: Answer must include contrasting attribute(s) to Lisa.

18. Answer must include contrasting attribute(s) to Corduroy.

19. Answers will vary: Answer must involve a name.

20. Answers will vary: Answer must involve a person, event, or item. 


\section{Level 1-Fact:}

\section{Appendix K \\ Bunny Cakes \\ by Rosemary Wells}

1.. What kind of animal is on the cover?

2. What color are the letters?

3. What is the bunny sitting in?

4. What color is the bowl?

5. What is next to the bowl?

\section{Level 2-Search:}

6. Can you find in the story where Max making a cake?

7. Can you find in the story where are eggs on the list?

8. Can you find in the story where there is a line Max can't step over?

9. Can you find in the story where Ruby makes a cake?

10. Can you find in the story where Ruby decorates a cake?

\section{Level 3-Inference:}

11. What did Max do?

12. What did Max spill?

13. Why didn't the grocer give Max squirters?

14. Why can't Max go in the kitchen?

15. What is the grocer giving Max?

\section{Level 4-Connection:}

16. How are you different than Max?

17. Max likes to eat red-hot marshmallow squirters. What do you like to eat?

18. Max likes to play in the dirt. What do you like to play?

19. Max made a mess in the kitchen. What is something messy you do?

20. Max made his Grandma happy. What makes you happy? 


\section{Bunny Cakes}

\section{Answer Key}

\section{Level 1: Fact}

1. A bunny or rabbit.

2. Black

3. A bowl.

4. Orange.

5. Acceptable answers: Eggs, milk, measuring cup.

\section{Level 2: Search}

6. Page where Max makes an earthworm cake.

7. Page with broken eggs.

8. Page with a yellow line.

9. Page where Ruby is in the kitchen with a cake.

10. Page with candles, stars, and hearts on cake.

\section{Level 3: Inference}

11. Any reference to dropping eggs.

12. Milk.

13. He couldn't read what Max wrote.

14. Any reference to Max making a mess.

15. Any reference to red-hot marshmallow squirters.

\section{Level 4: Connection}

16. Answer will vary: Answer must involve contrasting attribute(s) to Max.

17. Answer will vary: Answer must involve a food other than red-hot marshmallow squirters.

18. Answers will vary: Answer must involve a game, event, or item other than dirt.

19. Answers will vary: Answer must involve an event, or item other than a mess in the kitchen.

20. Answers will vary: Answer must involve a person, event, or item other than grandma. 


\section{Appendix L \\ I Took My Frog to the Library \\ by Eric A. Kimmel}

\section{Level 1-Fact:}

1.. Who is sitting on a book?

2. Who is holding a book?

3. Where does the story take place?

4. What color is the girl's shirt?

5. What color is the frog?

\section{Level 2-Search:}

6. Can you find in the story where the hen laid eggs?

7. Can you find in the story where the python sheds skin?

8. Can you find in the story where the hyena laughed?

9. Can you find in the story where the elephant wrecked the library?

10. Can you find in the story where a pelican takes a bath?

\section{Level 3-Inference:}

11. What is the librarian afraid of?

12. What are the kids looking for?

13. What is so big?

14. Where is the girl going?

15. Why are the animals happy?

\section{Level 4-Connection:}

16. How are you different from Bridgett?

17. How are you the same as Bridgett?

18. Bridgett has lots of animals What is your favorite animal?

19. Bridgett likes to go to the library. Where do you like to go?

20. The animals like stories. What is your favorite story? 


\section{Took My Frog to the Library \\ Answer Key}

\section{Level 1: Fact}

1. Frog

2. Girl

3. Library

4. Red

5. Green

\section{Level 2: Search}

6. Page where the hen lays eggs in filing cabinet.

7. Page where the python is in the library.

8. Page where the hyena is in story circle.

9. Page where the elephant looks in window.

10. Page with all the animals in the house.

\section{Level 3: Inference}

11. Any reference to the frog.

12. The dictionary, Also acceptable: book.

13. The elephant.

14. To the library.

15. Any reference to being read a story.

\section{Level 4: Connection}

16. Answer will vary: Answer must involve contrasting attribute(s) to Bridgett.

17. Answer will vary: Answer must involve similar attribute(s) to Bridgett.

18. Answers will vary: Answer must involve an animal.

19. Answers will vary: Answer must involve a destination.

20. Answers will vary: Answer must involve the name of a book or story. 


\section{Appendix M \\ Whistle for Willie \\ by Ezra jack Keats}

\section{Fact}

1. What is the boy doing?

2. What color are the letters?

3. Who is on the cover?

4. What is Peter leaning on?

5. What is Peter doing?

6. Who is Peter hiding from?

7. What does Peter draw?

8. What does Peter put on his head?

9. Who is hiding in the carton?

10. What is Peter doing?

\section{Search}

11. Can you find in the story where a boy plays with his dog?

12. Can you find in the story where Peter whirls around?

13. Can you find in the story where Peter hides?

14. Can you find in the story where girls are jumping rope?

15. Can you find in the story where Peter practices whistling?

16. Can you find in the story where Peter runs away from his shadow?

17. Can you find in the story where Peter sees Willie?

18. Can you find in the story where Willie races up to Peter?

19. Can you find in the story where Peter show his parents he can whistle?

20. Can you find in the story where Peter and Willie go to the store?

\section{Inference}

21. Who is Willie?

22. Who is Peter?

23. Why does the dog run to the boy?

24. Why does everything turn down, up and around?

25. Why doesn't Willie see Peter?

26. Who put on a hat to feel more grown up?

27. Who is pretending to be his father?

28. What does Willie hear?

29. What did Peter learn to do?

30. Where are Peter and Willie going?

\section{Connection}

31. Peter wishes he could whistle. What do you wish you could do?

32. Peter likes to spin. What do you like to do?

33. Peter is hiding from Willie. When where you hide from someone?

34. The girls are jumping rope. What is something you like to play?

35. Willie is pretending to be his dad. Who do you like to pretend to be?

36. Peter likes Willie the dog. What is an animal that you like?

37. Peter is proud he can whistle. What can you do that makes you proud?

38. Peter's parents are happy. What makes your parents happy?

39. Peter and Willie are going to the store. What store do you like to go to?

40. Peter likes to play with Willie. Who do you like to play with? 


\section{Whistle for Willie \\ Answer Key}

Fact

1. Whistling

2. White

3. Any variation of Boy, Dog, Willie

4. Streetlight or stoplight

5. Hiding

6. Willie/Dog

7. A line or circle

8. Hat

9. Peter

10. Whistling

Search

11. Page where Peter is playing.

12. Page by the streetlight.

13. Page of Peter in a carton or box.

14. Page where Peter draws a line.

15. Page where Peter looks in mirror.

16. Page where Peter is running outside.

17. Page where Peter looks around the corner.

18. Page where Peter is hiding and whistles.

19. Page where Peter is with parents.

20. Page where Peter and Willie are walking with shopping bag.

Inference

21. The dog.

22. The boy.

23. He whistled.

24. Any variation of Peter spinning.

25. He was hiding.

26. Peter.

27. Peter.

28. Peter whistling.

29. Whistle.

30. To the store.

\section{Connection}

31. Answers will vary: Reference to a skill or activity.

32. Answers will vary: Reference to an activity.

33. Answers will vary: Reference to hiding game or event.

34. Answers will vary: Reference to activity, item, or game.

35. Answers will vary: Reference to pretend play.

36. Answers will vary: Reference to animal /or animal name.

37. Answers will vary: Reference to activity or skill.

38. Answers will vary: Reference to happy event or activity regarding parents.

39. Answers will vary: Reference to a specific store or name of store.

40. Answers will vary: Reference to a name or names. 


\section{Appendix N \\ Alexander and the Wind-Up Mouse by Leo Lionni}

Fact

1. Who is the story about?

2. What kind of animal is Alexander?

3. What is Alexander sitting in?

4. What is Alexander looking at?

5. What is Alexander running from?

6. Where is Willy sleeping?

7. Who is Alexander talking to?

8. Who is in the box?

9. What is Alexander holding?

10. What are Alexander and Willy doing?

\section{Search}

11. Can you find in the story where cups and spoons fall?

12. Can you find in the story where Alexander sees a wind-up mouse?

13. Can you find in the story where Alexander sees a lizard?

14. Can you find in the story where Willy is in a box?

15. Can you find in the story where Alexander holds a purple pebble?

16. Can you find in the story where Alexander sees the lizard at night?

17. Can you find in the story where Alexander runs at night?

18. Can you find in the story where Alexander finds an empty box?

19. Can you find in the story where Willy turns into a real mouse?

20. Can you find in the story where Alexander and Willy dance?

\section{Inference}

21. Which mouse is the wind-up mouse?

22. Which mouse is Alexander?

23. What is Alexander scared of?

24. Is it day or night?

25. Are Alexander and Willy inside or outside?

26. Are Alexander and the lizard inside or outside?

27. Who is Alexander looking at?

28. What is Alexander giving the lizard?

29. Who is not in the box anymore?

30. Where is a mouse hiding?

\section{Connection}

31. Alexander doesn't like loud noises. What is a noise you don't like?

32. Alexander and Willy are friends. Who is your friend?

33. Willy sleeps with a doll and teddy bear. What where you sleep with?

34. Willy is Annie's favorite toy. What is your favorite toy?

35. Alexander is lonely without Willy. When where you feel lonely?

36. The lizard is many colors. What is your favorite color?

37. Willy doesn't like being in the box. What is something you don't like?

38. Alexander is sad that Willy is gone. What is something that makes you sad?

39. Alexander is scared when Willy is hiding. When did you feel scared?

40. Alexander is happy to be friends with Willy again. What is something that make you happy? 


\section{Alexander and the Wind-Up Mouse}

\section{Answer Key}

Fact

1. Alexander or reference to mouse.

2. Mouse

3. Cup

4. Mouse

5. Broom

6. Bed

7. Lizard

8. Willy or wind up mouse

9. Pebble/Purple Pebble

10. Dancing/holding hands

\section{Search}

11. Page where Alexander runs from spoons/ cups.

12. Page where Alexander sees Willy.

13. Page with Willy and toys in a box.

14. Page with Alexander/ lizard at night.

15. Page with Alexander/ lizard at night.

16. Page where Alexander runs after seeing lizard.

17. Page with empty box.

18. Page where Alexander is hiding.

19. Last page of Willy and Alexander together.

\section{Inference}

20. Reference to mouse with key/wheel.

21. Reference to mouse in cup.

22. The broom.

23. Night.

24. Inside

25. Outside

26. Willy

27. Pebble/purple pebble

28. Willy

29. Reference to a mouse hole or hole

\section{Connection}

30. Answers will vary: Reference to a noise.

31. Answers will vary: Name other than Alexander or Willy.

32. Answers will vary: Reference to specific animal or toy

33. Answers will vary: Reference to specific toy.

34. Answers will vary: Reference to lonely event.

35. Answers will vary: Name specific color.

36. Answers will vary: Reference to specific dislike.

37. Answers will vary: Reference to sad event.

38. Answers will vary: Reference to specific scared event.

40. Answers will vary: Reference to happy event. 


\section{Appendix O \\ Duck on a Bike \\ by David Shannon}

Fact

1. Who is the book about?

2. Who is on a bike?

3. What color is the bike?

4. What is around the cow's neck?

5. What is the dog doing?

6. What is the goat eating?

7. What is the duck standing on?

8. What animal is the duck looking at?

9. Who are riding bikes?

10. Who are riding bikes?

\section{Search}

11. Can you find in the story where a duck sees a cow?

12. Can you find in the story where a duck sees a dog?

13. Can you find in the story where a cat licks his paws?

14. Can you find in the story where a duck sees a horse?

15. Can you find in the story where a chicken runs away?

16. Can you find in the story where a goat eats trash?

17. Can you find in the story where pigs watch the duck stand on a bike?

18. Can you find in the story where kids ride bikes?

19. Can you find in the story where animals ride bikes?

20. Can you find in the story where it says The End?

\section{Inference}

21. What is the duck thinking about?

22. Is the duck inside or outside?

23. Is the duck going fast or slow?

24. Where does the horse live?

25 . Why is the chicken running?

26. What are the pigs laying in?

27. Are the kids going fast or slow?

28. What are the animals thinking of doing?

29. Whose bikes are the animals riding?

30. What is duck thinking of riding next?

\section{Connection}

31. The duck likes to ride his bike outside. What do you like to do outside?

32. The sheep doesn't want duck to get hurt. When is a time you got hurt?

33. The dog thinks riding bikes is fun. What is something you think is fun?

34. The cat thinks bikes are boring. What is something you think I boring?

35. The horse thinks he can go faster than the bike. What is something you can do fast?

36. The chicken is afraid of being hit by the bike. What is something that scares you?

37. The goat likes to eat garbage. What is something you like to eat?

38. The duck likes to do tricks on the bike. What is a trick you can do?

39. There are many animals on the farm. What animal is your favorite?

40. The duck learned to ride a bike. What is something you learned how to do? 


\section{Duck on a Bike}

\section{Answer Key}

Fact
1. Duck.
2. Duck.
3. Red/Red \& White.
4. Bell.
5. Running.
6. Garbage or Trash.
7. Bike.
8. Mouse.
9. Kids.
10. Animals.

\section{Search}

11. Page with cow and duck looking at each other.

12. Page where the dog runs next to the duck.

13. Page where cat is lying in front of barn.

14. Page where horse is in barn.

15. Page where chicken runs in front of bike.

16. Page where goat eats from garbage can.

17. Page of pigs in mud.

18. Page where kids ride bikes.

19. Page where animals ride bikes.

20. Page with The End caption at the end of the story.

\section{Inference}

21. Riding a bike.

22. Outside.

23. Fast.

24. Barn or farm.

25. Reference to the bike/duck or being hit by bike.

26. Mud or dirt.

27. Fast.

28. Riding bikes.

29. The kids' bikes.

30. Tractor.

\section{Connection}

31. Answers will vary: Reference to outdoor activity.

32. Answers will vary: Reference to accident or injury.

33. Answers will vary: Reference to fun activity.

34. Answers will vary: Reference to boring activity.

35. Answers will vary: Reference to a skill.

36. Answers will vary: Reference to a fear.

37. Answers will vary: Reference to food.

38. Answers will vary: Reference to a skill.

39. Answers will vary: Reference to an animal.

40. Answers will vary: Reference to a skill. 


\section{Level 1-Fact:}

\section{Appendix P \\ The Wolf's Chicken Stew \\ by Keiko Kasza}

1.. What kind of animal is next to the tree?

2. What is the other animal on the cover?

3. What color is the wolf?

4. What color is the chicken

5. What is the wolf holding?

\section{Level 2-Search:}

6. Can you find in the story where the wolf sees a chicken?

7. Can you find in the story where a chicken walks to her house?

8. Can you find in the story where the wolf carries pancakes?

9. Can you find in the story where the wolf carries a cake?

10. Can you find in the story where a chicken opens the door?

\section{Level 3-Inference:}

11. What is the wolf thinking about?

12. Are the wolf and chicken inside or outside?

13. Is the wolf inside or outside?

14. Is it day or night?

15. Why are the chicks thanking Uncle Wolf?

\section{Level 4-Connection:}

16. The wolf like to eat. What food do you like to eat?

17. The wolf loves to cook. What is something you love to do?

18. The wolf baked a cake. What is your favorite kind of cake?

19. The wolf made the chicks happy. What is something that makes you happy?

20. The chicken and the wolf became friends. Who is your friend? 


\section{The Wolf's Chicken Stew \\ Answer Key}

\section{Level 1: Fact}

1. A wolf.

2. A chicken.

3. Brown.

4. White.

5. Book or cookbook.

\section{Level 2: Search}

6. Page where wolf is behind a tree.

7. Page where chicken walks up a path.

8. Page where wolf caries pancakes.

9. Page where wolf carries a cake.

10. Page where the chicken opens the door to wolf.

\section{Level 3: Inference}

11. Any reference to food or eating.

12. Outside.

13. Inside.

14. Night.

15. Any reference to food, pancakes, donuts, cake.

\section{Level 4: Connection}

16. Answer will vary: Answer must involve a food or foods.

17. Answer will vary: Answer must involve an activity, or game.

18. Answers will vary: Answer must involve a flavor of cake.

19. Answers will vary: Answer must involve a person, event, or item.

20. Answers will vary: Answer must involve the name of a person. 
Level 1-Fact:

\section{Appendix Q \\ The Adventures of Taxi Dog \\ by Debra and Sal Barracca}

1. Who is the story about?

2. What kind of animal is on the cover?

3. What is the dog sitting in?

4. What color is the car?

5. What is the man doing?

\section{Level 2-Search:}

6. Can you find in the story where Jim finds a dog?

7. Can you find in the story where a lady is singing?

8. Can you find in the story where there is an airplane?

9. Can you find in the story where there are clowns?

10. Can you find in the story where Maxi gets a treat?

\section{Level 3-Inference:}

11. Where is the Maxi going to look for food?

12. Why is the plate empty?

13. What kind of car does Jim have?

14. What is the dog wearing?

15. What is the dog going to eat?

\section{Level 4-Connection:}

16. Maxi is Jim's pet. What is the name of your pet?

17. Jim likes dogs. What is your favorite animal?

18. Maxi was lonely before he lived with Jim When do you feel lonely?

19. Maxi likes to ride in the car with Jim. What is something you like to do?

20. Jim and Maxi live in an apartment. Where do you live? 


\section{The Adventures of Taxi Dog}

\section{Answer Key}

\section{Level 1: Fact}

1. Taxi Dog or Dog.

2. Dog.

3. Taxi or car.

4. Yellow or Orange.

5. Driving.

\section{Level 2: Search}

6. Page where Jim is petting Maxi.

7. Page where a lady is in the backseat of taxi.

8. Page where they are at the airport.

9. Page where there are clowns getting in taxi.

10. Page where a man gives Maxi a dog biscuit.

\section{Level 3: Inference}

11. Any reference to garbage cans/outside.

12. Any reference to Maxi eating it all.

13. Taxi or taxicab.

14. Any reference to glasses, mustache, disguise.

15. Any reference to a bone, treat, or biscuit.

\section{Level 4: Connection}

16. Answer will vary: Answer must involve a name or statement that they do not have a pet.

17. Answer will vary: Answer must involve a type of animal.

18. Answers will vary: Answer must involve an event or situation.

19. Answers will vary: Answer must involve a person, event, or item.

20. Answers will vary: Answer must involve a reference to a home or type of home. 
Appendix R

Child__ Baseline Data Sheet

\begin{tabular}{|c|c|c|c|c|c|c|c|c|}
\hline \multicolumn{3}{|l|}{$\begin{array}{l}\text { B- } \\
\text { Date: }\end{array}$} & & \multicolumn{2}{|l|}{$\begin{array}{l}\text { B- } \\
\text { Date: }\end{array}$} & & \multicolumn{2}{|l|}{$\begin{array}{l}\text { B- } \\
\text { Date: }\end{array}$} \\
\hline Question & $\begin{array}{l}\text { Random } \\
\text { Number }\end{array}$ & $\mathrm{C}$ & Question & $\begin{array}{l}\text { Random } \\
\text { Number }\end{array}$ & $\mathrm{C}$ & Question & $\begin{array}{l}\text { Random } \\
\text { Number }\end{array}$ & $\mathrm{C}$ \\
\hline 1. & & & 1. & & & 1. & & \\
\hline 2. & & & 2. & & & 2. & & \\
\hline 3. & & & 3. & & & 3. & & \\
\hline 4. & & & 4. & & & 4. & & \\
\hline 5. & & & 5. & & & 5. & & \\
\hline 6. & & & 6. & & & 6. & & \\
\hline 7. & & & 7. & & & 7. & & \\
\hline 8. & & & 8. & & & 8. & & \\
\hline 9. & & & 9. & & & 9. & & \\
\hline 10. & & & 10. & & & 10. & & \\
\hline 12. & & & 12. & & & 12. & & \\
\hline 13. & & & 13. & & & 13. & & \\
\hline 14. & & & 14. & & & 14. & & \\
\hline 15. & & & 15. & & & 15. & & \\
\hline 16. & & & 16. & & & 16. & & \\
\hline 17. & & & 17. & & & 17. & & \\
\hline 18. & & & 18. & & & 18. & & \\
\hline 19. & & & 19. & & & 19. & & \\
\hline 20. & & & 20. & & & 20. & & \\
\hline $\begin{array}{c}\text { Total } \\
\text { Correct }\end{array}$ & & & $\begin{array}{c}\text { Total } \\
\text { Correct }\end{array}$ & & & $\begin{array}{c}\text { Total } \\
\text { Correct }\end{array}$ & & \\
\hline
\end{tabular}

1. Record Child identifier

2. Record the number of baseline session and date

3. Record randomized number for questions $6-20$

4. Check box if answer is correct

Key:

C: Correct

Random Number Key:

1-5: Inference

6-10: Fact

11-15: Summarize

16-20: Connection 
Appendix S

Intervention Probe Data Sheet

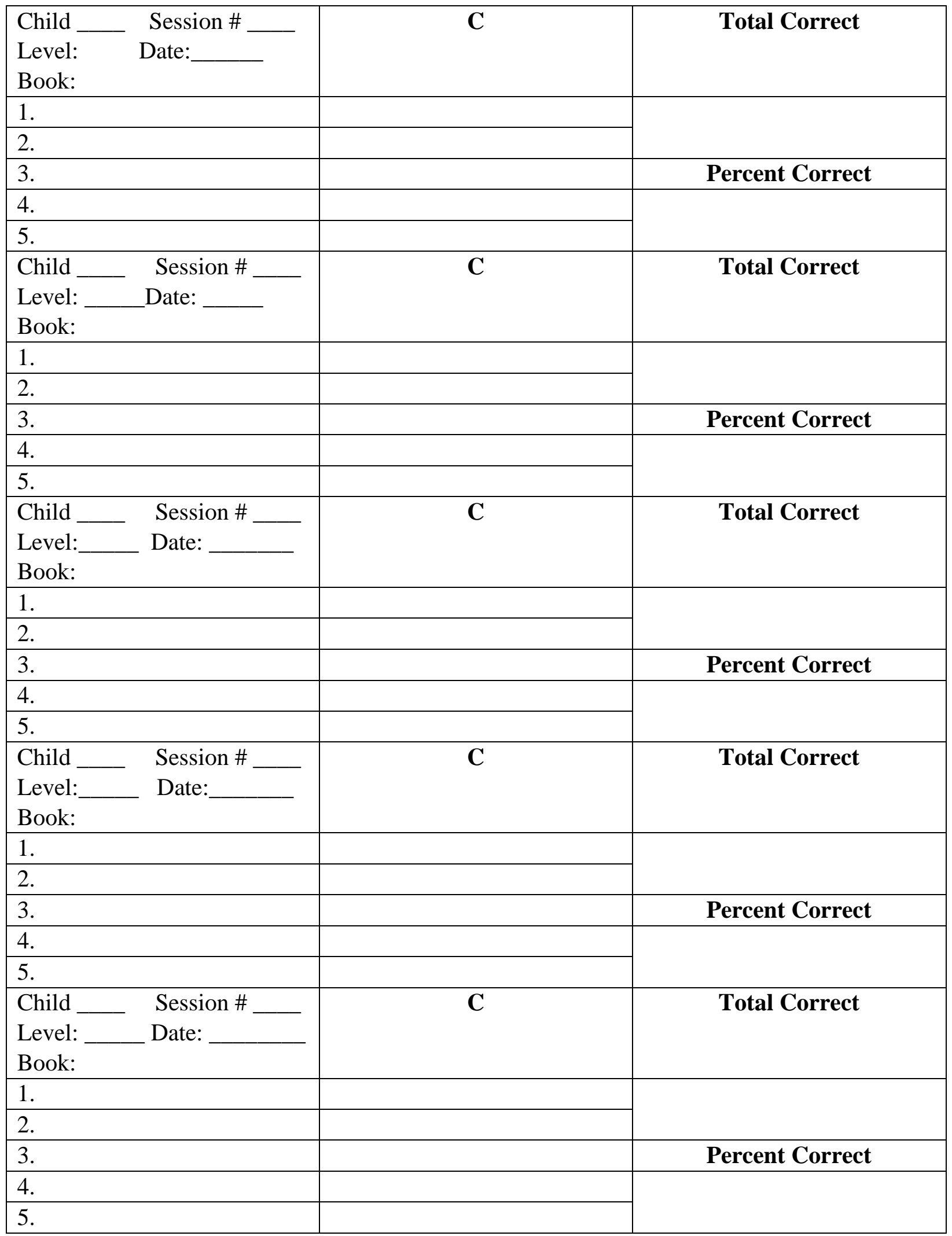




\section{Appendix T}

Intervention Data Sheet

\begin{tabular}{|c|c|c|c|c|c|}
\hline \begin{tabular}{l}
\multicolumn{1}{c}{ Correct } \\
Unprompted \\
The child answers the \\
question correctly \\
beginning the answer \\
within four to six \\
seconds with no \\
prompting from the \\
researcher.
\end{tabular} & $\begin{array}{l}\text { Correct Verbal } \\
\quad \text { Prompted: } \\
\text { The researcher } \\
\text { provides a verbal } \\
\text { prompt (e.g., } \\
\text { repeating question } \\
\text { or providing a hint) } \\
\text { if the child does } \\
\text { not begin a } \\
\text { response within } \\
\text { four to six seconds } \\
\text { and the child } \\
\text { answers the } \\
\text { question correctly. }\end{array}$ & $\begin{array}{l}\text { Correct Verbal + } \\
\quad \text { Gestural } \\
\quad \text { Prompted: } \\
\text { the researcher } \\
\text { provides a verbal } \\
\text { (e.g., repeating } \\
\text { question or } \\
\text { providing a hint) } \\
\text { and gestural prompt } \\
\text { (i.e., pointing to } \\
\text { picture) after four to } \\
\text { six seconds if the } \\
\text { child does not } \\
\text { respond to the } \\
\text { verbal prompt and } \\
\text { the child answers } \\
\text { the question } \\
\text { correctly, }\end{array}$ & $\begin{array}{l}\text { Incorrect Unprompted } \\
\text { The child answers the } \\
\text { question incorrectly } \\
\text { beginning the answer } \\
\text { within four to six } \\
\text { seconds with no } \\
\text { prompting from the } \\
\text { researcher, }\end{array}$ & $\begin{array}{l}\text { Incorrect Prompted } \\
\text { The researcher provides } \\
\text { a verbal prompt (e.g., } \\
\text { repeating question or } \\
\text { providing a hint) if the } \\
\text { child does not begin a } \\
\text { response within four to } \\
\text { six seconds and the } \\
\text { child answers the } \\
\text { question incorrectly. } \\
\text { Incorrect verbal + } \\
\text { gestural prompted: The } \\
\text { researcher provides a } \\
\text { verbal (e.g., repeating } \\
\text { question or providing a } \\
\text { hint) and gestural } \\
\text { prompt (i.e., pointing to } \\
\text { picture) after four to six } \\
\text { seconds if the child } \\
\text { does not respond to the } \\
\text { verbal prompt and the } \\
\text { child answers the } \\
\text { question incorrectly } \\
\text { IVR(Verbal) } \\
\text { IVG (Verbal + } \\
\text { Gestural) }\end{array}$ & $\begin{array}{l}\text { No Response } \\
\text { The child } \\
\text { doesn't answer } \\
\text { or says I don't } \\
\text { know even } \\
\text { when } \\
\text { prompted }\end{array}$ \\
\hline
\end{tabular}

Record the Child number, session, book title, Level, and date of intervention session.

Check the code which corresponds to Child answer.

Record the code totals and percentage of independent answers.

Child__ Session

Book

\begin{tabular}{|l|l|l|l|l|l|l|l|}
\hline $\begin{array}{l}\text { Level_ } \\
\text { Date: }\end{array}$ & C & VR & VG & IU & IVR & IVG & NR \\
\hline 1. & & & & & & & \\
\hline 2. & & & & & & & \\
\hline 3. & & & & & & & \\
\hline 4. & & & & & & & \\
\hline 5. & & & & & & & \\
\hline 6. & & & & & & & \\
\hline 7. & & & & & & & \\
\hline 8. & & & & & & & \\
\hline 9. & & & & & & & \\
\hline 10. & & & & & & & \\
\hline Totals & & & & & & & \\
\hline
\end{tabular}


Appendix U

Child

Maintenance Data Sheet

\begin{tabular}{|c|c|c|c|c|c|c|c|c|}
\hline \multicolumn{3}{|l|}{$\begin{array}{l}\text { M- } \\
\text { Book: } \\
\text { Date: }\end{array}$} & \multicolumn{3}{|l|}{$\begin{array}{l}\text { M- } \\
\text { Book: } \\
\text { Date: }\end{array}$} & \multicolumn{3}{|l|}{$\begin{array}{l}\text { M- } \\
\text { Book: } \\
\text { Date: }\end{array}$} \\
\hline Question & $\mathrm{C}$ & $\begin{array}{l}\text { Random } \\
\text { Number }\end{array}$ & Question & $\mathrm{C}$ & $\begin{array}{l}\text { Random } \\
\text { Number }\end{array}$ & Question & $\mathrm{C}$ & $\begin{array}{l}\text { Random } \\
\text { Number }\end{array}$ \\
\hline 1. & & & 1. & & & 1. & & \\
\hline 2. & & & 2. & & & 2. & & \\
\hline 3. & & & 3. & & & 3. & & \\
\hline 4. & & & 4. & & & 4. & & \\
\hline 5. & & & 5. & & & 5. & & \\
\hline 6. & & & 6. & & & 6. & & \\
\hline 7. & & & 7. & & & 7. & & \\
\hline 8. & & & 8. & & & 8. & & \\
\hline 9. & & & 9. & & & 9. & & \\
\hline 10. & & & 10. & & & 10. & & \\
\hline 11. & & & 11. & & & 11. & & \\
\hline 12. & & & 12. & & & 12. & & \\
\hline 13. & & & 13. & & & 13. & & \\
\hline 14. & & & 14. & & & 14. & & \\
\hline 15. & & & 15. & & & 15. & & \\
\hline 16. & & & 16. & & & 16. & & \\
\hline 17. & & & 17. & & & 17. & & \\
\hline 18. & & & 18. & & & 18. & & \\
\hline 19. & & & 19. & & & 19. & & \\
\hline 20. & & & 20. & & & 20. & & \\
\hline $\begin{array}{c}\text { Total } \\
\text { Correct }\end{array}$ & & & $\begin{array}{l}\text { Total } \\
\text { Correct }\end{array}$ & & & $\begin{array}{l}\text { Total } \\
\text { Correct }\end{array}$ & & \\
\hline $\begin{array}{l}\text { Percent } \\
\text { Correct }\end{array}$ & & & $\begin{array}{l}\text { Percent } \\
\text { Correct }\end{array}$ & & & $\begin{array}{l}\text { Percent } \\
\text { Correct }\end{array}$ & & \\
\hline
\end{tabular}

1. Record Child identifier

2. Record the number of Maintenance session, book title, and date

3. Record random number from answer sheet

4. Check box if answer is correct

Key:

C: Correct

Random Number Key:

1-5: Level 1 (Fact)

6-10: Level 2 (Search)

11-15: Level 3 (Inference)

16-20: Level 4 (Connection) 
Appendix V

QAR Procedural Fidelity Checklist

\begin{tabular}{|c|c|c|c|}
\hline $\begin{array}{l}\text { Baseline, \& } \\
\text { Maintenance Probes }\end{array}$ & Not Observed (NA) & Support Not Provided & Support Provided \\
\hline $\begin{array}{l}\text { The researcher greets } \\
\text { the child and says "I am } \\
\text { going to read you a } \\
\text { story and then I will ask } \\
\text { you questions. Tell me } \\
\text { if you know the } \\
\text { answer" }\end{array}$ & & & \\
\hline $\begin{array}{l}\text { The researcher has the } \\
\text { appropriate list of } \\
\text { baseline or } \\
\text { maintenance } \\
\text { questions. }\end{array}$ & & & \\
\hline $\begin{array}{l}\text { The researcher recites } \\
\text { the title and author of } \\
\text { the story and asks } \\
\text { Level } 1 \text { questions. } \\
\text { The researcher waits } \\
\text { four to six seconds for } \\
\text { the child to begin an } \\
\text { answer before moving } \\
\text { to next question. }\end{array}$ & & & \\
\hline $\begin{array}{l}\text { The researcher begins } \\
\text { to read the story and } \\
\text { asks the embedded } \\
\text { Level } 2 \text { and Level } 3 \\
\text { questions during the } \\
\text { story. The researcher } \\
\text { waits four to six } \\
\text { seconds for the child to } \\
\text { begin an answer before } \\
\text { moving to next } \\
\text { question. }\end{array}$ & & & \\
\hline
\end{tabular}




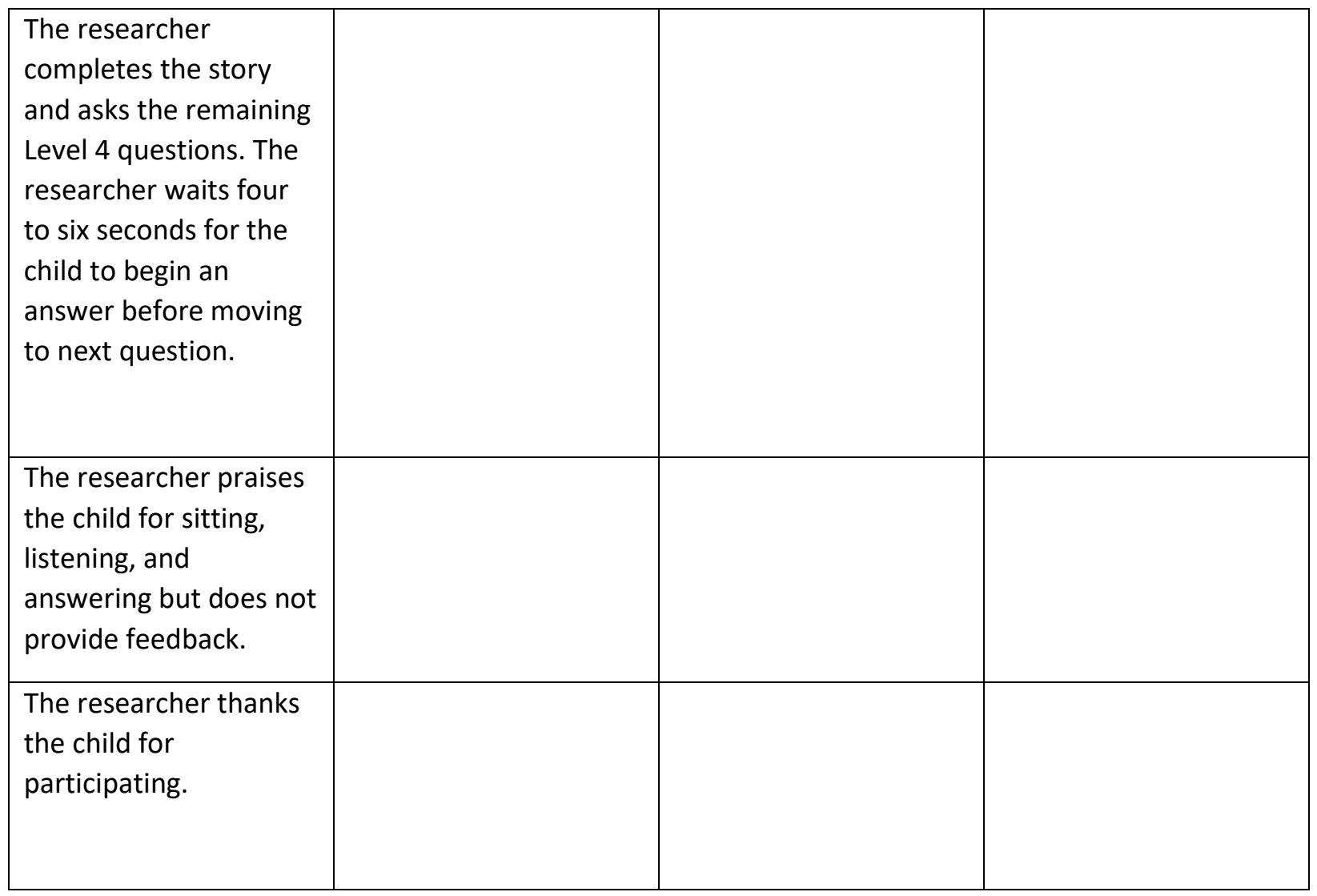


Appendix W

QAR Intervention Procedural Fidelity Checklist

\begin{tabular}{|c|c|c|c|}
\hline Intervention: Probe & Not Observed (NA) & $\begin{array}{l}\text { Support Not } \\
\text { Provided }\end{array}$ & Support Provided \\
\hline \multicolumn{4}{|l|}{$\begin{array}{l}\text { The researcher greets } \\
\text { the child and says "I } \\
\text { am going to read you } \\
\text { a story and then I will } \\
\text { ask you questions. } \\
\text { Tell me if you know } \\
\text { the answer" }\end{array}$} \\
\hline \multicolumn{4}{|l|}{$\begin{array}{l}\text { The researcher states } \\
\text { the level, title, and } \\
\text { author of the book } \\
\text { from the previous } \\
\text { session and } \\
\text { reads/reviews story. }\end{array}$} \\
\hline \multicolumn{4}{|l|}{$\begin{array}{l}\text { The researcher asks } \\
\text { five questions from } \\
\text { the previous session } \\
\text { and waits } 4-6 \text { seconds } \\
\text { for the child to begin } \\
\text { an answer before } \\
\text { moving to the next } \\
\text { question. }\end{array}$} \\
\hline \multicolumn{4}{|l|}{$\begin{array}{l}\text { The researcher } \\
\text { praises the child for } \\
\text { sitting, listening, and } \\
\text { answering but does } \\
\text { not provide corrective } \\
\text { feedback. }\end{array}$} \\
\hline \multicolumn{4}{|l|}{ Pre-Intervention: } \\
\hline $\begin{array}{l}\text { The researcher says, } \\
\text { "I'm going to show } \\
\text { you a card that will } \\
\text { teach you how to } \\
\text { answer questions in } \\
\text { the book." The } \\
\text { researcher shows the }\end{array}$ & & & \\
\hline
\end{tabular}




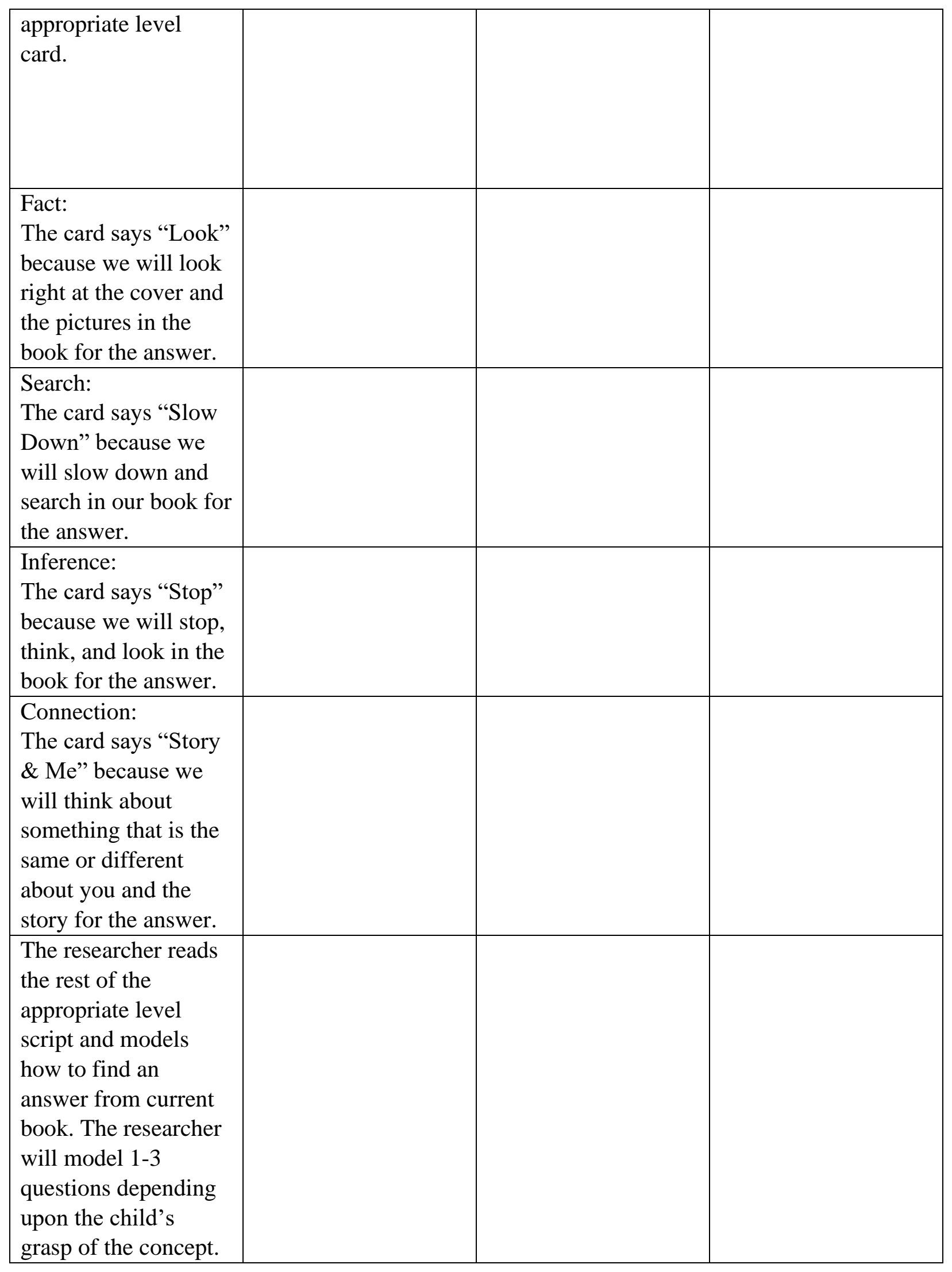




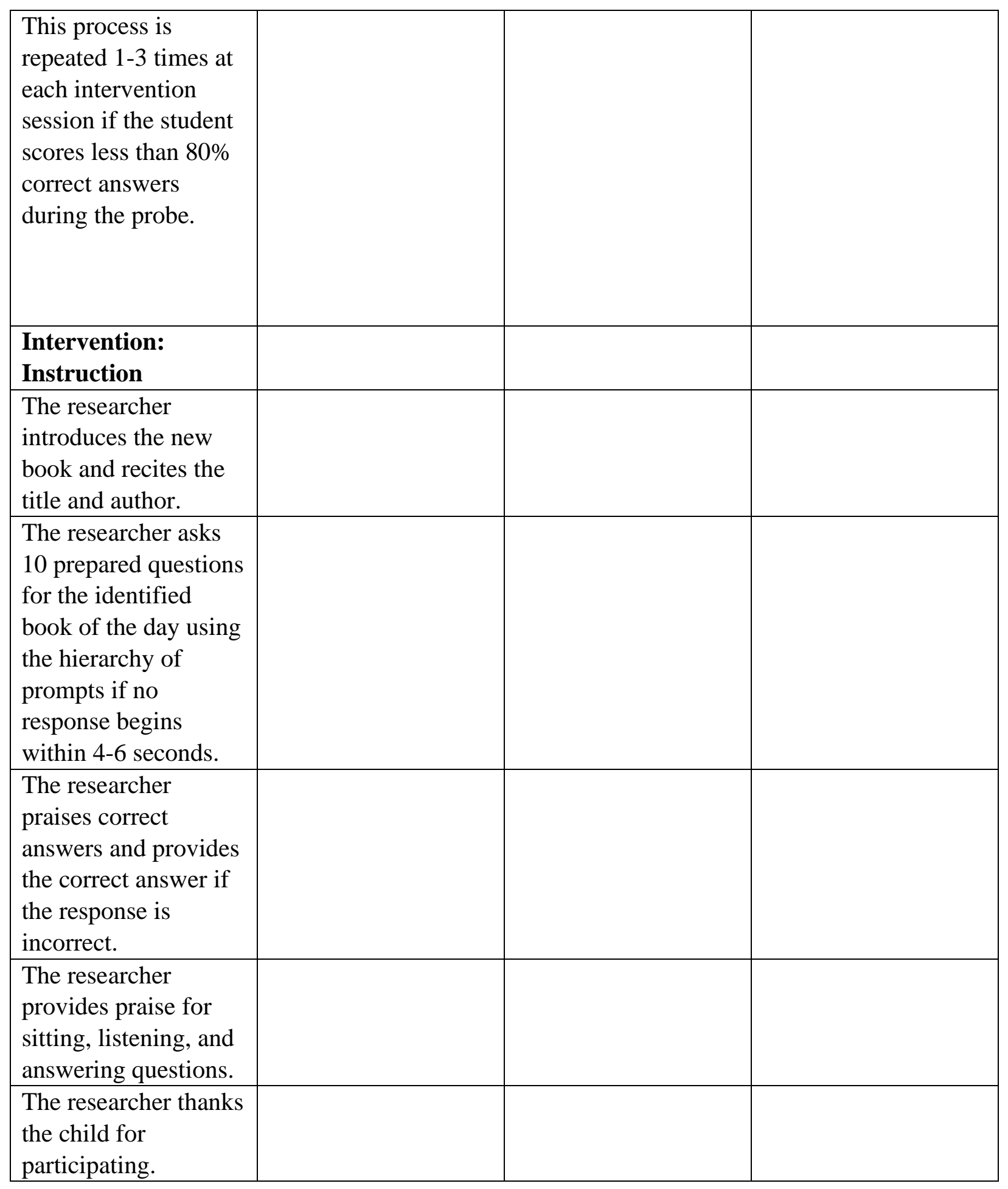


Appendix X

Social Validity Survey

Circle the face below that shows if you agree or disagree with the statements below.

1. I liked answering questions using the Look, Slow Down, Stop, and Story \& Me cards.

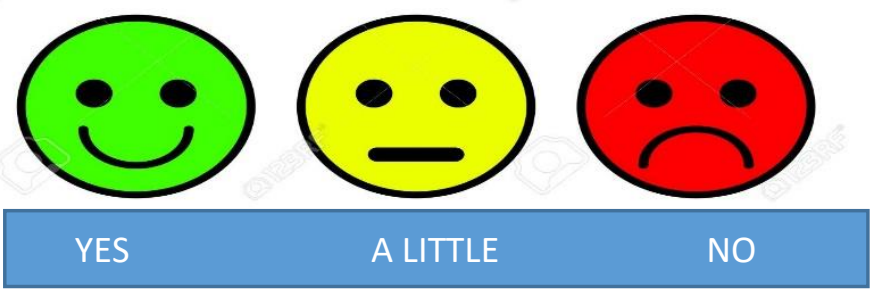

2. The cards helped me to answer the questions in the book.

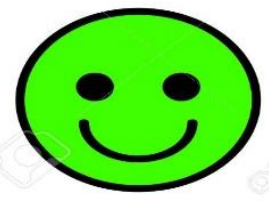

YES

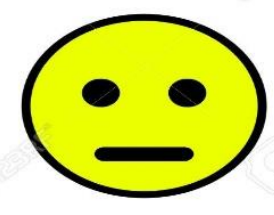

A LITTLE

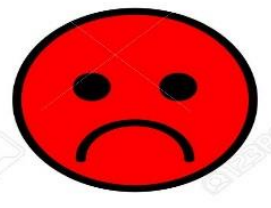

NO

3. I liked the books that we read.

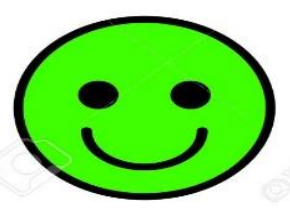

YES

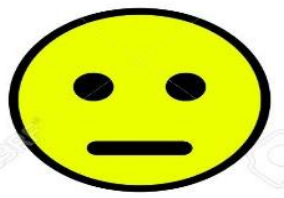

A LITTLE

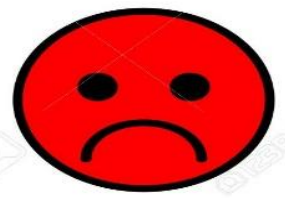

NO

4. I would like to use the cards again to answer questions in the book.

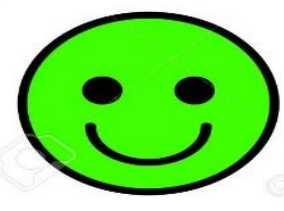

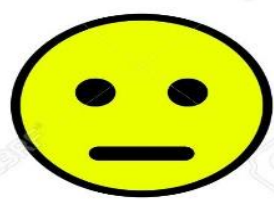

A LITTLE

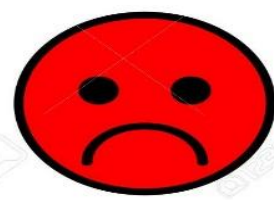

NO 


\section{Appendix Y}

RBT Social Validity Survey

The Question and Answer Relationship Strategy (QAR)

Please check appropriate answer.

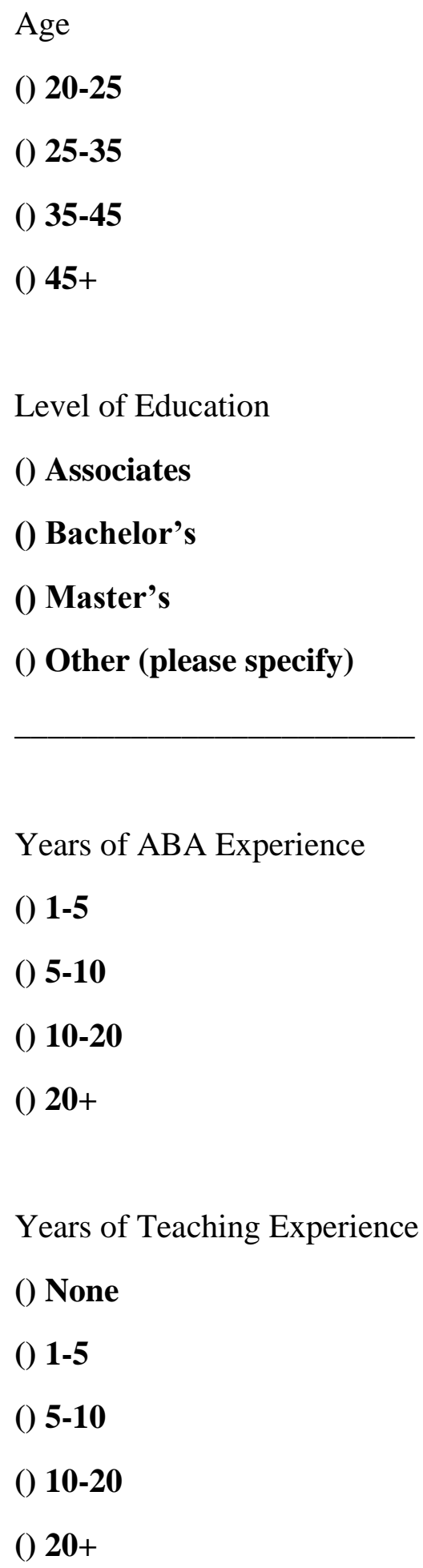


Please circle the corresponding number to the statements 1-10 below.

\section{1-Strongly Agree}

\section{2- Agree}

\section{3- Neutral}

\section{4- Disagree}

\section{5- Strongly Disagree}

1. The QAR intervention helped my client to answer Level 1, Fact comprehension questions. $125 \quad 3 \quad 4 \quad 5$

2. The QAR intervention helped my client to answer Level 2, Search comprehension

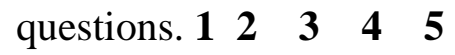

3. The QAR intervention helped my client to answer Level 3, Inference comprehension

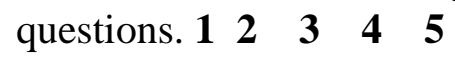

4. The QAR intervention helped my client to answer Level 4, Connection comprehension questions. $12 \begin{array}{llll}\mathbf{2} & \mathbf{4} & \mathbf{5}\end{array}$

5. The use of the QAR intervention helped my client to facilitate expressive language skills. $12 \begin{array}{llll}\mathbf{2} & \mathbf{4} & \mathbf{5}\end{array}$

6. I would be interested in learning the QAR strategy to use with my client.

$\begin{array}{lllll}1 & 2 & 3 & 4 & 5\end{array}$

7. The QAR strategy would be easy to implement in my client's program.

$$
\begin{array}{lllll}
1 & 2 & 3 & 4 & 5
\end{array}
$$

8. The QAR strategy would help my client achieve goals at the center.

$$
\begin{array}{lllll}
1 & 2 & 3 & 4 & 5
\end{array}
$$

9. The QAR strategy could help my client achieve academic goals at school.

$$
\begin{array}{lllll}
1 & 2 & 3 & 4 & 5
\end{array}
$$

10. The QAR sessions were a positive experience for my client.

$$
\begin{array}{lllll}
1 & 2 & 3 & 4 & 5
\end{array}
$$


Please answer the following questions as briefly or as in depth as you prefer. You may attach extra sheets if desired.

1. What do you feel was the most helpful part of the QAR intervention?

2. What was the least helpful part of the QAR intervention?

3. How could the QAR intervention be improved?

4. Have you participated in a research study before? If yes, please briefly explain.

5. What do you consider the most important thing you learned during this study? 
Curriculum Vitae
Lisa A. Phalen, M.S.Ed., CAS
820 Avant Court
Virginia Beach, Virginia
23454

Telephone: 757-376-0826 / e-mail: Lphalen@odu.edu

\section{EDUCATION}

2020-Present

Doctoral Student: PhD in Education with a Concentration in Special Education.

Old Dominion University, Norfolk, VA.

1994

M.S.Ed., Special Education

Old Dominion University, Norfolk, VA.

1992 B.S., Human Services Counseling

Old Dominion University, Norfolk, VA.

PROFESSIONAL ASSOCIATIONS

2013-Present

Certified Autism Specialist

International Board of Credentialing and Continuing Education Access

Standards (IBCCES)

2012

Autism Certificate Program,

Old Dominion University, Norfolk, VA,

1994-Present

Post-Graduate Professional License, Virginia Department of Education

PROFESSIONAL EXPERIENCE

Instructor

Old Dominion University, Norfolk, VA

2018-Present

Responsibilities: Teach graduate/undergraduate course: SPED 417, Collaboration and Transitions in Special Education

\section{Coach Coordinator}

Old Dominion University, Norfolk, VA

2018-Present

Responsibilities: Provide training and support to educational coaches for early education research project. 


\section{Early Education Coach}

Old Dominion University, Norfolk, VA

2016-2018

Responsibilities: Provide Bug-in Ear coaching/professional development to early education teachers

\section{Research Assistant}

Old Dominion University, Norfolk, VA

2016-2018

Responsibilities: Coding, data collection, transcribing

\section{Special Educator}

Autism Consulting \& Therapy, Virginia Beach, VA

2014-2015

Responsibilities: Developed and implemented Kindergarten readiness program for students with Autism Spectrum Disorder.

\section{ABA Therapist \\ Butterfly Effects Virginia Beach, VA}

2012-2014

Responsibilities: Implemented behavioral and academic goals in home and school environments for students with Autism Spectrum Disorder.

\section{Records Review Team,}

Office of Programs for Exceptional Children (OPEC)

Virginia Beach City Public Schools Virginia Beach, VA

2011-2012

Responsibilities: Review of IEPS in Virginia Beach school district for legal and compliance aspects of IDEA and special education regulations.

Compilation of final report for school administrators.

\section{Special Educator}

Virginia Beach City Public Schools Virginia Beach, VA

2010-2011

Responsibilities: Conducted phonological awareness and literary screenings Grades K-2. Instruction and support of language arts objectives K-1.

\section{Early Childhood Educator}

Virginia Beach Friends School, Virginia Beach, VA

2005-2010

Responsibilities: Developed and implemented early childhood Pre-K.

Update and revision of early school curriculum for school accreditation

Faculty representative for Early School Division. 


\section{PUBLICATIONS}

Roitsch, J. E., Phalen, L., \& Watson, S. (2019, online ahead of print). Predictors of comfort level in speech-language pathologists working with students with attentiondeficit/hyperactivity disorder. Perspectives of the ASHA Special Interest Groups. https://doi.org/10.1044/2019_PERS-SIG16-2019-0012

\section{PRESENTATIONS}

Phalen, L. (April, 2019). The impact of sensory processing deficits on students with autism spectrum disorder in classroom settings. Paper presented at the Southeastern School Behavioral Health Conference, Myrtle Beach, SC.

Phalen, L., Hester, P., Morin, L., \& Gear, S. (October, 2018). Affective supports to promote the centrality of early childhood teacher/child relationships. Poster presented at Division for Early Childhood Conference, Orlando, FL.

Phalen, L. (April, 2018). Identifying sensory processing deficits as a barrier to learning in autism spectrum disorder. Poster presented at 5th Annual Southeastern School Behavioral Health Conference, Poster Presentation, Myrtle Beach, SC.

Phalen, L. (November, 2017). The relationship between sensory processing and inclusion in autism spectrum disorder. Poster presented at Virginia Council for Exceptional Children, Richmond, VA.

Phalen, L. (September, 2017). The educational effects of sensory processing deficits in autism spectrum disorder. Poster presented at Thompson Center for Autism and Neurological Disorders, St. Louis, MO.

Phalen, L. (June, 2017). Autism spectrum disorder and related disorders; overview and support Strategies. Presented at Virginia Beach Friends School, Faculty Training, Virginia Beach, VA.

Phalen, L. (March, 2017). Autism spectrum disorder; overview and support strategies. Presented at Community United Methodist Church, Continuing Education Training, Virginia Beach, VA.

Phalen, L., Hester, P., Morin, L., \& Gear, S. (November, 2016). A model of affective supports for early childhood teachers of students with disabilities. Poster presented at Virginia Council for Exceptional Children, Poster Presentation, Richmond, VA.

Phalen L. (August, 2014). Early intervention and classroom strategies for students with autism spectrum disorder. Presented at London Bridge Preschool Faculty Training, Virginia Beach, VA. 
Phalen, L. (May, 2012). Meeting the social and academic needs of children with high functioning autism. Presented at Virginia Beach Friends School, Faculty Training, Virginia Beach, VA.

Phalen, L. (April, 2008). Child development and learning stages in early education. Presented at Virginia Beach Friends School, Open House Forum, Virginia Beach, VA.

Phalen, L. (May, 2000). Stages of sharing in preschool. Presented at Early Stages Education Conference, La Plata, MD.

Phalen, L. (September, 1999). Overview of autism; recognizing characteristics. Presented at Head Start Training, F.B. Gwynn Center, La Plata, MD.

\section{POST-GRADUATE EDUCATION AND TRAINING}

2014

2008

2007

2000

2000
Applied Behavior Analysis Training, Autism Consulting and Therapy, Virginia Beach, VA

Understanding Numbers and Operations, PBS Teacherline, Norfolk, VA

Teaching Phonemic Awareness and Phonics, PBS Teacherline, Norfolk, VA

Behavior Management; Special Education, Trinity College, Washington DC, 2000

Special Education; Inclusion, Maryland State Dept. of Education, Baltimore, MD. 